Ann. Zootech., I97I, 20 (2), I93-246.

\title{
LA VALEUR BIOLOGIQUE DES PROTÉINES : QUELQUES ACQUISITIONS RÉCENTES
}

\author{
A. RERAT \\ Aves la collaboration teshniqu d: Francine Desuccro \\ Station de Recherches sur l'Élevage des Porcs, \\ Cenire national d? Rechsrches zoxtochniques, I.N.R.A., \\ 78 - Jouy-en-Josas
}

PLAN

\section{INTRODUCTION}

I. - Facteurs conditionnant la Valeur biologique des protéines

$$
\text { A. - Facteurs intrinsèques }
$$

I. L zs bssoins d'acides aminés du Rat, de la Volaille et du Porc.

a) Méthodes de détermination du besoin d'acides aminés, basées sur l'aminoacidémie.

b) Recommandations (Rat, Volaille, Porc).

c) Apport d'azote non indispensable.

2. Déséquilibres d'acides aminés.

3. Conclusion.

I. Taux protéique.

B. - Facteurs extrinsèques

2. Épargne de l'azoto par l'apport énergétique.

II. - Méthodes de mesure de la VAleur biologique

$$
\text { A. - Méthodes biologiques }
$$

r. Poicls, rétention azotéz et valeur nutritive des protéines.

a) Méthode des poids.

b) Rétention azotée.

- Méthode des bilans.

- Méthodes basées sur l'analyse corporelle.

- Valeur nette des protéines alimentairzs.

- Comparaison des méthodes biologiques sur l'animal entier. 
2. Autres méthodes biologiques.

a) Variations des activités enzymatiques tissulaires.

b) Méthodes basées sur les variations des teneurs plasmatiques d'azote non protéique.

3. Disponibilité des aminoacides in vivo.

4. Conclusion.

\section{B. - Méthodes microbiologiques}

C. - Méthodes chimiques et enzymatiques

I. Index chimiques.

2. Index intégrant tous les acides aminés essentiels.

3. Index tenant compte de la disponibilité des acides aminés.

a) Disponibilité de tous les acides aminés.

b) Disponibilité de la lysine.

4. Limites des méthodes in vitro.

\section{CONCLUSIONS}

\section{IN'TRODUCTION}

Au cours des vingt dernières années, bon nombre de revues ont été consacrées à la valeur biologique des protéines (Allison, 1955, 1956; Mitchell, 1944, I948, I959; Frost, I959; AlBANESE, 1959) et il ne saurait être question d'entreprendre à nouveau une étude bibliographique extensive de ce sujet. Cependant, certains problèmes le concernant ont été l'objet de recherches qui ont permis d'améliorer nos connaissances scientifiques tant sur le plan des facteurs influençant la valeur biologique des protéines, que sur celui de la méthodologie. Cesontles diverses acquisitions récentes dans ce domaine qui seront ici décrites, en rappelant seulement succinctement les faits déjà connus, pour la bonne compréhension du texte, ceux-ci ayant du reste été analysés dans une revue antérieure (JACQUOT et RÉRAT, I966).

\section{I. - FACTEURS CONDITIONNANT}

\section{IA VALEUTR BIOLOGIQUE DES PROTÉINES}

Plusieurs facteurs sont en cause : les uns, de nature intrinsèque, sont liés à la composition des protéines et à leurs conditions d'hydrolyse digestive ; les autres, de caractère extrinsèque, relèvent des autres constituants de la ration.

\section{A. - Facteurs intrinsèques}

Parmi ceux-ci, il faut citer (Terrorne, 1953):

- la présence de tous les acides aminés indispensables pour une espèce et un état physioogique clonné ; 
- l'équilibre optimum de ces acides aminés qui varie non seulement d'espèce à espèce, mais ćgalement d'un état physiologique à un autre;

- la libération simultanée de tous les acides aminés au cours de l'hydrolyse digestive, ce qui assure la simultanéité d'apport au niveau de l'absorption intestinale.

C'est surtout la notion d'équilibre quantitatif qui a retenu l'attention des auteurs au cours; des dernières années, tant sur le plan des besoins que sur le plan des excès ou des carences. Ces deux points seulement feront l'objet de développements.

\section{1. - Les besoins d'acides aminés du Rat, de la V'olaille et du Porc}

Un grand nombre de travaux ont été réalisés sur ce point au cours des dernières années, soit en utilisant des critères classiques (vitesse de croissance, rétention azotée) selon diverses méthodes, clont le principe a été discuté ailleurs (RÉRAT et LOUGNOx, I966) soit surtout en utilisant de nouveaux critères tels que l'aminoaciclémic.

a) Méthodes de détermination du besoin d'acides aminés basées sur l'aminoacidémie.

Ces méthodes sont basées sur le fait que la tencur en acides aminés du plasma sanguin dépend d'une part des apports alimentaires et tissulaires (notamment la composition des protéines alimentaires et le catabolisme tissulaire), d'autre part de la ponction faite sur ces acides aminés circulants pour le renouvellement et la synthèse des tissus.

Ainsi, alors que les premiers travaux montraient que l'ordre d'abondance d'un acide aminé libre dans le plasma varie directement avec la concentration relative de cet acide aminé dans les proténes alimentaires (CHARKEY et al., I950; Richardson et al., I953 a et $b$ ), et que l'augmentation des concentrations dans lo plasma est généralement proportionnelle aux apports alimentaires (Dhaton et Elvehjex, I954), Longenecher ct Hause (1959) montraient ultérieurement que l'interprétation de ces faits devait être nuancée.

Ainsi, quand la concentration d'un acide aminé est la plus faible dans la protéine alimentaire, son taux dans le plasma présente une variation qui n'est pas forcément la plus faible de toutes quand c'est une augmentation ou la plus forte quand c'est une diminution. De même, l'acide aminé dont la concentration est la plus forte dans la protéine alimentaire ne fournit pas forcément l'augmentation la plus importante de concentration dans le plasma. Par contre, si l'on tient compte des besoins en aminoacides de l'animal en exprimant les changements de concentrations d'acides aminés dans le plasma par rapport à ceux-ci, il existe une relation directe démontrée statistiquement, entre ces variations d'aminoacidémic après le repas et la composition en aminoacides du régime. İn d'autres termes, la soustraction d'un acide aminé du plasma, après ingestion de la protéine, est fonction du besoin qu'a l'organisme de cet acicle aminé ; lorsque l'acide aminé est fourni à l'organisme en quantité insuffisante vis-à-vis de son besoin, les tissus, s'ils ont à leur disposition suffisamment des autres acides aminés, vont prélever l'acide aniné limitant dès son arrivée dans lesang après la digestion et sa teneur sera diminuée. Par contre, si cet acide aminé cst fourni dans le régime en excédent par rapport au besoin, sa teneur clans le sang augmentera dans les limites permises par le catabolisme tissulaire.

A partir cle ces faits ont été conçues des méthodes destinées à estimer la valeur biologique des protéines, en précisant surtout la nature des facteurs limitants primaire et secondairc (McLAUghlan et Morrison, ig68) ou à apprécier in vivo lá disponibilité des acides aminéz (GugGenheim et al., 1960; (HILD et Comps, 1964), méthodes sur lesquelles nous reviendrons dans le chapitre correspondant. Par ailleurs, les besoins ont été appréciés selon deux variantes :

Selon LoNGenecker (I963), les rapports entre le changement de concentration plasmatique de chaque acide aminé et son besoin doivent ctre identiques pour tous les acides aminés lorsque les besoins sont couverts, et c'est là-dessus qu'il se base pour estimer les bosoins de l'Homme en supplémentant un régime à base d'ovalbumine à l'aide de plusieurs acides aminés en proportions variables.

D'autres auteurs utilisent une série de méthodes plus analytiques, mettant en ralation la concentration de l'acide aminé limitant fourni en doses croissantes dans un régime bien équilibré 
par ailleurs, et la concentration plasmatique de cet acide aminé limitant. Selon certains d'entre eux (Morrison et al., r96I; PAwlak et Pion, $1966 \mathrm{chez}$ le Rat; Z ZMmerman et Scotr, i965 chez la Volaille; Mrtchell et al., 1968 b chez le Porc), la concentration de l'acide aminé limitant dans le plasma demeure faible et invariable tant que le besoin n'est pas couvert, puis augmente brutalement dès qu'il l'est; ces auteurs basent donc la mesure du besoin sur la détermination du point cl'inflexion de la courbe. A noter au passage que les teneurs d'acides aminés libres dans le muscle pourraient représenter un critère encore plus sensible car elles y sont beaucoup plus élevées que dans le sang et leurs variations sont beaucoup plus importantes (PAwLAK et Pron, 1966, I969; Rogers et Harper, 1968). Un peu différente est la méthode de McLaughlan et Illman (I967) chez le Rat, qui fixe le besoin au taux alimentaire du facteur limitant permettant un retour de la concentration plasmatique du facteur limitant au niveau de celle enregistrée durant le jeûne. Les modalités do prélèvement du sang sont très variables et FAUConneaU et PIon (I969) notent que, chez le Porc, certains auteurs exécutent les prélèvements sans jeune préalable, les animaux étant nourris ad libitum (Рuchal et al., 1962); d'autres procèdent à un jeûne préalable à la prise de sang (Chaxce, r962; Richardson et al., i965); enfin, d'autres préconisent l'administration du repas et prélèvent le sang à des heures variables après ce repas (Long et al., I965; KrYsčiak et al., 1966; Combs et al., I967; CoOKE et al., 1966; Long, 1966). Ces modalités ont été particulièrement bien étudiées chez le Rat par STockland et al. (r970).

C'est du reste à ce niveau que réside la difficulté principale de ces études : quelle période doit-on considérer comme optimum pour procéder au prélèvement afin d'éviter que la concentration d'acide aminé ne soit pas trop sensibiliséc soit à l'apport alimentaire, soit au catabolisme? Quclle durée de jeûne choisir comme référence quand cela est nécessaire (cas de la méthode de McLaughlan et Illman) quand on sait que les teneurs en acides aminés du plasma varient sclon la durée de jeûne (Chance, rg62; Richardsox ct al, I965) ? De l'avis de la plupart des promoteurs de ces techniques, nos connaissances dans ce domaine demandent à être précisées avant de pouvoir conclure et McLaughlan et Morrison (rg68) font ressortir que le taux de l'acide aminé limitant (thréonine, méthionine, cystine, tryptophane), dans le plasma est fonction de plusieurs facteurs, notamment le taux azoté, le degrré d'insuffisance de l'apport de cet acide aminé, la durée de l'essai et la vitesse de croissance de l'animal. L'influence du taux azoté a été confirmée par bien d'autres auteurs (notamment Sharrer et al., I967; Harker et al., ig68; Kučukalic et Milenkovic, I968; Swexseid ct al., 1968). Il faut bien sûr rappeler également le rôle très important de l'énergie consommée clans la variation du taux plasmatique d'acide aminé (CuperLovic et Stosic, I970; Saunders et al., 1967). En outre, l'apport alimentaire de sucre est susceptible de modifier les rapports entre acides aminés dans le sang (KNIPFel et al., I969) et il existe d'importantes différences entre espèces animales (Boomgandet et McDosaln, ig69). Quoi qu'il en soit, les besoins de certains acicles aminés, ainsi déterminés chez la Volaille (Zimmerman et Scott, 1965) chez le Rat (McLaughlan et Illman, ig67) et chez le Porc (Mrtchell et al., ig68 a et $b$ ) montrent une concordance certaine avec ceux obtenus par d'autres méthodes chez ces espèces.

\section{b) Recommandations (Rat, Volaille, Porc).}

La plupart des travaux réalisés par l'ensemble de ces méthodes, anciennes ct nouvelles, au cours des dernières années ont été examinés et triés par diverses instances telles que le National Research Council (États-Unis) et l'Agricultural Research Council (Grande-Bretagne) ou par divers autcurs (Rérat et Lougron, 1966, I969 pour le Porc), ce qui aboutit à des recommandations provisoires parfois discordantes ; l'analyse de ces désaccords a été faite par Fauconneau (1967), Fauconneau et Pion (1969). A titre d'excmples sont clonnées dans le tableau I les recommandations du N. R. C. pour une espèce de laboratoire (Rat) et deux espèces domestiques (Volailles, Porc).

Une remarque générale doit d'abord être faite concernant le mode d'expression de ces besoins: les recommandations sont faites en pourcentage du régime. Cette façon de faire, si elle est intéressante sur le plan pratique, n'est pas très rigourcuse en raison des variations possibles de consom. 


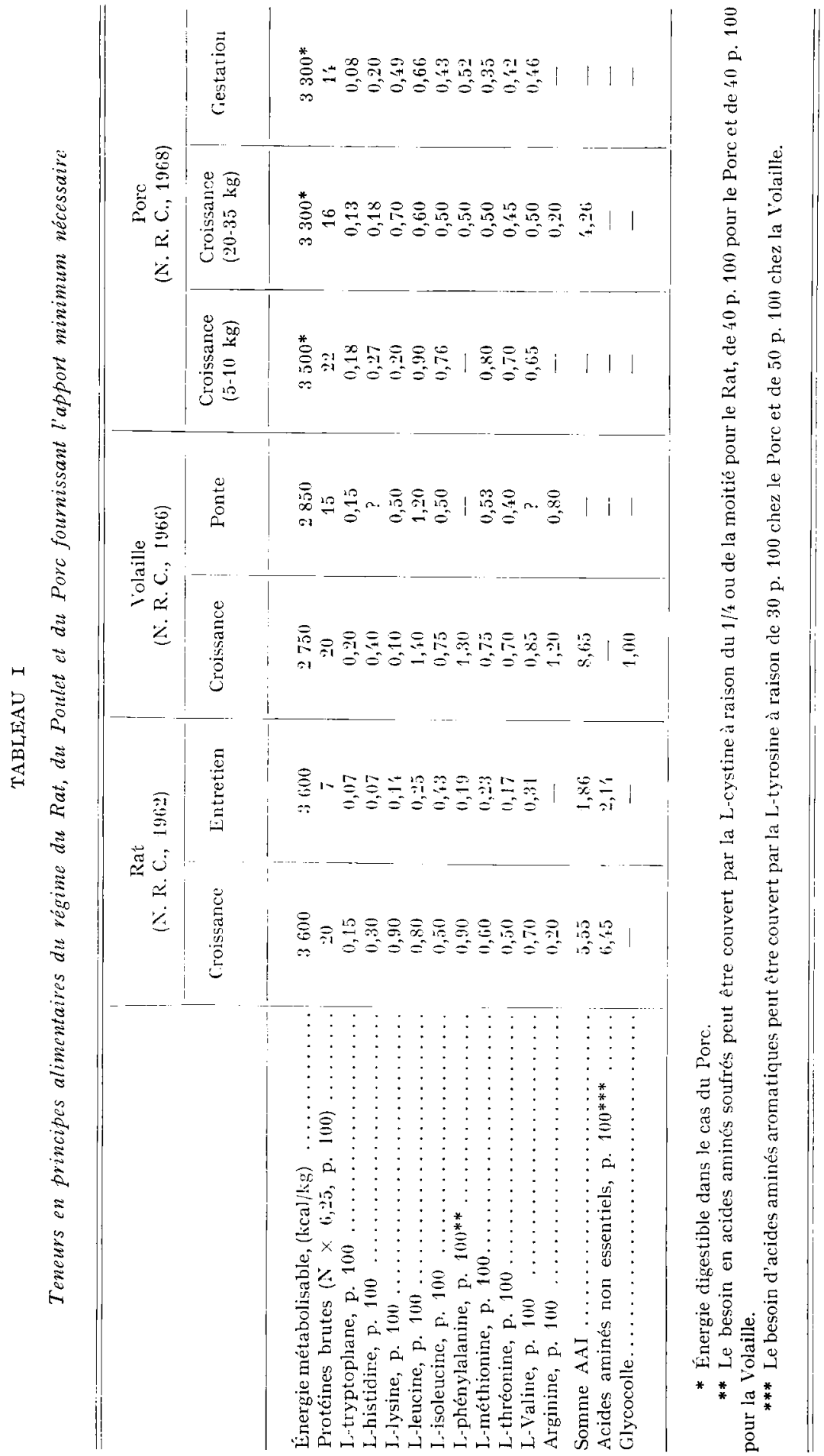


mation de régime $\mathrm{en}$ fonction du taux énergétique du régime (HENRY et RéRAT, I966). Il serait préférable d'exprimer les besoins en quantités journalières en relation avec l'âge et le gain de poids des animaux ou le volume des productions, et de rapporter ensuite ces besoins à la quantité de principes énergétiques consommée en alimentation à volonté ou rationnée (RÉRAT et LougNon, r966).

Quoi qu'il en soit, un certain nombre d'observations peuvent être faites sur les recommandations établies par le N. R. C. pour les différentes espèces.

- En ce qui concerne le Rat en croissance, les normes trouvées au cours des dix dernières années par Connor-Johnson et son équipe (SMith et Johnson, 1967) diffèrent de celles du N. R. C. (1962) essentiellement pour l'arginine, la valine et la phénylalanine (FAUCoNNEAU, I967).

- En ce qui concerne la Volaille, par rapport aux normes éditées en I96I, le N. R. C. (1966) admet une augmentation importante des besoins d'histidine, d'isoleucine et de thréonine, plus faible de lysine et de valine et une diminution des besoins d'acides aminés soufrés et aromatiques. Les désaccords avec les besoins définis par l'équipe de Scott (Dean et Scotr, r965; Zimmerman et Scott, 1965) ne portent plus que sur le tryptophane et la leucine.

- Chez le Porc en croissance, les modifications des normes du N. R. C. entra I96 + et 1968 se traduisent par une diminution légère (5 à ro p. roo) des besoins en isoleucine, lysine, histidine et acides aminés soufrés. $A$ noter que le besoin journalicr de lysine augmente moins rapidement que le besoin d'acides aminés soufrés lorsque le Porc prend du poids et de l'ầge (Poppe et WiesemÜLler, I968, 1969 ; Wiesemuller et Poppe, 1968 a), en raison sans doute du besoin important de méthionine pour l'entretien (BAKER et al., 1966) et de sa faible tencur dans les protéinez musculaires relativement ì la lysine (FAUCONNEAU et PION, I969). Par ailleurs, de nombreux travaux ont souligné les relations entre le besoin d'acides aminés (exprimé en pourcentage du rágime) et la teneur énergétique du régime, le besoin d’acides aminés augmentant lorsque la teneur énergétique du régime s'élève (Anderson et Bowland, I967; Lerner, i968; Rérat et al., 197o). Enfin, le Porc pose un problème particulier du fait de la restriction alimsntaire qui lui est imposée dans le but d'obtenir une carcasse maigre : qu'advient-il dans ces conditions de l'apport nécessaire d'acides aminés ? Compte tenu de l'utilisation très différente de l'énergie alimsntaire par le Porc et par le Rat (Meyer et Nelson, I963), il ne peut être question d'extrapoler les résultats obtenus chez le Rat (Rérat et Desmoulin, 1970) : une expérience récemment réaliséz sur la Pore (RÉrat et al., I97 I) montre cependant que la restriction du niveau d'alimentation se traduit, chez le Porc comme chez le Rat, par un ralentissement de la croissance; s'il ne s'agit que d'une restriction énergétique, lc déficit de croissance existe toujours, mais il est moins marqué. Tout so passe donc comme si une partie des acides aminés était utilisée à des fins égergétiquas lors d'une restriction énergétique : si l'on exprime les recommandations en pourcentaga de la matière sèche dans le régime, elles doivent être accrues en alimentation restreinte et en tout état de cause, il semble difficile d'obtenir dans ces conditions une croissance maximum.

- Variations de la valeur biologique selon l'âge des animaux, selon leur typ z de production, et d'une espèce à l'autre.

Un simple examen du tableau I permet de comprendre pourquoi la valeur biologique des protéines ne peut être la même aux divers stades de la vie de l'animal : ses bəsoins évoluent en effet en fonction de son âge, comme le soulignent les obsərvations de Wiesemüluen et Poppe (I968), pour le Porc; ils évoluent également en fonction de sa production et, par exemple, les besoins d'acides aminés de la truie gestante sont fort différents des bəsoins d'acid 3 a aminés de la truie au repos comme le soulignent les travaux de RIPPEL et al. (1965).

Par ailleurs, afin de comparer les besoins de ces différentes espèces, les bəsoins selon le N. R. C. ont été calculés en pourcentage de la somme des acides aminés indispensables et des səmi-indispensables selon une méthode préconisée par Fauconneau (1964, I967). Prov et al. (I953 a) et la W. H. O. (1) (1965) et exprimés en pourcentage de ceux du Rat (tabl. 2). On peut ainsi constater la grande analogie des besoins du Rat et du Porc sauf pour l'isoleucine, les acides aminés aroma-

(1) World Health Organization. 
VALEUR BIOLOGIQUE DES PROTÉINES

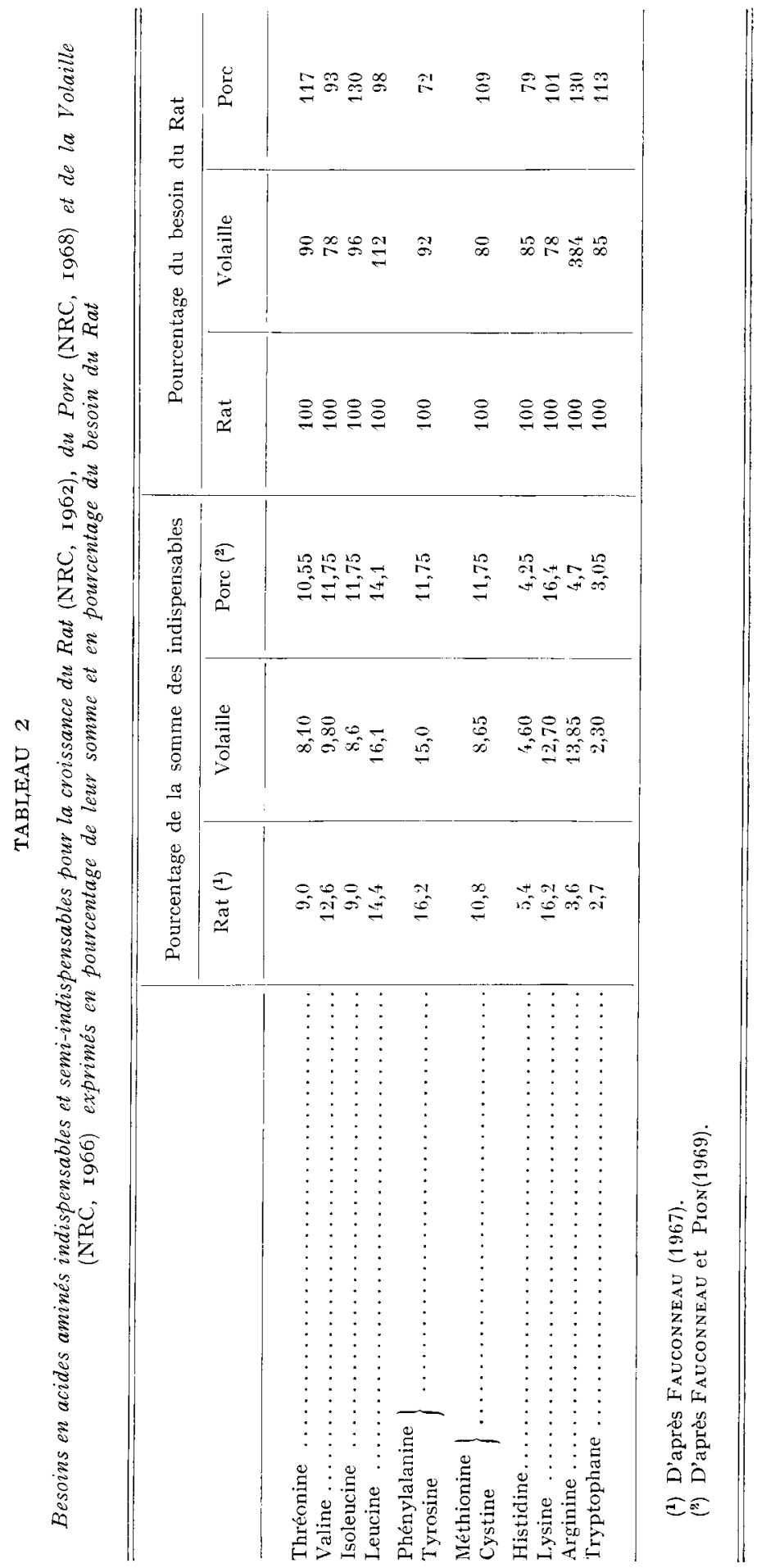


tiques, l'arginine et à un moindre degré l'histidline. Compte tenu de ce que l'on sait de la composition des protéines, on peut en déduire que la valeur biologique des protéines a de fortes chances d'être identique pour ces deux espèces puisque les acides aminés cités sont généralement fournis en larges quantités par les protéines alimentaires. Par contre, le besoin en acides aminés aromatiques du l'oulet est analogue à celui du Rat et son besoin d'arginine est, en comparaison de celui du Rat et du Porc, très élevé, ce qui diminue passivement le besoin de la plupart des autres acides aminés : à noter que les diminutions relativement les plus marquées portent sur la valine, la lysine et les acides aminés soufrés; ceci explique que les données concernant la valeur biologique des protéines sont divergentes chez le Rat ct la Volaille.

\section{c) Apport d'azote non indispensable.}

A ce sujet, il faut rappeler qu'il existe un besoin azoté indifférencié (TERrorne, I933) dont la réalitć a été démontréc à maintes reprises. Par exemple, chez des rats soumis à une déplétion azotée préalable, un mélange équilibré cle tous les acides aminés essentiels se révèle moins efficace pour la réplétion des animaux qu'un régime isoazoté formé du même mślange d'acides aminés essentiels auquel on a substitué partiellement diverses sources d'azote non indispensable : dans ces conditions, la valeur de remplacement de l'urée est doux fois moins élevée que celle du citrate d'ammonium, de l'arginine ou de l'acide glutamique (Frost, 1959). Il apparaît ainsi que l'aptitude des rats à convertir des acides aminés indispensables en acides aminés non essentiels est limitéc et l'apport de ces derniers se révèle ainsi particulièrement utile.

En ce qui concerne cet apport d'acides aminés dispensables, nous avons souligné clans notre clernière revue (JAcguot et RÉRAT, I966) que l'acide glutamique pouvait représenter la presque totalité de l'apport d'azote indifférencié, et couvrait partiellement, comme la proline, le besoin en arginine. Par contre, le glycocolle et l'acide aspartique ne représentaient pas des sources universelles d'azote indifférencié. De nombreux travaux réalisés depuis cette époque montrent que l'asparagine est nécessaire au Rat à chaque stade de sa croissance (Rogirs ct Haropro, I965) ; contrairement à l'acide aspartique, l'asparagine alimentaire est incorporée dans les tissus de croissance à raison de plus de 80 p. Ioo et une partic peut être remplacée par la glutamine (BReUer et al., I966). A nouveau, l'intérêt cle lá proline est mis en évidence puisque cet acide aminé est capable de remplacer un mélange de six acides aminés non essentiels (alanine, acides aspartique et glutamique, glycine, proline, sérinc) pour promouvoir la croissance maximum de rats recevant des rations à taux élevés cl'acides aminés essenticls (ADkixs et al., I966), mais son apport excessif, comme celui d'hydroxyproline et de grlycine provoque une dépression de croissance (ABERNATHY et Miller, 1965; Yokota, 1964); à notor que l'incorporation d'eau au régime du Rat semble favoriser l'utilisation des acides aminés lorsqu'ils sont présents dans des mélanges de certaine composition (ADKins et al., 1967).

En ce qui concerne l'urée et les sels d'ammonium, leur valeur nutritionnelle a soulevé un regain d'intérêt au cours des dernières années. Il était connu depuis longtemps que l'azote ammoniacal peut rapidement être incorporé dans les protéines tissulaires du Rat (Foster et al., 1939) ; cc fait a ćté retrouvé chez le Porc (Liu et al., I955), l'Homme (Kies et al., I965) et le Chien (Gafbler et Choitz, 1965). La presque totalité des expárienczi réaliséss depuis cette période et rapportées dans le rableau 3 montre une réponse positive des animaux et de l'Homme à l'addition de ces composés, qu'ils soicnt sous forme de citrate ou d'acétate (Rose et al., 1949).

Par contre, l'urée serait moins efficace ainsi que le démontrent les travaux anciens de ScHoenheimer (I942), de Rose et al. (1949) et de Lardy et lieldott (1949) ; une proportion faible de l'azote uréique ingéré, après dégraclation par l'uréase microbienne (FAUconveau et Michel, 1970) peut toutefois être incorporée dans les protéines corporelles (LEIFER et al.,.1948; L LU et al., 1955; Levenson et al., I959; Walser et Bodeislos, 1959). Cette question fait l'objet de nombreuses controverses comme le soulignent les expériences rapportées dans le tableau 3. Les contradictions relevées dans ces résultats tiennent probablement aux conditions expérimentales fort. 
différentes. Il apparaît ainsi que le bénéfice lié à la présence de ces substances, qu'il s'agisse d'urée ou de sels ammoniacaux, n'est visible que lorsque le taux azoté du régime auquel elles sont ajoutées n'est pas suffisant pour couvrir les besoins; par ailleurs, une réponse suboptimum de croissance ne pourra être obtenue que si l'apport d'aminoacides essentiels est suffisant pour couvrir le besoin d'azote indispensable (Kornegay et al., 1970).

\section{TABLEAU 3}

Réponse de diverses espèces animales à l'addition d'urée ou de sels d'ammonium dans les régimes

\begin{tabular}{|c|c|c|c|c|}
\hline Fspèce & $\begin{array}{l}\text { Nature de } \\
\text { l'azote (1) }\end{array}$ & Action positive & $\begin{array}{l}\text { Nature de } \\
\text { l'azote }\left({ }^{1}\right)\end{array}$ & Action nulle \\
\hline Homme & $\begin{array}{l}\text { SA } \\
\text { SA } \\
\text { SA } \\
\text { U } \\
\text { SA }\end{array}$ & $\begin{array}{l}\text { KiEs et al., } 1965 \\
\text { WATTS et al., } 196, \mathbf{1} \\
\text { SCRIMSHAw et al., } 1969 \\
\text { SNydERMAN et al., } 1962 \\
\text { READ et al., } 1969\end{array}$ & & \\
\hline Rat & $\begin{array}{l}\text { U } \\
\text { SA } \\
\text { SA } \\
\text { SA }\end{array}$ & $\begin{array}{l}\text { Rose et DEKKER, } 1956 \\
\text { IROST et SANDY, } 1951 \\
\text { LARDY et FELDOTT, 19:9 } \\
\text { WOMACK, } 1969\end{array}$ & $\begin{array}{l}\mathrm{U} \\
\mathrm{SA}\end{array}$ & $\begin{array}{l}\text { KRISS et MARCY, } 1940 \\
\text { WoMACK et al., } 1953\end{array}$ \\
\hline Poulet & $\begin{array}{l}\text { U } \\
\text { SA-U } \\
\text { SA } \\
\text { SA } \\
\text { SA } \\
\text { U }\end{array}$ & $\begin{array}{l}\text { Sullivan et Bird, } 1957 \\
\text { FEATHERston et al., } 1962 \\
\text { ChaVEz et al., } 1966 \\
\text { YounG et al., } 1965 \\
\text { SHANNON et al., } 1969 \\
\text { ZENISEK et I.AUTNER, } 1969\end{array}$ & $\begin{array}{l}\mathrm{U} \\
\mathrm{U} \\
\mathrm{SA}-\mathrm{U}\end{array}$ & $\begin{array}{l}\text { ARKERSON et al., } 19 \prime 0 \\
\text { VAN DER MEULEN, } 1943 \\
\text { JONES et COMBS, } 1952\end{array}$ \\
\hline Chien & SA & GaEBLER et Choitz, 1965 & & \\
\hline l'orc & $\begin{array}{l}\text { SA } \\
\text { SA } \\
\mathrm{U} \\
\mathrm{U}\end{array}$ & $\begin{array}{l}\text { DUDLEY et al., } 1962 \\
\text { SHELTON et al., } 1950 \\
\text { KORNEGAY et al., } 1965 \\
\text { KORNEGAY et al., } 1970\end{array}$ & $\begin{array}{l}U \\
U \\
U \\
U\end{array}$ & $\begin{array}{l}\text { HANSON et FERRIN, } 1955 \\
\text { HAYS et al., } 1957 \\
\text { PASTLSZEWSKA, } 1967 \\
\text { HINTZ et al., } 1969\end{array}$ \\
\hline
\end{tabular}

(1) U : Urée.

SA : Sels d'ammonium.

En tout état de cause, on peut conclure que l'utilisation, à des fins de synthèse protéique, de ces substances n'est que très partielle, surtout chez des animaux à grande vitesse de croissance, ce qui rend nécessaire l'apport d'acides aminés non essentiels et on peut actuellement douter de l'intérêt économique de l'incorporation de telles substances dans le régime cles animaux producteurs de viande.

Quoi qu'il en soit, l'apport d'azote non essenticl, surtout sous l'aspect d'acides aminés dispensables, représente une composante non négligeable de la valeur biologique des protéines.

\section{II. - Déséquilibre d'acides aminés}

Il faut que les protéines alimentaires fournissent des acides aminés en quantités correspondantes aux besoins d'acides aminés pour deux raisons complémentaires :

- les acides aminés indispensables doivent être apportés simultanément sur les lieux de la synthèse protéique (GEIGER, 1947) ; 
- il n'existe que de faibles stocks d'acides aminés libres dans les tissus (essentiellement 1ysine, thréonine) (PAwLAK et PIoN, I967). Une source complémentaire d'acides aminés est représentée par les protéines à "turnover " court comme celles du tube digestif (FAUCONNEAU et MICHEL, 1970). Mais ce facteur de régulation de l'équilibre des protéines ne peut évidemment intervenir que sur des périodes brèves.

Il est donc généralement admis que l'efficacité avec laquelle une protéine est utilisée comme source d'aminoacides indispensables pour les animaux dépend avant tout de la correspondance plus ou moins étroite entre les proportions des divers acides aminés indispensables. qu'elle contient, et la proportionnalité des besoins, compte tenu des phénomènes de digestibilité. Lorsqu'un des acides aminés n'est présent dans l'apport protidique qu'en quantité suffisante pour satisfaire les besoins, il entraîne une inaptitude partielle de la protéine en question à couvrir les. besoins. L'acide aminé indispensable qui provoque ainsi la déficience partielle ou totale de la protéine est appelé facteur limitant car c'est de son apport que dépend la vitesse de synthèse đes. tissus protéiques pendant la croissance ou leur renouvellement à l'entretien.

Cependant, la notion de facteur limitant ne peut se traduire en valeur absolue ; un acide. aminé ne devient nullement limitant à partir d'un certain seuil quantitatif ; il le devient à partir d'un certain seuil de déficience velative. C'est uniquement l'équilibre entre les acides aminés qui conditionne la nature du facteur limitant. Autrement dit, le rôle propre d'un acide aminé est fonction de sa quantité relative par rapport aux autres et non de son taux en valeur absolue. Chaque protéine est caractérisée par une architecture particulière et le pourcentage d'un acide aminé donné n'a pas la même signification nutritionnelle dans un cas ou dans l'autre. Les protéines de tournesol renferment à peu près le même pourcentage d'acides aminés soufrés que la farine de hareng de Norvège (soit respectivement 4 , io et 3,95 p. Ioo des protéines). Malgré cela, l'adjonction. d'extra méthionine valorise les protéines de poisson (tabl. 4), alors que la lysine se révèle efficace pour supplémenter le tournesol; la teneur du tournesol en lysine est, en effet, beaucoup plus. faible (3,6 p. Ioo des protéines) que celle des protéines de poisson (8, I 5 p. Ioo). A noter cependant que l'addition de lysine, de telle façon que son taux global dans les protéines soit de 6,6 p. Ioo. permet au tournesol d'acquérir une valeur nutritionnelle comparable à celle de la farine de poisson non supplémentée par la méthionine, précisément parce que c'est la méthionine qui devient alors. le facteur limitant du régime tournesol + lys ine au même niveau que dans le poisson.

\section{TABI EAU 4}

Supplémentation comparée des protéines de tournesol et de farine de poisson (RÉrat et Henry, 1963, 1965). Taux protidique: 8 p. 100

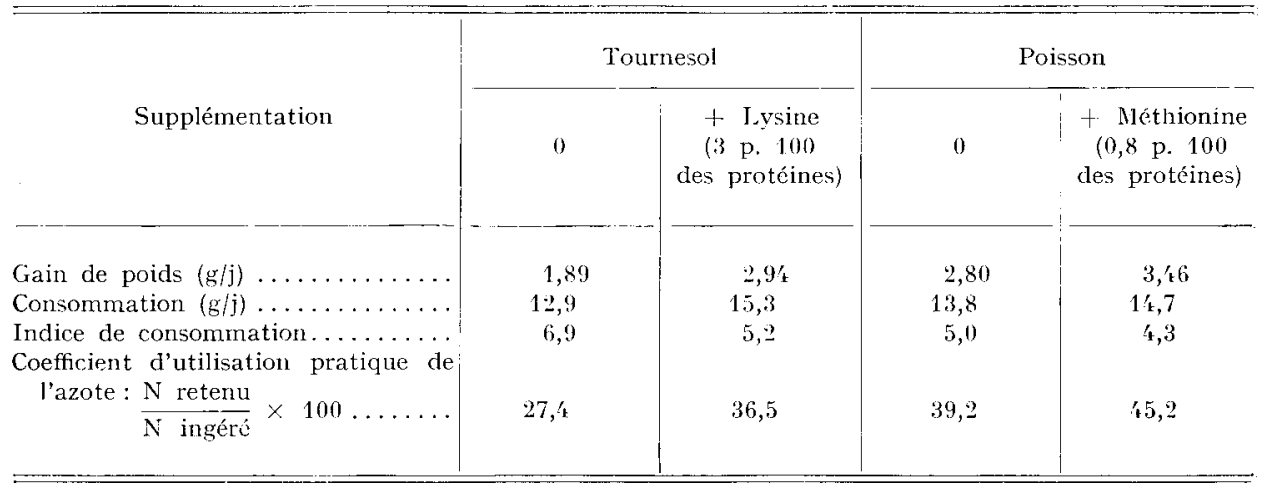

S'il existe un équilibre optimum fondé sur un apport minimum, il existe également un équilibre fondé sur un apport maximum. C'est ainsi qu'en 1952, JAcQuot a étendu la notion de facteur limitant par défaut à celle de facteur limitant par excès. 
Les phénomènes se produisant en présence d'excès d'un acide aminé ont été précisés et analysés, notamment par l'équipe de ELVEHJEM et de HARPJer. Ils ont fait l'objet d'un certain

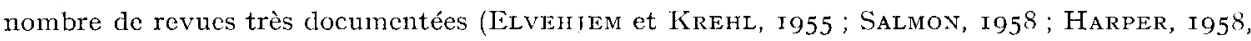
1964). Il semble ainsi qu'il soit possible de diviser ces phénomènes en trois grandes catégories (HARPER et RoGers, 1965) : les déséquilibres, les antagonismes et les toxicités.

En ce qui concerne les déséquilibres, il en existe deux types dont les consécuences, généralement une clépression de croissance et une perte d'appétit peuvent être prévenues ou complètement guéries par la simple addition de l'acide aminé facteur limitant primaire du régime.

Le premicr type de déséquilibre est mis en évidence lorsque de faibles quantités d'un ou deux acides aminés (indispensables ou non) autres que le facteur limitant sont ajoutées au régime : il n'apparaît que quand le taux azoté est faible (inférieur ou égal à 8 p. Ioo). L'aminoacide qui crée lo déséquilibre est généralement celui qui est le facteur limitant secondairc pour la croissanco (Hanies et al., i949; Henderson et al., i953; Rosexberg et al., 1959). Ce type de déséquilibre ne se produit pas ae façon régulière ct il est difficile à prévoir. Un exemple en est donné dans le tableau 5 .

\section{TABLEAU 5}

liffets de supplements de lysine et de thréonine sur la croissance de liats recevant un régime contenant $90 \%$ p. 109 de viz (ROSEXBERG et al., 1959)

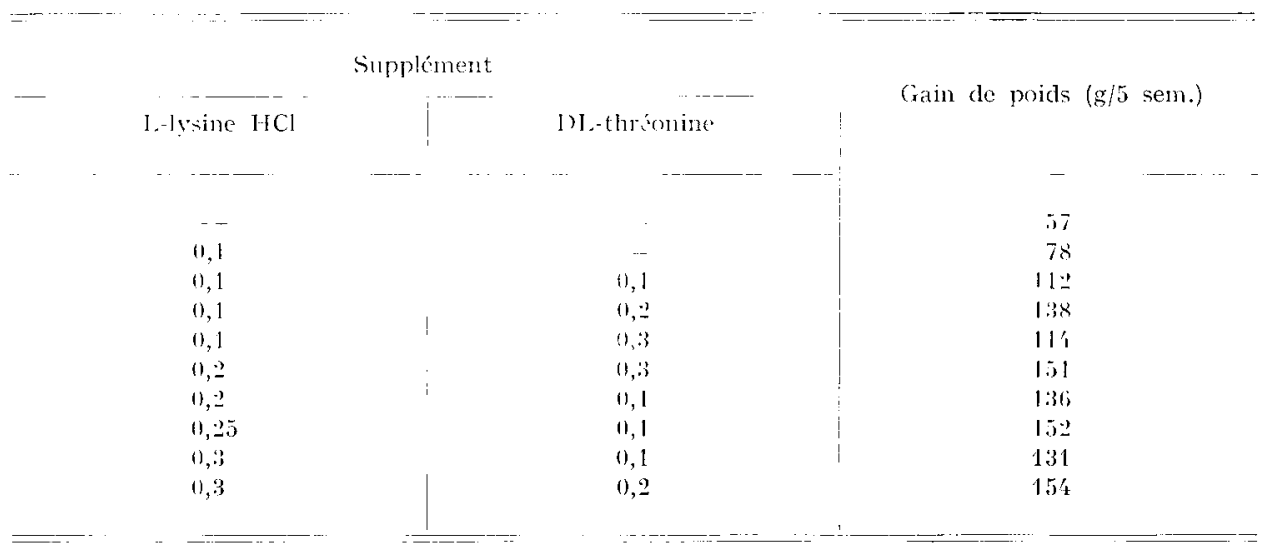

Des variations de concentration d'acide aminé aussi faibles que celles enregistrées dans cette expérience (O, I p. Ioo) ont ainsi des conséquences très marquées sur la croissance et la consommation.

Le second type de déséquilibre se produit quand on ajoute au régime un apport important d'une protéine (ou d'un mélange d'acides aminés) totalement déficiente en un acide aminé donné ; ce déséquilibre apparaît à tous les niveaux azotés, même à ceux permettant une croissance maximum. Ainsi, un régime à 12 p. Ioo de casćine additionné cle méthionine permet à des rats d'atteindre une vitesse de croissance maximum; si on ajoute I5 p. Ioo de gélatine, protéine déficiente en tryptophane, il se produit une dépression de croissance qui ne disparaît qu'après addition cle tryptophane. La teneur en tryptophane du régime initial à base de caséine, qui était suffisante pour couvrir le besoin en cet acidc aminé lorsque les matières azotées du régime étaient équilibrécs, se révèle trop faible lorsque le taux azoté du régime a été augmenté à l'aide d'une protéine déséquilibrée (tabl. 6). Contrairement au précédent, le deuxième type de déséquilibre se produit de façon régulière et prévisible.

L'explication de ces phénomènes cst encore loin d'avoir été fournis. Cependant, dans le domaine des déséquilibres, certains faits ont été précisés par HARPER et son équi pe et confirmés 
par d'autres équipes, faits qui permettraient d'ébaucher une hypothèse concernant leur méca. nisme.

\section{TABLEAU 6}

Prévention par le tryptophane de la dépression de croissance

induite par la gélatine chez le Rat recevant des régimes contenant divers taux de caséine (Elias, Kumta et Harper, i959-ig6i)

\begin{tabular}{|c|c|c|c|}
\hline \multicolumn{3}{|c|}{ Régime } & \multirow{2}{*}{$\begin{array}{l}\text { Gain de poids } \\
\text { (g/2 semaines) }\end{array}$} \\
\hline Caséine p. 100 & Gélatine p. 100 & DL-tryptophane p. 100 & \\
\hline 6 & - & - & 22 \\
\hline 6 & 12 & - & 13 \\
\hline 6 & 12 & 0,2 & 51 \\
\hline 8 & - & - & 53 \\
\hline 8 & 15 & - & $2 \prime^{\prime}$ \\
\hline 8 & 15 & 0,2 & 77 \\
\hline
\end{tabular}

— La dépression de croissance due à un déséquilibre par excès est secondaire à une dépression de la consommation : souvent précédée d'une augmentation fugitive $(4 \mathrm{~h})$ de la consommation (SANAHUjA et Rio, I968), cette dépression se produit dans les six heures après la création du déséquilibre (HARPER ct Kumta, I959). La vitesse de croissance initiale est retrouvée lorsque le niveau de consommation primitif est restauré à l'aide de diverses techniques : injection d'insuline (KumTA et HarPer, I962) ou de cortisone (LeUng et al., I964; LeUng et al., rg68 c), exposition au froid (Klain et al., r962 ; Klain et Vaughan, 1963 ; Beaton, I967 ; Harper et Rogers, 1966), alimentation forcéc (LeUng et al., I964, I968 b), alimentation "séparéc " (Peretianu et Abraham, I964, i965; Morrison et Caldwell, I966). Cette restauration de la vitesse de croissance ne s'accompagne pas de lésions diverses, comme dans le cas des déficiences d'acides aminés compensées par l'usage de techniques identiques (Sidransky et Verney, I968).

- Des rats soumis au libre choix préfèrent consommer un régime sans azote qui ne peut leur permettre de survivre plutôt qu'un régime déséquilibré par excès qui pourtant pourrait leur permettre de croître (SANAhUja et HARPER, I962, I963; LeUng et al., I968 a).

- L'acide aminé qui représente le facteur limitant du régime déséquilibré par excès voit sa concentration diminuer dans le plasma du sang au cours des quelques heures qui suivent l'ingestion de ce régime (Kunta et Harper, I962; Sanahuja et Harper, 1963); cette diminution est accompagnée d'un changement de même sens dans le foie et le muscle et précède la dépression d'appétit (Ellison, I968). Il existe en outre une relation étroite (négative) entre la concentration plasmatique d'acides aminés totaux pendant la même période et la consommation spontanée (PENG et HARPER, I970) et l'injection de ce facteur limitant préalablement à l'ingestion du régime déséquilibré restaure un niveau normal de consommation (LEUNG et RoGers, I969). Tous ces changements sont variables selon les régimes antérieurement distribués aux animaux (ANDERSON et al., I969; PenG et al., I969) et selon l'intensité du catabolisme plus ou moins marqué pour chaque acide aminé.

- L'acide aminé limitant n'est pas catabolisé de façon plus active lorsque le régime est déséquilibré par excès ; son incorporation dans les protéines du foie est augmentée alors que son incorporation dans les protéines musculaires n'est pas modifiée (Yoshida et al., I966; Sanahuja et Rio, I967 ; Benevenga et al., I968; Hartman et King, I967; Yamashita et Ashida, 1969) ou n'est que légèrement augmentée (Soliman et KING, I969). Il apparaît donc que son utilisation pour la croissance reste non altérée (NETKE et al., x969).

Certains de ces faits, notamment ceux qui concernent la consommation ad libitum et le 
libre choix (GreEnstein et Winitz, i96I) ainsi que le niveau de l'acide aminé limitant dans le plasma (Longenecker et Hause, i959: McLaughlan et Morrison, ig68) sont également mis en évidence quand il existe un déséquilibre par défaut.

A titre d'hypothèse, Harper et Rogers (1965) expliquent de la façon suivante la séquence des événements succédant à l'ingestion d'un régime déséquilibré : "la protéine alimentaire est apparemment digérée normalement, et les aminoacides du repas sont absorbés de façon efficace. Ces phénomènes provoquent l'apport dans le sang porte irriguant le foie d'un surplus de tous les acides aminés indispensables sauf un (le facteur limitant). Le surplus d'acides aminés stimule la synthèse ou supprime le catabolisme des protéines si bien que l'acide aminé limitant est retenu en quantité plus grande dans le foic des animaux recevant le régime déséquilibré que dans celui des animaux recevant le régime normal. L'apport de l'acide aminé limitant aux tissus périphériques est, par là-mème, réduit, mais non à un niveau qui puisse influencer la synthèse protéique. Les protéines musculaires continuent d'être synthétisées selon une vitesse normale, si bien que les contenus en acides aminés libres du muscle et du plasma deviennent gravement déséquilibrés, leurs proportions ressemblant à celles provoquées par l'ingestion d'un régime sévèrement carencé. Certaines de ces modi fications sont contrôlées par un centre de régulation de l'appétit et la consommation de nourriture est réduite. De la climinution de la consommation résulte un apport amoindri d'énergie et d'aminoacides et la croissance est retardée. "

Quoi qu'il en soit, quand l'efficacité d'utilisation de l'acide aminé limitant est calculée, il est évident que le gain par unité d'acide aminé limitant ingéré est plus faible pour les animaux recevant un régime déséquilibré par excès, corrigé par addition de l'acide limitant, que pour ceux recevant le régime témoin et présentant la même vitesse de croissance.

Selon Salmon (1958) l'excès inutilisable induirait un catabolisme exacerbé des autres acides aminés y compris le facteur limitant. HARPER ne considère pas que ce catabolisme est le phénomène déterminant; d'après lui, l'excès d'un acide aminé provoque une diminution de l'appétit qu'on ne peut pallier que par addition de l'acide aminé limitant par défaut ; ce qui conduit finalement à apporter un surplus de cet acide aminé par rapport au besoin de la synthèse protéique. Dès lors, cet apport supplémentaire est purement et simplement catabolisé.

Les antagonismes se distinguent des déséquilibres par excès du fait que l'addition du facteur limitant primaire ne corrige pas les conséquences dues à l'excès d'un aminoacide; par contre, l'addition de certains acides aminés, de même famille sur le plan de leur structure, et dont aucun n'est limitant, permet aux performances de croissance de redevenir normales.

Un exemple d'antagonisme avec un régime limité en thréonine est donné dans le tableau 7.

\section{TABLEAU 7}

Influence de suppléments de divers acides aminés sur la dépression de croissance causée chez le Rat par l'excès de leucine

(HARprer et Rogers, I965; Benton et al., 1956)

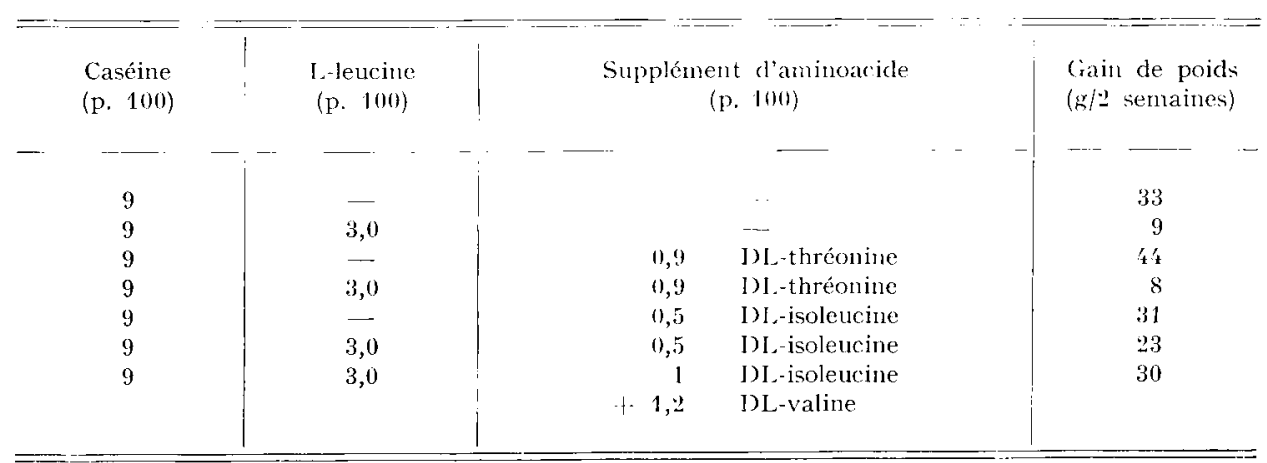


Les cas les plus connus d'antagonisme concernent les relations entre leucine, isoleucine et valine (SPOLter et HARPER, I96I ; Rogers et al., I962 ; Rogers ct al., 1967) et les relations cntre lysine et arginine (Jones, I964 ; Lewis, I965 ; SMITH et Lewis, I96.1 ; BoorMAN et Fisher, I 966 ; DEAN et SCOTT, I968). Une forte surcharge de leucine dans le régime provoque une baisse importante de la concentration plasmatique d'isoleucine et de valine (SWENSEID et al., I965; CLARK et al., I968), alors que cette diminution aurait dû porter sur l'acide aminé limitant clu régime qui est représenté par la thréonine (TAxxous et al., ig66). De la même façon, un excès delysine chez la Volaille déprime le taux d'arginine libre dans le plasma sanguin, mais pas à la suite des repas ce qui signifie que la lysine ne modifie pas la digestion ct l'absorption de l'arginine (Jones et al., 1967). Ces faits sont intéressants à considérer en relation avec ce quí est rapporté par HaRper et son équipe pour expliquer les déséquilibres.

Les toxicités, généralement dues à de larges apports d'un acide aminé donné, se distinguent des cléséquilibres par le fait que leurs effets ne sont que partiellenent estompés lorsqu'on augrmente de façon concomitante le taux de l'acide aminé limitant primaire ou celui de la protéine dans le régime. Ces cffets sont d'ordre multiple, allant de la perte de poids à la création de lésions diverses au niveau de clivers organes; citons notamment les lésions oculaires et podales crées par l'excès de L-tyrosine (Schweizer, I947). La plapart des acicles aminés ingérés en excès sont susceptibles de créer un retard de croissance et même parfois une mortalité importante (SMrтf I968 b). Ceci a été montré par les études extensives réalisées sur un grand nombre d'acides aminés (Sauberlich, i96i ; Daniel et Waismax, i968; Harper et al., ig66).

Les effets toxiques des acides aminés en excès sont moins marqués, mais existent toujours lorsqu'on élève le taux azoté du régime (SAUBERLICH, I96r) et ceci est vrai même quand on augrmente dans les mêmes proportions l'excès d'acide aminé et le taux d'azote du récrime (HARPER et al., i 966). Il en est de même lorsqu'on élève le taux de l'acide aminé limitant du régime (HARPER et al., I 966). Les effets dépressifs sur la croissance semblent liés à une diminution de l'appétit, et non à une diminution d'utilisation du régime (HARPER et al., I966) et les effets toxiques ne disparaissent pas lorsqu'on augmente artificiellement l'appétit à l'aide de cortisol (ALAM et al., I 967).

Des études plus particulières ont été réalisées récemment soit sur la toxicité de la phénylalanine (Tamimie et Pscheidt, i966; Dolax et Godin, I966), de la lysine (Bergner, ig66) de la méthionine (BERGNER, 1967) et sa prévention par le glycocolle (BENEvenga et HARPER, 1967; BERGNER et al., I968 a). Citons enfin les très importants travaux réalisés sur les excès de tyrosine, qui méritent d'être décrits : Ainsi, l'intoxication due à l'excès de tyrosine (3 p. Ioo) peut être prévenue par un large apport de thréonine $(0,8$ à $1,2.5 \mathrm{p}$. 100), mais les lésions apparaissent toutefois après deux mois si l'on n'ajoute pas un faible supplément de glycocolle au régime (ALAM et al., i966 b) ; cette action préventive de la thréonine, facteur limitant du régime, serait due, selon Godrv (I967) non pas à une augmentation du catabolisme ou de l'excrétion de tyrosine, mais à sa meilleurc utilisation pour la synthèse tissulaire et il se produit une diminution du taux de tyrosine dans le plasma (Alam et al., I966 a). Harper (1968) en conclut que, si un acide aminé en excès a un effet toxique qui lui est propre - c'est du reste également l'opinion de Daniel et Watsman (I968) il crée en outre un effet de déséquilibre qui fait que les effets toxiques sont partiellement diminués par l'addition du facteur limitant du résime; ce facteur limitant améliore la synthèse protéique et tend à normaliser les niveaux d'acides aminés dans le plasma.

En conclusion, quel que soit le mécanisme impliqué dans l'ensemble de ces phénomènes, il en résulte que l'équilibre quantitatif des acides aminés est un factcur très important de la valeur biologique des protéines.

\section{II - Conclusion}

Un certain nombre de travaux importants ont été réalisés au cours des dernières années, et certains faits ont pu être précisés.

Ainsi, le besoin d'acides aminés des diverses espèces a été étudié à l'aide de nouvelles techniques basées sur l'aminoacidémie, et de nouvelles recommandations ont pu être établies par 
comparaison entre ces techniques et les techniques plus anciennes basées sur le poids et la rétention azotée.

L'importance de l'apport d'acides aminés non essenticls a été à nouveau mise en évidence, et l'existence d'une hiérarchie parmi ces acides aminés a été établie dans la couverture clu besoin d'azote non essentiel. La très faible utilisation de l'uréc alimentaire par les monogastriques a été de nouveau soulignée.

Lc phénomène de déséquilibre par excès a été particulièrement étudié et un certain nombre de faits ont été fournis qui permettent d'étayer partiellement unc théorie aminostatique de l'appétit.

Il faut rappeler qu'outre l'apport et l'équilibre des acides aminés, un autre facteur très important de variation de la valeur biologique est représenté par la disponibilité des acides aminés. Ce facteur a été longuement discuté dans notre précédente revue (JAcquot et RÉrat, ig66) et relativement peu d'éléments nouveaux ont été fournis par l'expérimentation au cours des dernières années, sauf sur le plan de la méthodologie (cf. chap. II c 3).

\section{B. - Facteurs ExtrinsṫQues}

$\Lambda$ côté de ces facteurs intrinsèques, il existe des facteurs extrinsèques cn rapport avec la consitution du régime alimentaire. Parmi ceux-ci, il faut citer :

- le taux azoté qui conditionne à la fois l'apport du facteur limitant primaire et l'apport d'acides aminés non essenticls;

-- le taux énergétique clu régime et le niveau de consommation de ce régime; à ce sujet, l'accent sera mis sur la solidlarité étroite qui relie le besoin énergétique au besoin azoté, et sur les relations cntre la consommation spontanée d'énergie et la rétention azotée qui dépend à la fois de la valeur biologique des protéines et de la quantité des protéines administrées.

- L'apport de sucres qui ont un rôle propre d'épargne d'azote.

- Les apports vitaminiques et minéraux, et la présence d'adjuvants de l'alimentation tels que les antibiotiques dont un des mécanismes d'action pourrait passer par le relais d'une épargne sur le métabolisme azoté.

Seuls les deux premiers facteurs seront discutés, les autres ayant été développés dans une revue précédente (JACQUOT et RÉRAT, I966).

\section{I. - Taux protólque}

Ia valeur biologique d'une protéine dépend du taux auquel elle est introduite dans la ration. Il existe une limite inférieure et une limite supérieure de la teneur protéique clu régime en dehors desquelles l'utilisation de l'azote à des fins anaboliques se fait mal.

Une série d'essais réalisés sur le Rat blanc par HENRY et Rérat (in JACQUot et Rérat, 1966) permet de préciser certains de ces phénomènes. Au cours de ces expériences étaient administrées, en alimentation ad libitum ou selon la méthode "paired-feeding " de Mitchell (MitCHELL et BEADLES, 1930), plusieurs sources azotécs de qualité variable (farine de hareng de Norvège, tourteau d'arachide, gluten de blé, tourteau de tournesol), introduites à différents taux dans des régimes semi-synthétiques. L'examen des résultats de ces diverses expériences, a permis d'aboutir à un certain nombre de conclusions. Ainsi, pour une protéine donnée, la vitesse de croissance et de rétention azotée, au cours des $5^{6}$ jours d'expérience, augmentent avec le taux protidique du régime jusqu'à un maximum variable avec la nature de la protéine. Les gains moyens journaliers maximum et les taux des matières azotées correspondants sont rapportés dans le tableau 8.

Comme on peut le constater, le taux de matières azotées qui assure la croissance maximum est d'autant plus faible et la vitesse de croissance maximum est ellc-même d'autant plus élevée 
que la source azotée est de meilleure qualité. En d'autres termes, une protéine de mauvaise qualité ne se substitue pas complètement à une protéine de bonne qualité lorsqu'on augmente son taux d'administration dans le régime.

TABLEAU 8

Croissance maximum autorisée par diverses protéines et taux optimum correspondant

(RÉRAT-HENRy (1))

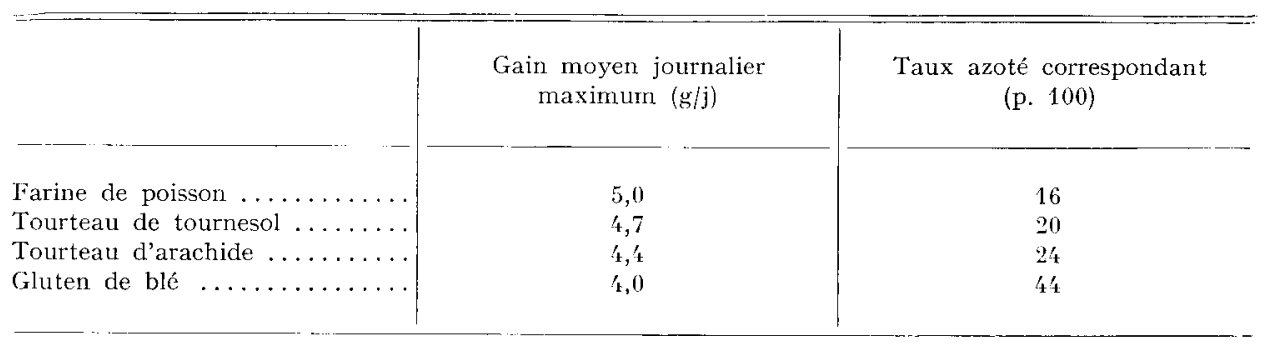

(1) In JACQUOT-RéRAT (1966).

En ce qui concerne les critères d'efficacité azotée (coefficient d'efficacité protidique, coefficient d'utilisation pratique de l'azotej l'évolution est la même que pour le gain de poids. Les différences d'une source azotée à l'autre sont d'autant plus importantes que le taux azoté est plus faible; inversement, lorsque ce dernier est élevé, l'efficacité azotée a tendance à être la même pour des protéines de qualité différente.

Ces observations confirment les résultats obtenus par d'autres auteurs, en particulier OsBorne et Mendel (I9I5, I9I6, I9I7), Barnes et Bosshardt (1946) et plus récemment Allison et al. (1959), Hegsted et Chang ( 1965 a). Sur le plan métabolique, il est facile d'expliquer ce qui se passe : lorsque l'apport d'acides aminés indispensables excède ce qui est nécessaire pour une synthèse protéique naximum, le surplus de ces acides aminés est catabolisé à des fins énergétiques. (BUNCE et KInG, Ig69a et $b$ ) et l'azote supplémentaire est excrété par l'urine. Le rendement de la rétention azotée est ainsi diminué.

Cependant, certains points soulèvent la discussion :

- Ainsi, si tous les auteurs sont d'accord sur le fait que la NPU (net protein utilization) $q_{i}$ exprime le rendement de la rétention azotée est constante pour les apports azotés en dessous et au niveau de l'entretien, certains (Milder et PAyne, Ig6i ; Morrison et al., I963) considèrent qu'elle décroît pour les taux qui dépassent le niveau d'entretien; par contre, pour d'autres. (Hegsted et Chang, ig65 $b$; Hegsted et Worcester, ig67; Barnes et Bosshardt, 1946) la NPU resterait constante jusqu'au taux azoté assurant une croissance maximum, et ne décroitrait qu'à des taux supérieurs.

- Par ailleurs, la relation entre la diminution du rendement de la rétention azotée traduit par la NPU, et le taux des calories protidiques dans le régime serait selon MiLler et PAyNE. (I96I b) et d'autres auteurs (LeHmann et Hock, 1968) de forme linéaire et la pente est une caractéristique de chaque protéine (Miller et PAyne, I96I $b$ ) ; mais tel n'est pas l'avis d'autres auteurs qui l'expriment sous forme semi-logarithmique (Morrison et al., I963; TAGLE et Donoso, 1967) ou hyperbolique (Rafalski et al., I968).

- Selon Miller et Payne (I96I b), la NPU s'annulerait pour un taux d'introduction commun à toutes les protéines. correspondant à 54 p. Ioo de calories d'origine protidique dans le régime. Sur ce point, les autres auteurs ne sont pas d'accord, ni sur le plan théorique (NJAA, I962), ni sur un plan plus pratique (MoRrisos et al., I963); sans s'annuler complètement, la 
NPU atteint une valeur minimum aux hautes teneurs azotées, et le taux azoté correspondant est une caractéristique de chaque protéine.

A noter que le taux azoté peut intervenir également par l'apport qu'il représente d'acides aminés non essenticls. Selon Stucki ct HArper, (1962) chez le Rat, le rapport acides aminés indispensables

acides aminés dispensables $=$ (I/D) dans l'aliment, rapport établi à l'aide de régimessynthétiques, pourrait varier de 4 à I sans qu'il en résulte de diminution de la croissance ou de la rétention azotée : des rapports supérieurs seraient, par contre, défavorables. Les Volailles semblent beaucoup plus sensibles aux variations du rapport I/D dans le régime; l'optimum étant de 2 selon STUCki et Harper (I96I) ou de I,5 selon Sugahara et Ariyoshi (1968), et le rendement alimentaire est le meilleur quand I/D est situé entre I et I,5. A noter que, pour les Volailles, cc rapport est supérieur à celui qui est trouvé dans la plupart des protéines naturelles (FAuconNead, ig64). Mais l'apport excessif d'acides aminés non essentiels est probablement négligeable dans la variation de la valeur biologique des protéines.

\section{II. - Epargne de l'azote par l'apport énergétique}

La valeur biologique d'une protéine dépend également du taux énergétique du régime et du niveau de consommation de ce régime. La fourniture d'énergie, assurée principalement par les apports glucidiques et lipidiques, est indispensable à la synthèse protéique et les relations entre ingéré éncrgétique et besoin azoté ont fait l'objet de nombreuses études résumées dans plusieurs revues (Maignon, I933; Swanson, 1959; Munro, 1951, I964).

Il existe ainsi, pour les différents niveaux d'ingestion azotée, une consommation optimum d'éléments énergétiques correspondant à une rétention maximum d'azote (Calloway et Spector $1954,1955 a, b, c)$. En fait, le besoin énergétique se révèle prioritaire et s'il n'est pas couvert par, l'apport de sucres et de lipidcs, il doit être satisfait à l'aide des autres principes alimentaires contenus dans le régime, les protéines ; celles-ci sont alors détournées de leur rôle essentiel qui est (le fournir spécifiquement des éléments nécessaires à la synthèse protéique (RAo et Morrison, 1966). De nombreuses études faites chez les animaux en croissance, il résulte qu'il existe également un rapport calories/protéines optimum pour chaque stade de la croissance ; ceci a été vérifié aussi bien chez le Poulet que chez le Rat (Hill et Dansky, 1950; Combs et Romoser, 1955 ; L.eong et al., 1955; Matterson et al., 1955; Donaldson et al., 1955, 1956 ; Sunde, 1956; Yoshid a al., 1957). Mais il n'existe pas de niveau absolu car tout organisme peut s'adapter à des niveaux caloriques et azotés divers en fonction de son état physiologique préalable (Allison, I957).

Cette action d'épargne qu'exercent les calories pour l'azote se manifeste durant une assez longue période après l'ingestion de la source d'énergie : ainsi, un surplus d'énergie, administré quelques heures après le repas contenant de l'azote, est à peu près aussi efficace pour accroître la rétention azotée que si on le procure simultanément; son action est seulement plus lente à se faire sentir puisqu'il faut un à deux jours de délai (Munro et Vikramakayake, 1954); en outre, clle est durable et se maintient pendant quelques jours après la suppression de la source d'énergie supplémentaire.

Quoi qu'il en soit, compte tenu de l'influence de l'ingéré énergétique sur la synthèse protéique, tous les facteurs susceptibles de modifier, soit le taux énergétique du régime (teneurs cellulosique et lipidique), soit le niveau de consommation (nature des glucides alimentaires, exposition au froid) sont à même d'influencer l'utilisation de l'azote alimentaire et par là même l'estimation $\mathrm{du}$ besoin. Il faut d'ailleurs bien préciser, lorsqu'il s'agit de l'alimentation ad libitum que ces facteurs sont le plus souvent liés car l'animal en croissance a tendance à ajuster sa consommation d'après la densité énergétique de son régime (Volaille: HILl et DaNSKY, I950; Porc: Clawson et al., I962 ; Bowland, I962; Henry et Rérat, I964; Poley et Seerley, 196i; Henry, ig68; Henry et Rérat, ig66). 
Un ensemble de travaux récents réalisés en France met l'accent sur la solidarité étroite qui relie le besoin énergétique au besoin azoté. En I96r, à l'aide de la technique dite de l' "alimentation séparée " (distribution simultanée dans deux mangeoircs séparées d'un régime protéique en quantité fixe et d'un régime protéiprive distribué ad libitum), Calet et al. montraient que chez le Poussin le rapport optimum entre les principes énergétiques spontanément ingérés et les protéines alimentaires dépend de la nature de ces dernières. Une précision était apportée par la suite, montrant que la consommation spontanée d'énergie est en relation étroite avec la valcur biologique des protéines chez le Rat et le Poulet (АвRанам et al., I96r). Elle est également en relation avec la quantité de protides ingérés (Henry et Rérat, i962; Guillaume et Fendry, 1964) et tous ces faits sont mis en évidence dans le tableau 9.

En fait, ce phénomène d'ajustement s'effectue par l'intermédiaire du poids vif de l'animal : dans un intervalle de poids donné ( 60 à $\mathbf{I} 50 \mathrm{~g}$ ), la consommation journalière de calories est proportionnelle au poids élevé à une même puissance (voisine de 0,5 ) quelles que soient la quantité d'azote distribuée et la nature de la source azotée ; elle est en outre directement proportionnelle à la quantité d'azote retenue dans les tissus (HENRy et Rérat, 1962; Rérat et Henry, 1963 $b$ et $c$; RéRAT et al., 1963) et ce dernier point est illustré dans la figure I. La régulation des ingérés

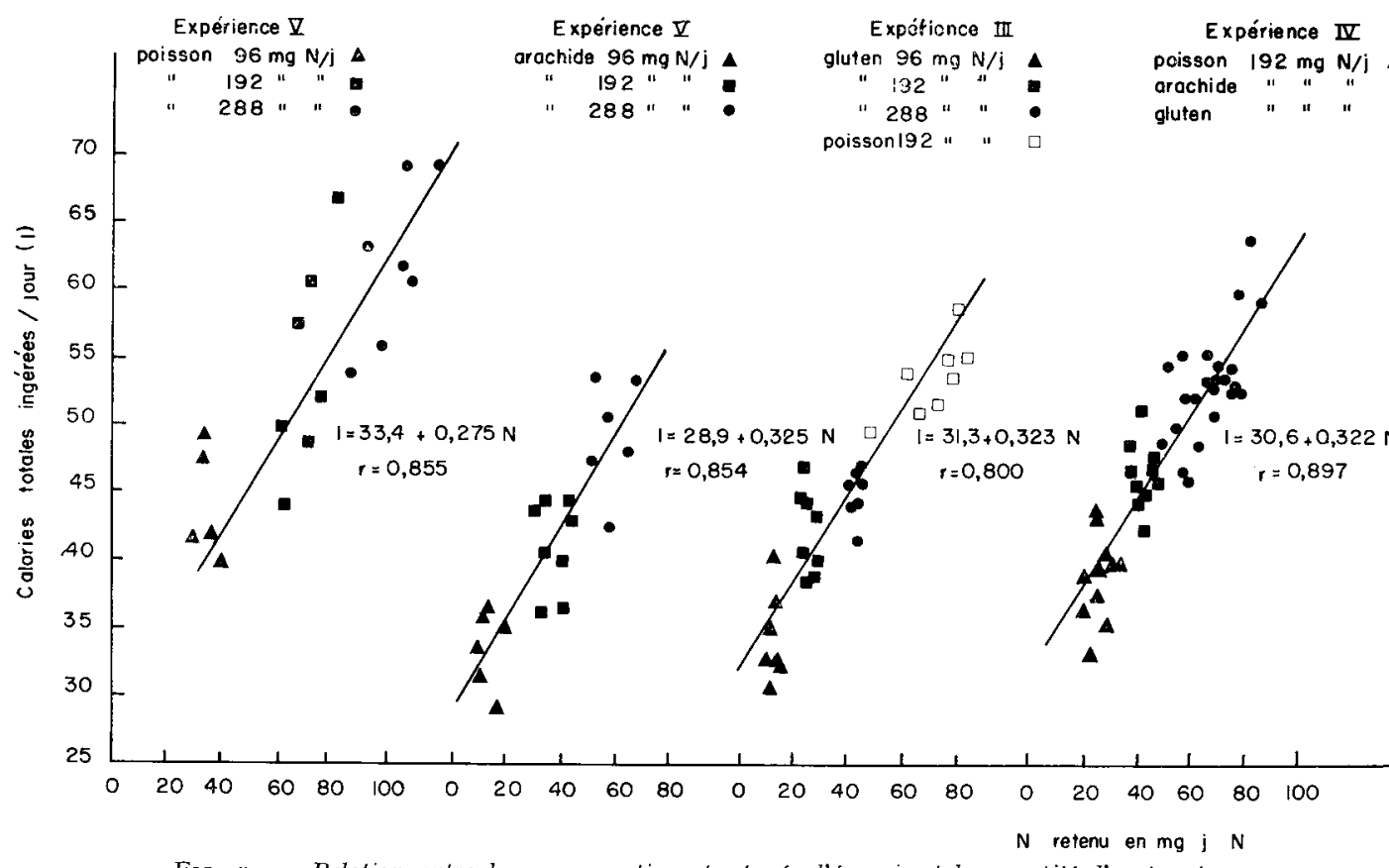

FIG. X. - Relation entre la consommation spontanée d'ênergie et la quantité d'azote retenu

(RÉrat, Henry, JACovot, I962)

caloriques en alimentation séparée n'est pas sous la dépendance des capacités digestives du Rat puisqu'elle se manifeste de façon identique lorsque varie la " densité "énergétique du régime. Faisant varier le taux lipidique du régime protéiprive, Peretianu et Abraham (I963 b) ont montré que l'ajustement calorico-azoté se fait avec une précision remarquable en alimentation séparée, quelle que soit la valeur énergétique du régime protéiprive et par là-même la quantité de matière sèche ingérée. Des études ultérieures de HENRY et RÉRAT (1966) ont précisé que l'ajustement porte sur l'énergie digestible (tabl. Io). Il ne dépend pas des facteurs sensoriels liés à la prise de nourriture; on l'observe également en introduisant directement dans l'estomac des protéines ou 


\begin{tabular}{|c|c|c|c|c|c|}
\hline 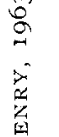 & 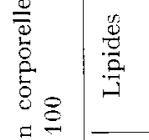 & 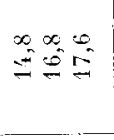 & 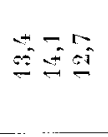 & 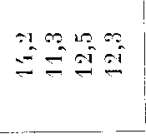 & 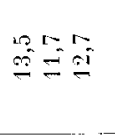 \\
\hline 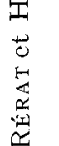 & 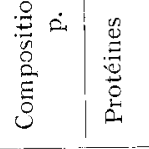 & $\begin{array}{ll}1 & = \\
0 & 0\end{array}$ & $x=0$ & 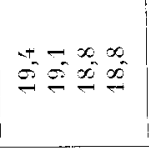 & 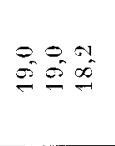 \\
\hline $\begin{array}{l}\infty \\
\infty \\
2 \\
2 \\
\cdots \\
8\end{array}$ & 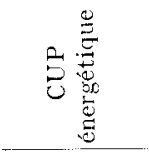 & $\begin{array}{l}0=5 \\
30=0\end{array}$ & $\Leftrightarrow$ & 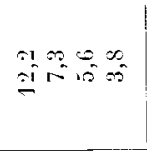 & $\begin{array}{l}10 \\
=0\end{array}$ \\
\hline 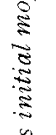 & 总 & 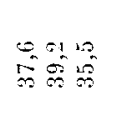 & 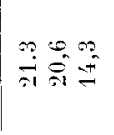 & $\begin{array}{lll}\infty & +\infty \\
8 & 0\end{array}$ & 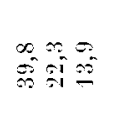 \\
\hline 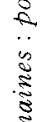 & 乙离离 & 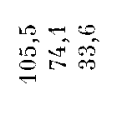 & 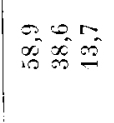 & 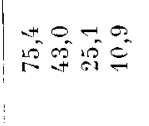 & $\begin{array}{l}0=0 \\
10=50\end{array}$ \\
\hline $\begin{array}{l}\infty \\
\infty \\
\infty \\
\infty \\
\vdots\end{array}$ & 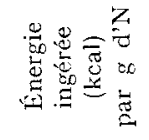 & $\stackrel{8}{8}$ & $\vec{x}=\overrightarrow{a t}$ & 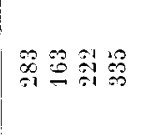 & 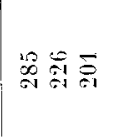 \\
\hline : & 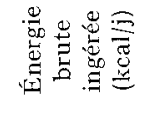 & $\frac{6}{6}=5$ & 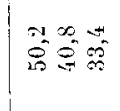 & 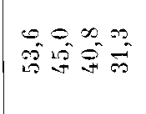 & 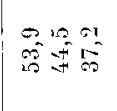 \\
\hline 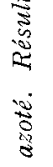 & 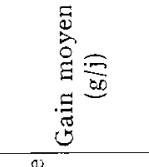 & 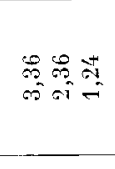 & $\stackrel{0}{0}=$ & 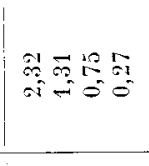 & 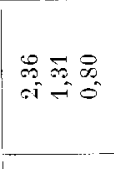 \\
\hline 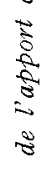 & 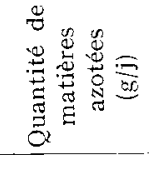 & \begin{tabular}{cc}
$\infty$ & 0 \\
\hdashline & 0
\end{tabular} & 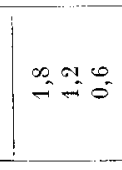 & 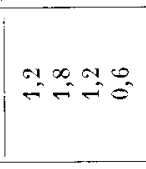 & $\stackrel{1}{9} \stackrel{103}{-}$ \\
\hline 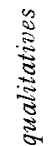 & 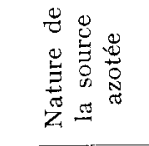 & $\begin{array}{ll}0 \\
0 \\
0 \\
0 \\
0 \\
0\end{array}$ & 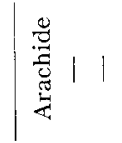 & 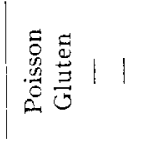 & 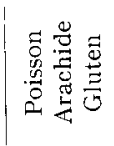 \\
\hline 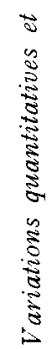 & 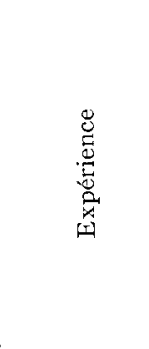 & \multicolumn{2}{|r|}{$>$} & $\Xi$ & Z \\
\hline
\end{tabular}




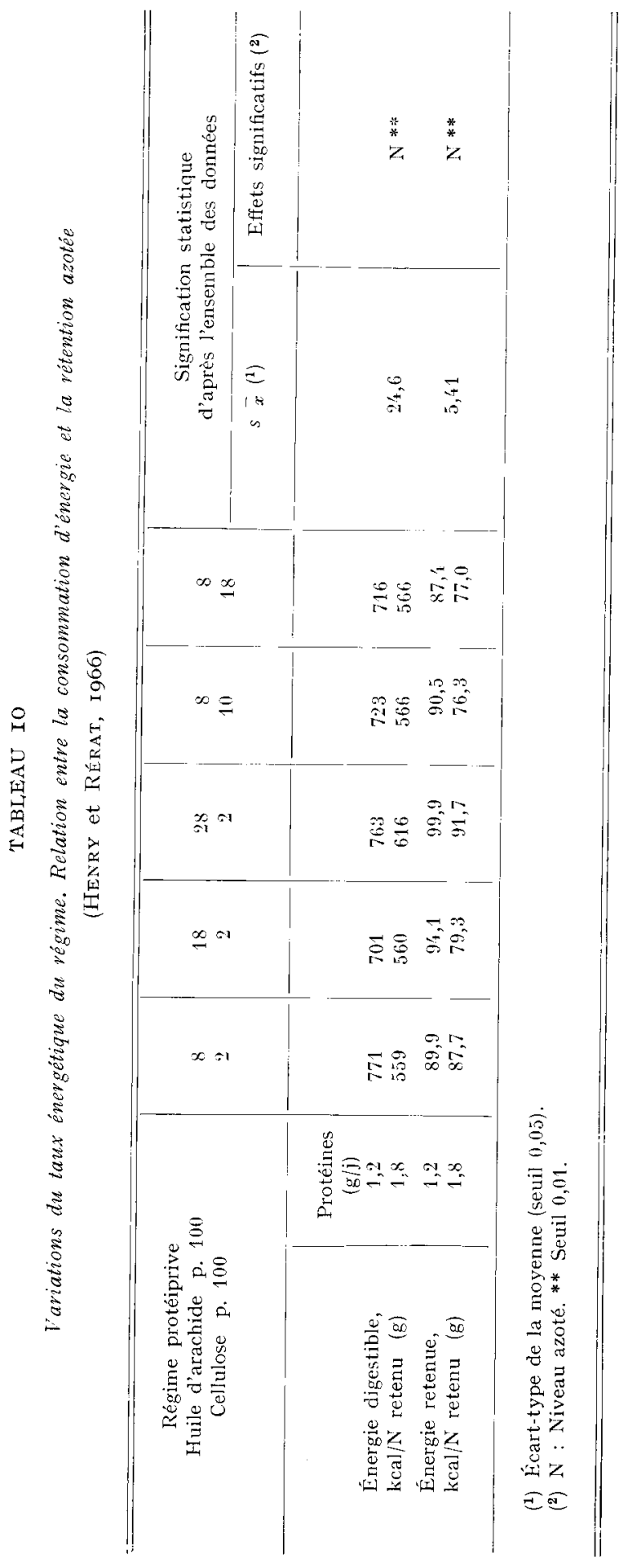


des mélanges d'acides aminés à l'aide d'une fistule gastrique (Peretianu, résultats non publiés). La plupart de ces faits ont été vérifiés par Poz et Den Hartog (I966) chez le Rat, et chez le Porc par Hentry et Rérat (1968) et par Henry (ig68).

Ces règles générales d'ajustement de la consommation d'énergie établies grâce à la technique d'alimentation séparée ne sont pas valables sans quelques nuances pour le mode d'alimentation classique : en effet, lorsque la source azotée est mélangée aux aliments énergétiques, l'adiposité des animaux à un poids donné varie en fonction đu taux protidique utilisé (HENRY et Rérat, 1965). On peut penser que les animaux recevant les régimes mixtes à apport insuffisant de protéines réagissent en tentant d'en ingérer le plus possible pour couvrir leur besoin azoté ; ils consomment ainsi un excès d'énergie qui se dépose sous forme de lipides dans les tissus. Par contre, dans le cas de l'alimentation séparée, l'animal a la possibilité de régler son ingestion énergétique en fonction du niveau de croissance permis par le facteur limitant ; il n'y a plus de consommation de principes énergétiques en excès par rapport aux matières azotées, comme dans le cas précédent ; c'est ce qui explique que les animaux sont plus maigres (tabl, II).

\section{TABLEAU II}

Comparaison des performances d'animaux recevant journellement une égale quantité de protéines par deux modes d'alimentation différents

(régimes mixtes ou séparés) (poids moyen initial : $72 \mathrm{~g} ; 6$ animaux par lot)

(HENRY et RÉRAT, 1965)

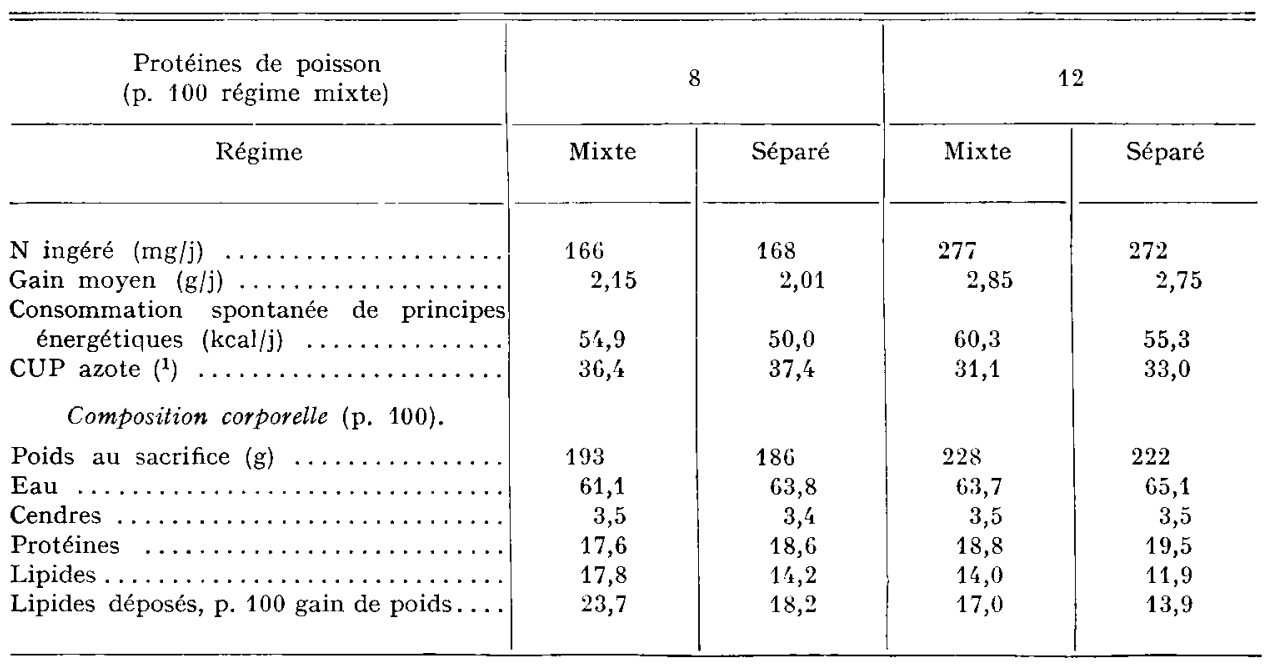

(1) CUP azote $=\frac{\mathrm{N} \text { retenu }}{\mathrm{N} \text { ingéré }} \times 100$.

Le phénomène d'ajustement calorico-azoté qui se produit en alimentation séparée montre que le besoin énergétique est contingent des modalités de couverture du besoin azoté. Inversement, l'efficacité d'une protéine donnée dépend des modalités de couverture du besoin calorique.

\section{II. - MÉTHODES DE MESURE DE LA VALEUR BIOLOGIQUE}

Pour obtenir la précision la plus grande, la valeur biologique devrait être mesurée chez des animaux de même espèce et dans le même état physiologique que ceux auxquels doivent être

Annales de Zootechnie. - Ig7r. 
appliqués les résultats de cette mesure. Ceci n'est pas toujours possible et on est ainsi amené à utiliser des espèces voisines. Pour des raisons de simplification, et de diminution du cout de ces mesures, elles sont souvent remplacées par des méthodes faisant appel à des microorganismes réagissant vis-à-vis des protéines de façon proche de celle des animaux concernés. Enfin, quand cela est possible, on a recours à des méthodes reposant sur le dosage des acides aminés permettant de comparer la composition des protéines alimentaires utilisées avec les besoins. On dispose ainsi de méthodes variées - biologiques, microbiologiques et chimiques - pour estimer la valeur nutritive des protéines : il est évident que ces diverses méthodes doivent être éprouvées les unes par rapport aux autres pour pouvoir connaître leur validité et leurs limites. Ces méthodes ont fait l'objet d'un certain nombre de revues (Allison, I955; MITCHELL, I944, I948, I954, I959; AdRIAN et Rerat, I958 ; Bender, I958; Campbelt, 1963 ; Jacguot et Rerat, I966 ; Wiesemuller $e^{t}$ al., 1967).

\section{A. - MÉthodes BIOLOGIQUES}

La plupart des méthodes envisagées tentent de mettre en relation la qualité des protéines alimentaires et leurs effets sur l'animal entier, en prenant comme critère soit le changement de poids, soit le gain de tissu protéique. D'autres méthodes tentent de relier les variations enregistrées au niveau de certains organes ou liquides biologiques et la valeur biologique des protéines. Ces méthodes sont appliquées sur l'animal en croissance et à l'entretien, ou encore sur l'animal soumis à une déplétion suivie de réplétion de ses ressources azotées.

\section{I. - Poids, vétention azotée et valeur nutritive des protéines}

Pour le premier groupe de méthodes, un certain nombre de coefficients ont été définis dont la correspondance a été illustrée par Ali.ison (I964) (fig. 2).

Ces coefficients sont les suivants:

- Coefficients basés sur le changement de poids

— Coefficient d'efficacité protidique $=\frac{\text { Gain de poids corporel }}{\text { Ingéré protidique }}$ d'après OsBorNe et al., (I919).

- Coefficient protidique net (Net protein ratio).

$\frac{\text { Gain de poids avec protéine expérimentale + perte de poids avec régime sans } N}{\text { Ingéré protidique }}$ d'après

Bender et Doell (I957).

$$
\text { Ingéré protidique }
$$

- Index azoté de croissance (Nitrogen growth index) : pente de la portion linéaire de la courbe reliant gain de poids à ingéré azoté.

- Coefficients basés sur le changement de contenu azoté dans l'organisme. bilans.

- Valeur biologique $=\frac{\mathrm{N} \text { retenu }}{\mathrm{N} \text { absorbé }} \times$ roo (MITchelL, 1924) ${ }^{(1)}$ mesurée par la technique des

- Utilisation protidique nette (Net protein utilization) ( $\left.{ }^{1}\right)$.

$\mathrm{N}$ corporel groupe expérimental $-\mathrm{N}$ corporel groupe ne recevant pas d'azote Azote ingéré d'après Miller et BENDER (1955), mesurée par la technique d'analyse corporelle, définie soit dans des conditions standardisées ( $\mathrm{St}$ ), soit à des niveaux supérieurs aux besoins d'entretien et définis comme opératoires (op).

— Index du bilan azoté : pente de la portion droite de la courbe reliantle bilan azotéet l'ingéré azoté.

(1) Rappelons que deux coefficients sont également utilisés qui ont été définis par Terroine (I933) : le coefficient de rétention azotée qui correspond à la valeur biologique non corrigée pour tenir compte du métabolisme endogène de l'azote ; le coefficient d'utilisation pratique de l'azote, qui correspond à la * Net Protein Utilization non corrigee. 


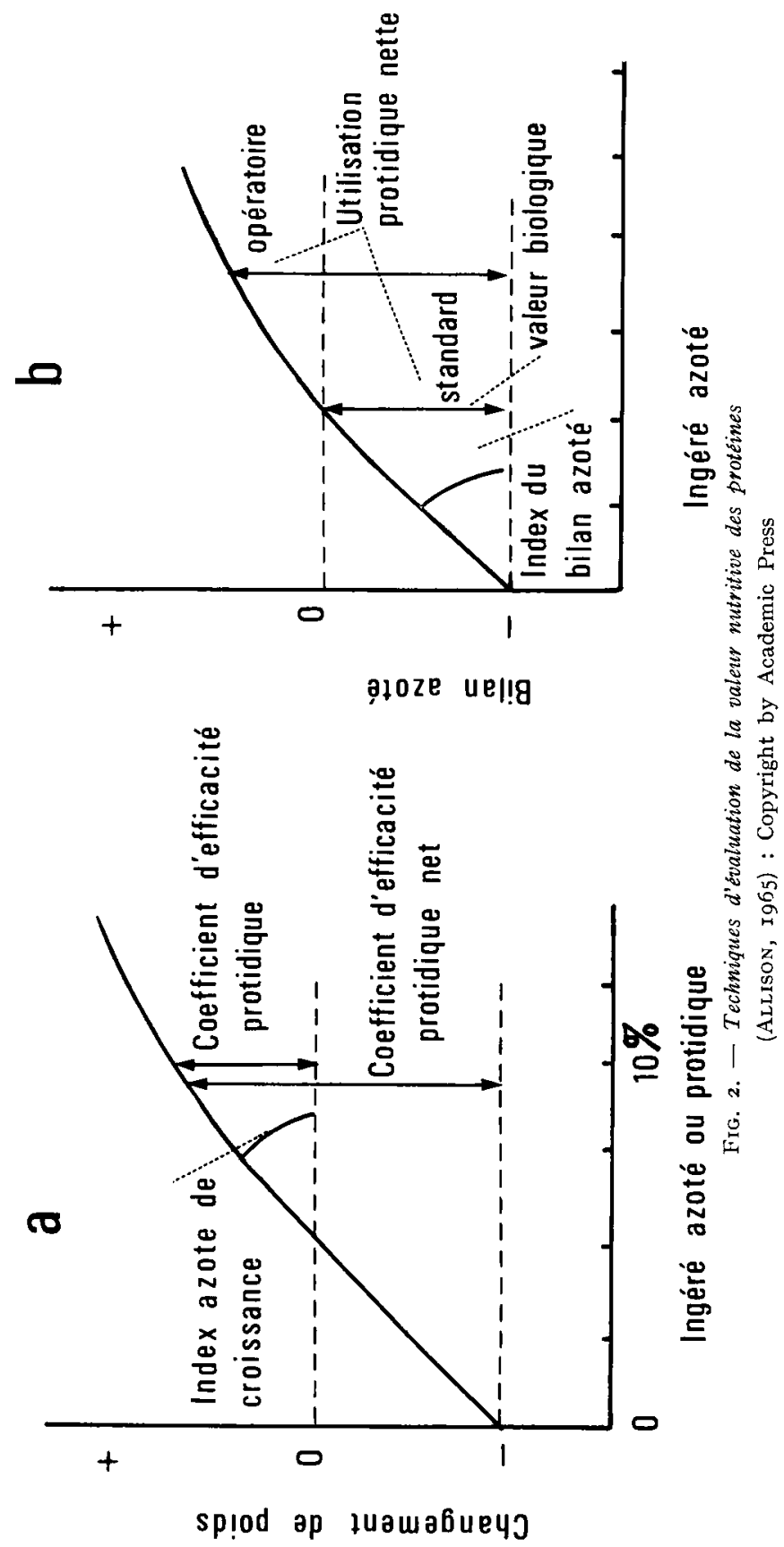


Les modalités de ces techriques, ainsi que leurs avantages et inconvé nients, ont été détaillés par ailleurs (JacQUot et RéRat, I966; J ACQUot et PERETIANU, I970) et elles ne seront que résumées en n'en conservant que les nouveaux aspects.

a) Méthode des poids.

La mesure du coefficient d'efficacité protidique (CEP) présente un certain nombre d'inconvénients. Certains de ces inconvénients proviennent de la varialilité du CEP en fonction du réactif animal (espèce, race, sexe, âge) et des conditions expérimentales (durée de l'essai, composition des régimes et notamment taux de matières azotées, mode d'alimentation). Un autre inconvénient de cette méthode réside dans le fait que les variations de poids vif ne sont pas toujours le reflet des variations du contenu d'azote corporel : il faut citer des cas, tels que ceux signalés par Alison (1957) sur le Chien, mettant en évidence une disparité entre gain de poids et rétention d'azote, représentant, semble-t-il, une exception, et à l'exemple de Block et Mitchel. (I946), la plupart des auteurs s'accordent à reconnaître de fortes corrélations entre CEP et valeur biologique mesurée par la méthode des bilans.

La plupart des inconvénients méthodologiques soulignés plus haut peuvent être minimisés par la standardisation de la méthode (DERSE, I965), par ailleurs adaptée auYPoulet (Woodham et McDonald, $1968 a$ et $b$ ). Cependant, les résultats obtenus de cette façon présentent encore une forte variabilité, qui se situe par exemple entre $\mathrm{r} 2$ et $29 \mathrm{p}$. Ioo dans les lakoratoires travaillant en coopération (DERSE, I962). Cette variabilité peut être attribuée pour sa plus grande part, à la définition d'un taux protidique arbitraire de Io p. ıoo, taux qui ne permet pas toujours aux protéines alimentaires d'exprimer leur valeur nutritive pour la croissance, puisque le CEP d'une même protéine varie en fonction de la teneur en azote du régime (BARNes et BosshaRdT, 1946).

Pour pallier cet inconvénient, deux techniques ont été proposées. L'une préconisée par Allison et al. (1959) et étudiée ultérieurement par Hegsted et CFang (1965 a) rapporte le gain de poids à l'ingéré; la pente de la droite qui met en relation ces deux variables lorsque l'ingéré azoté n'est pas trop élevé, est indépendante de l'ingéré azoté et peut, pour cette raison, être considérée comme une mesure plus quantitative de la valeur nutritive des protéines. Il suffit d'administrer à différents groupes de rats des régimes contenant plusieurs taux différents de"la protéine à tester ainsi qu'un régime protéiprive et de calculer la régression entre gain de poidscet azote ingéré.

La deuxième méthode permet en outre de réaliser correctement la couverture du besoin énergétique en fonction de l'apport azoté. Très utile pour l'étude de l'ajustement calories/azote, la technique des repas séparés, initialement utilisée chez le Poulet par CALET et al. (I961) est également intéressante pour pallier les inconvénients des régimes mixtes dans la détermination de la valeur biologique des protéines. Dans la nouvelle méthode, basée sur cette technique des repas séparés et décrite par Peretianu et Abraham ( 1963 a), l'animal reçoit uñapport azoté quantitativement et qualitativement contrôlé et dispose ad libitum d'un régime protéiprive qui apporte les glucides, les lipides, les vitamines et les minéraux. Dans ces conditions, on n'impose plus un taux protéique arbitraire, c'est l'animal lui-même qui réalise l'ajustement entre ingéré protéique et ingéré calorique. La technique mise au point pour le Rat en croissance consiste à faire ingérer I $80 \mathrm{mg}$ d'azote sous forme de différentes protéines, cette ingestion se faisant le matin en moins d'une heure. Puis, on laisse l'animal libre d'accéder à la ration protéiprive 23 heures sur 24 heures. Il suffit de peser régulièrement les animaux et de calculer le CEP d'après $N$ ingéré $\times 6,25$ et le gain de poids correspondant.

Les valeurs obtenues en alimentation séparée montrent que le CEP varie parallèlement au gain de poids, ce qui n'est pas nécessairement le cas lorsqu'on fait appel au régime mixte. En outre, alors qu'avec les régimes mixtes, le taux azoté utilisé représente pour une protéine don née un facteur de variation important du CEP, en alimentation séparée, le fait de fixer la quantité d'azote administrée journellement à trois niveaux différents (de $96 \mathrm{mg}$ à $288 \mathrm{mg}$ ), ne provoque que de faibles variations du CEP (HeNry et RÉrat, ig62, ig63). Enfin, l'analyse des variances indique que la variation individuelle à l'intérieur des lots est faible; il en résulte que la plus petite 
différence entre traitements est toujours très faible, ce qui n'arrive pas toujours avec les régimes mixtes. De ce fait, la technique proposée a un caractère plus sélectif que la méthode standard.

Du point de vue pratique, la méthode est facile à conduire. Du fait que les animaux mangent intégralement leur repas protéique, il n'est pas nécessaire de peser l'ingéré calorique et on peut se limiter à déterminer le poids final des animaux. Le seul inconvénient est constitué par le conditionnement préexpérimental en vue de dresser les animaux à l'alimentation séparée, c'est-à-dire à consommer intégralement et rapidement le repas protéique. La méthode gagne en précision si l'on offre l'apport azoté en deux repas journaliers (A BRAHAM et al., I969).

Que l'on utilise la technique des repas séparés ou celle des repas mixtes, la mesure du CEP directement applicable à une espèce donnée (sauf l'Enfant dont la croissance est trop lente) est d'un emploi relativement facile, car elle ne requiert qu'un minimum d'opérations (pesée des animaux et des ingesta). Elle peut être conduite sur des lots expérimentaux importants, cequi facilite l'interprétation statistique des résultats.

\section{b) Rétention azotée.}

La rétention azotée est mesurée par différence entre l'azote ingéré et l'azote excrété dans l'urine et les fèces (méthode des bilans), ou encore par analyse directe des variations du contenu azoté corporel (méthode de l'analyse des carcasses). On peut mesurer la valeur de remplacement des protéines alimentaires vis-à-vis des tissus usés pendant l'entretien en tenant compte des pertes d'azote endogène, ou leur valeur de construction vis-à-vis des tissus synthétisés au cours de la croissance en tenant compte ou non des pertes d'azote endogène.

Les modalités de ces méthodes ainsi que leurs avantages et leurs inconvénients ont été précisés par ailleurs (JACQUOT et RERAT, I966),

\section{Méthodes des bilans.}

Leurs inconvénients majeurs résident dans leur côt en temps et main-d'œuvre, mais ils peuvent être compensés en partie par l'utilisation d'indicateurs permettant de n'avoir pas à récolter quantitativement les excreta (FURUyA et al., 1970). Par ailleurs, les valeurs obtenues pèchent souvent par excès en raison des pertes lors de la récolte des excreta. Les pertes urinaires $\left(\mathrm{NH}_{3}\right)$ sont difficiles à éviter. L'analyse de ces pertes a été du reste faite par de nombreux auteurs parmi lesquels il faut citer BECKER et HARnisch (I958), DAvidSon et Williams (I968), IsAKSSON et Sjögren (1967), Wiesemüller et al. (I967), Wiesemüller et Poppe (I969); bien d'autres raisons analytiques interviennent pour fausser le sens des bilans (OwEN, 1967).

En outre, la signification profonde du bilan est à préciser, étant donné que les diverses masses protéiques de l'organisme n'obéissent pas à une régulation globale. Certains organes, tels le foie, sont plus sensibles que d'autres à la quantité ct à la qualité de l'azote ingéré, surtout après déplétion des réserves protidiques (KosterLitz et CAMPBELL, I945-1946).

Enfin, de nombreux autres facteurs de variation de la rétention azotée sont liés au choix du réactif animal et de son environnement (MULLER, I964) : citons l'espèce animale (BRUNE et al., I968: MUnchow et Bergner, ig68; AnAntharaman et al., ig68), l'âge des animaux (WieseMÜLLER et POPPE, I $969 a$ et $b$ ) l'environnement et notamment la température (LEIBETSEDER et Hamed, I968; Hock et Lehman, I968 $a$ et $b$; PAYNe et JACoB, I965), la nature du régime (DE Muelenaere et al., I965), la restriction calorique (RAo ct Morrison, i966; Richardson et al., I968), le traitement des animaux pendant la période préexpérimentale ct la durée de l'essai (Braham et al., I967; Uhlemann et Poppe, i969; Wiesemüller et Poppe, I968 $b$ ).

Comme dans le cas de la définition du CEP, la valeur du coefficient de rétention azotée varie en fonction du taux d'introduction de la protéine dans le régime, surtout lorsque la croissance maximum est atteinte et la fixation arbitraire d'un taux déterminé ne permet pas toujours de quantifier les différences de valeur nutritive entre protéines. Pour y parvenir, Alltson et ANDERSON (I945) utilisent la relation linéaire unissant le bilan azoté et l'ingéré azoté aux faibles niveaux d'ingestion azotée et déterminent l'index du bilan azoté à partir de la pente de cette droite; cette 
méthode présente ainsi le double avantage de fournir des résultats indépendants du taux azoté et de n'avoir pas recours à des mesures arbitraires d'azote endogène.

Enfin, deux techniques rapides d'estimation des pertes endogènes ont été récemment préconisées, soit pour l'azote fécal métabolique (DREYER, 1968), soit pour l'azote endogène urinaire (Berdanier et al., 1967).

Méthodes basées sur l'analyse corporelle.

La méthode d'estimation du gain protéique à l'aide de l'analyse corporelle présente la plupart des mêmes inconvénients de méthodologie ct de principe que la méthode des bilans. En outrc, elle ne permet pas de définir la répartition entre excrétion fécale et excrétion urinaire, et ainsi de distinguer entre azote digestible et azote retenu. Par contre, les pertes lors des dosages scmblent beaucoup plus faibles; elles font cependant varier la rétention en sens opposé à ce qui se passe dans le cas des bilans puisqu'clles portent sur les tissus alors que celles des bilans portent sur l'excrétion (Davidson et Williams, I968).

Bien entendu, comme le CEP, la NPU ainsi mesurée est variable selon le taux azoté du régime (Fisher et Griminger, I969) et selon les taux de lipides et de cellulose; cependant, entre les taux de o,8 p. Ioo et Io p. Ioo de cellulose, et ceux de $I, 7$ et io p. Ioo de lipides, la NPU ne semble pas varicr (BRAHAM ct Bressani, I 969), ce qui laisse des marges méthodologiques appréciables. Il est néanmoins recommandé d'utiliser des taux standardisés (5 p. roo de cellulose, 5 p. roo de lipides).

Des critiques particulières peuvent être faites à la méthode initialement préconisée par Bender et Miller (1953) et Bender et Doell (1957) qui portent accessoirement sur le faible nombre d'animaux mis en jeu et la durée de l'expérimentation, et principalement sur la détermination de l'azote corporel à partir de la teneur en eau de l'organisme (SCRIMSHaw, r962; Henry et ToотнILl, 1962). En effet, si l'équation reliant $\frac{\mathrm{N} \text { corporel }}{\overline{\mathrm{H}}_{2} \mathrm{O} \text { corporel }}$ à l'âge de l'animal a été déterminée par Bender et MiLler (I953), cette équation ne paraît directement applicable qu'à des animaux de même souche et de même sexe que ceux qu'ils ont utilisés; une équation différente est ainsi trouvée par RÉRAT et al. (1964) pour des rats blancs mâles de souche Wistar et par DREYER (1968) pour des animaux de sexe différent. En outre, la teneur en eau de l'organisme peut dépendre de la nature du régime soit sur le plan azoté (Bressani et al., i 965 ; Pelletr 1967; Sanahuja et Rio, 1968 ; RIo et al., I970), soit encore du fait de la présence de certains sucres comme le lactose (FÉvrier et Rérat, 1964). Standal (r963) montre que l'azote corporel peut ainsi être surestimé (I à 20 p. Ioo d'erreur) et Hegsted et Worcester (1967) concluent que la mesure directe de l'azote corporel est préférable à sa détermination indirecte.

Cependant, du fait de la simplicité du dosage de l'eau et de la réduction possible des sources éventuelles d'erreurs à l'aide de certaines précautions, c'est tout de même à cette estimation indirecte de la teneur azotée de l'organisme qu'ont recours les diverses méthodes modifiées préconisées au cours des dernières années (RAFAlski et NogAL, 1964, i967; Hegsted et al., r968).

Ainsi tout récemment, Rafalski et Nogal (1967) font l'analyse d'un certain nombre de facteurs possibles de variation (âge, gain de poids, poids initial des animaux, longueur de l'essai, taux azoté) et proposent une méthode, identique dans son principe à celle de Miller et BENDER (1955), mais comportant la standardisation du régime sans azote et du groupe d'animaux recevant ce régime.

Hegsted et al. (1968) de leur côté, au lieu de fixer la pente de la droite unissant la rétention azotée de l'ingéré azoté à l'aide de deux points (régime protéiprive, régime expérimental), comme le font RAFALSKI et NogAL (I967), précisent cette pente à l'aide de 3 points; leur technique est ainsi analogue dans son principe à celle préconisée par AlLison et ANDERSON (1945), le critère servant à déterminer la rétention azotée étant seul différent (analyse corporelle au lieu de bilans). Ainsi, les relations linéaires entre l'azote corporel, l'eau corporelle et l'ingéré azoté, qui existent pendant la croissance (Hegsted et Worcester, 1967) ou pendant l'entretien (SAID et Hegsted, 
I969) sont mises à profit par ces auteurs pour préconiser une technique d'évaluation de la NPU : dans cette technique, les auteurs considèrent comme suffisante l'utilisation de 3 niveaux azotés et de 3 animaux par niveau, l'eau corporelle pouvant être un critère aussi valable que l'azote.

\section{Valeur nette des protéines alimentaires (Net dietary protein value).}

Les méthodes précédentes permettent d'apprécier la qualité des protéines en tant qu'entités, mais ne reflètent pas la valeur nutritive des protéines sous leur forme alimentaire, compte tenu du rapport protéines/calories des aliments, et des apports calorique, minéral et vitaminique. Les travaux de Miller et PAYNE (I96I) permettent de combiner la qualité et la quantité des protéines en fournissant le contenu total de protéines utilisables dans l'aliment tel qu'il est ingéré habitucllement. L'expression proposée, le " Net Dietary Protein Value" (NDP V = Valeur nette des protéines alimentaires) est la suivante :

$\mathrm{ND}_{\mathrm{P}} \mathrm{V}=$ concentration de protéines $\times$ utilisation protidique nette (opératoire).

L'utilisation protidique nette étant ici déterminée dans des conditions pratiques (opératoires) et non dans des conditions standardisées.

Du fait que la consommation d'aliment est réglée par le besoin énergétique, les auteurs anglais ont ensuite exprimé cette valeur sous la forme du nombre de calories qui pourraient dériver des protéines alimentaires, si elles étaient utilisées complètement à des fins énergétiques, nombre de calorics calculées en pourcentage de l'énergie métabolisable du régime. Cette valeur est appelée le pourcentage net de calories alimentaires d'origine protidique (Net dietary-Protein Calories p. Ioo : NDP Cal p. Ioo). Cette valeur peut être obtenue par l'équation :

$$
\mathrm{ND}_{\mathrm{P}} \mathrm{Cal} \text { p. } \text { IOO }=\frac{\mathrm{ND}_{\mathrm{P}} \mathrm{V} \times 4}{\mathrm{kcal} / \mathrm{g} \text { d'aliment }}
$$

Les valeurs de ce pourcentage peuvent être obtenues à partir des données de la valeur protidique nette in vizo. Mais en fait. les auteurs ont étudié les relations entre ce pourcentage, l'index chimique des protéines [F.A. O., 1957 (voir II CI)] et le pourcentage de calories protidiques, ct montrent qu'il est possible de les exprimer pour une très large échelle de concentrations protidiques, sous forme d'un abaque; il est ainsi possible d'obtenir le pourcentage net de calories alimentaires d'origine protidique à partir de l'index chimique et du contenu de calorics d'origine protidique dans le régime. Selon NJAA (I962), bien que des objections théoriques puissent être élevées concernant l'équation permettant d'obtenir la $N D_{P} V$, et donc la $N D_{P}$ Cal p. roo, cette équation peut constituer une solution empirique utile pour prévoir la valeur nutritionnelle des protéines.

\section{Comparaison des méthodes biologiques sur l'animal entier.}

La comparaison de ces diverses méthodes permet de montrer la plus forte variabilité des résultats du coefficient d'efficacité protidique, que ceux du coefficient protidique net (NPR) ou que l'utilisation protidique nette (NPU). Contrairement au CEP, ces deux derniers coefficients ne dépendent ni des quantités ingérées, ni du poids initial, ni du gain de poids (Bender et Doell 1957). Il existe en outre une relation très étroite $(r=0,99)$ entre les deux derniers coefficients traduits par l'équation NPR $\times$ I8,9I $=$ NPU, ce qui n'est pas étonnant du fait que la seule différence entre ces deux coefficients est le critère (gain de poids contre azote retenu), les modalités expérimentales étant rigoureusement les mêmes (RAFALsKi et Nogal, I967 $b$ ). Cependant, selon Henry ( (1965), il existe également une relation étroite entre CEP et NPU surtout lorsque ce coeffcient est obtenu par la méthode des bilans $(r=0,95)$, mais aussi par la méthode des carcasses $(r=0,88)$, ce qui confirme des résultats antérieurs (BENDER, 1956).

Par ailleurs, comparée avec la méthode basée sur l'analyse d'azote dans les carcasses, la méthode des bilans surestime aussi bien l'azote perdu avec les régimes sans azote que l'azote retenu avec certaines protéines et ces désaccords sont accentués quand l'azote est déduit de la teneur en eau de l'organisme (HENRY, 1965).

Que peut-on conclure de cet ensemble de faits? 
L'utilisation d'une méthode dépend à la fois du but poursuivi et de ses caractéristiques (précision, difficultés, reproductibilité). D’une façon générale, les méthodes basées sur la rétention azotée, quoique plus lourdes à mettre en œuvre, sont souvent préférées car elles sont considérées comme plus précises; certaines d'entre elles permettent en outre de distinguer entre digestibilité et rétention et les résultats obtenus sur le Rat sont généralement applicables à l'Homme $(r=0,9 \mathrm{I}$ entre le Rat et l'Homme d'après la Rutgers Universiry, r950) etau Porc, à un facteur de correction près (Munchow et BERGNER, 1968 b). La méthode des poids ne devrait cependant pas être abandonnée pour les analyses de routine et on peut même penser qu'avec la technique d'alimentation séparée, les résultats sont aussi précis et leur obtention demande moins de travail que ce qui se passe pour les méthodes de rétention.

\section{II. - Autres méthodes biologiques}

Parmi les autres méthodes, décrites et discutées par ailleurs (ADrian et RÉrat, I958; JACQUot et RÉRAT, I966), il faut tout d'abord citer les méthodes de déplétion et de régénération dont les critères portent soit sur les variations du poids vif (CANNoN, I948; CANNON et al., I944), soit sur la restauration des protéines plasmatiques (WHIPPLE, 1948; WHIPPLE, et al., 1946), soit sur la régénération des protéines hépatiques (KosterLITZ et CAMPBELL, I946).

Un groupe de méthodes a, par ailleurs, été développé au cours des dernières années : c'est celui basé sur les variations du taux de certains composés azotés dans le plasma sanguin (acides aminés libres, urée) ; un autre a subi un renouveau d'intérêt, c'est celui basé sur les activités enzymatiques tissulaires.

a) Variations des activités enzymatiques tissulaives.

Les activités enzymatiques tissulaires présentent des relations avec pratiquement tous les principes alimentaires. Ce fait a été particulièrement étudié pour les protéines et MAURoN (r967) a récemment passé en revue les données les plus importantes dans ce domaine. On sait ainsi que certains systèmes enzymatiques, notamment ceux du foie, sont particulièrement sensibles à la déplétion protidique (LITwaCk et al., 1952; MILlER, I948). Les relations entre taux azoté et activités enzymatiques du foie ont été particulièrement étudiées par Muramatsu et AsHIDA (I962) qui ont divisé les enzymes hépatiques en quatre groupes : ceux dont l'activité augmente rapidement avec la concentration azotée dans le régime jusqu'à l'obtention d'un plateau (ex. : xanthine oxydase et D-aminooxydase) ; ceux dont l'activité augmente pour chaque élévation du taux azoté (ex. : arginase et enzymes du cycle de l'urée) ; ceux qui restent inchangés (ex. : cathepsine) ; ceux dont l'activité diminue (ex. : phosphatase alcaline).

De la même façon, ces enzymes du foie réagissent à la qualité des protéines et notamment aux déficits d'acides aminés : ainsi une déficience de lysine provoque une diminution de l'activité xanthine oxydasique du foie (WILliams et ElveHJEM, I950) et de l'activité D-aminooxydasique (Mauron et Motro, I965) et un accroissement de l'activité de la phosphatase alcaline (Mauron et Motтu, I965).

Deux autres points ont été soulignés par les études de l'équipe de MAURoN, dont les conséquences peuvent être importantes pour la mesure de la valeur biologique à l'aide de ces techniques : le premier concerne l'évolution du contenu enzymatique du foie avec l'âge de l'animal (Motru et Mauron, I966) : certains systèmes enzymatiques voient leur activité s'accroître avec l'âge (ex. : xanthine oxydase, D-aminoacidoxydase), d'autres voient leur activité diminuer (ex.: phosphatase alcaline). Le deuxième concerne la différenciation, par les systèmes enzyma* tiques, de protéines rééquilibrées par l'addition d'acides aminés et présentant ainsi la même valeur nutritive (tabl. I2).

Ces différences proviennent peut-être de l'apport des acides aminés non essentiels qui n'a pas été corrigé, ou encore de la séquence des aminoacides dans la protéine.

Quoi qu'il en soit, c'est surtout la xanthine oxydase et à moindre degré la succino déshydrogénase qui ont été retenues jusqu'à présent pour évaluer la valeur nutritive en raison de l'excellente 
corrélation qui existe entre leurs activités (surtout pour la première) et la valeur de croissance des protéines alimentaires : la xanthine oxydase est notamment sensible aux déficits de tryptophane (Williams et Elvehjem, 1950) de méthionine (Williams et al., 1949), de lysine (Bothwell et Williams, I954) ou d'isoleucine (V. Pilsum $e t$ al., I957). Il est cependant probable selon MaUroN (I967) que de nombreuses autres enzymes pourraient servir dans le même but, particulièrement la transamidinase du rein et la $\mathrm{D}$-amino acide-oxydase đu foie. A noter qu'il est nécessaire d'annuler l'effet d'une éventuelle diminution d'appétit de l'animal, qui peut créer une déficience calorique, source de variation de l'activité enzymatique, en pratiquant la technique d'égalisation des consommations. Les modalités de ces techniques ont été rapportées par ailleurs (ADRIAN et RéRAT, I958).

TABLEAU I2

Activité enzymatique tissulaire et nature de la protéine Expérience de 52 jours (MAURON, 1967)

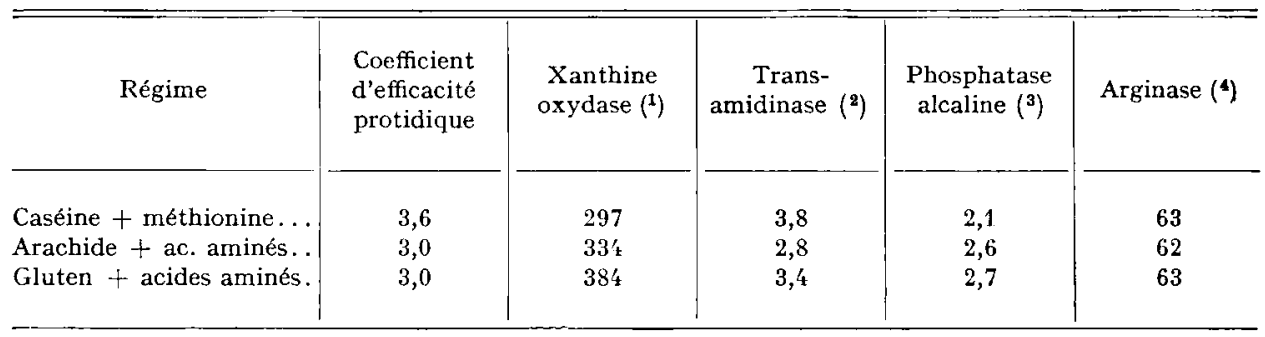

(1) Xanthine oxydase : microlitre d'oxygène/heure par g de foie ; $\left({ }^{2}\right)$ transamidinase : mg d'acide guanidoacétique/heure par $\mathrm{g}$ de rein. foie.

( $\left.{ }^{3}\right)$ Phosphatase alcaline : $\mathrm{mg}$ de phosphore/heure par $\mathrm{g}$ de foie; ( $\left.{ }^{4}\right)$ arginase $=\mathrm{mg}$ d'urée/mn par g de

Au cours des dernières années, un certain nombre d'améliorations ont été apportées à la méthode de la xanthine oxydase (Scholz et Featherston, I968; Bergner et al., I964; Sugahara et Sugahara, I963) et des précisions ont été fournies sur les activités transamidinasique du rein (KEAN, 1967), arginasique du foie (KIRIYAMA et al., 1967) et transaminasique glutamate-pyruvate et glutamate-oxalacétate dans le foie du Rat et dans le sérum des porcs (BERGNER et al., I967, I968).

En conclusion, du fait des lacunes de nos connaissances dans ce domaine, les méthodes basées sur les variations d'activité enzymatique dans les tissus ne peuvent remplacer les techniques classiques d'évaluation de la valeur biologique, mais peuvent fournir des indications complémentaires. Les deux seules de ces techniques qu'il soit possible d'utiliser actucllement sont celles à la xanthine-oxydase et celle à la succino-déshydrogénase.

b) Méthodes basées sur les variations des teneurs plasmatiques d'azote animé et non protéique.

Ces méthodes sont basées sur les observations rapportées dans le chapitre I A. Plus que d'établir la valeur biologique des protéines, elles permettent de préciser la nature des facteurs limitants primaire et secondaire (MCLAUGHLAN, 1964; RAo et al., 1968). L'équation initialement utilisée par LONGENECKER et HAUSE (I959) était la suivante :

Rapport des acides aminés plasmatiques (PAA ratio) $=\frac{\mathrm{B}-\mathrm{A}}{\text { besoin d'acide aminé }} \times$ roo où $\mathrm{B}$ est la moyenne des concentrations plasmatiques ( $\mathrm{mg} /$ Ioo $\mathrm{ml}$ ) trouvées dans les prélèvements horaires de sang pendant 5 heures après le repas, et A la concentration correspondante après I 8 heures de jeûne immédiatement avant le repas expérimental, qui dans cette méthode, est 
unique ; la plus faible valeur ainsi obtenue indiquait le facteur limitant, et l'ordre dans lequel les acides aminés devenaient limitants était le même qu'avec les index chimiques.

Cette méthode a, par la suite, été modifiée en des épreuves à plus long terme sur poulets (Hill et Olsen, I963) et sur rats (Swenseid et al., I963). McLaughlan (i 964) chez le Rat, préconise en outre l'administration d'un régime sans azote permettant de fixer les taux plasmatiques de référence des acides aminés et la formule est la même que celle précédemment utilisée, mais A représente alors le nouveau taux de référence. De leur côté, SMith et Scotr (1965) fixent ce taux témoin à l'aide d'un mélange d'acides aminés de référence.

Une erreur peut être apportée par la méconnaissance du besoin réel d'acides aminés et McLAUGHLAN (1964) propose un autre coefficient, l'index d'acides aminés plasmatiques (PAA score) :

$\frac{\text { Taux moyen d'acides aminés plasmatiques avec le régime expérimental }}{\text { Taux moyen d'acides aminés plasmatiques avec le groupe à jeun }}$

Le chiffre le plus bas ainsi obtenu pour une protéine donnée indique le facteur limitant. Selon ses promoteurs, cette technique semble donner des résultats plus en accord avec les autres techniques biologiques que la technique des rapports d'acides aminés plasmatiques, mais les résultats obtenus par ces deux techniques sont, sauf exception, généralement concordants.

Ces techniques sont simples, rapides, applicables directement à l'Homme, mais l'un de leurs inconvénients pratiques réside dans le fait qu'elles doivent être utilisées avec des régimes riches en azote (McLaughlan et MorR Ison, I968). Elles sont très complémentaires des autres techniques biologiques car, si elles ne permettent pas d'évaluer la valeur biologique des protéines, elles précisent la nature du facteur limitant primaire ou des colimitants primaires, sans toutefois définir l'ordre de déficience des autres acides aminés.

L'un des obstacles théoriques les plus importants à l'application de ces techniques réside dans notre connaissance imparfaite des lois de la variation d'aminoacidémie, tant dans le sang à jeûn qu'après divers types de repas, malgré les travaux récents qui tendent à préciser ces règles : variation avec la durée du jeûne (Hill et OLSEN, I963), avec la durée de la période préexpérimentale (McLaughlan, I964), avec le taux azoté (Young et Scrimshaw, ig68; Kučukalic et MiLENKović, I968; HARKER et al., I968; HARKER, I967) et le rapport des acides aminés essentiels/acides aminés non essentiels (Young et ZAMORA, I968; Hariharan et al., I968), avec l'intervalle entre les repas et le prélèvement de sang quand il est unique (MCLAUGHLAN et al., 1967).

Une des applications évidentes est la mesure de la disponibilité de l'acide aminé limitant primaire, déjà préconisée chez le Rat (GugGenherm et al., i960), chez le Poulet (Kelly, i967; Smith et Scott, I965; Childs et Combs, 1964) et chez le Porc (PFander et al., ig68). Il faut toutefois préciser que, dans ce domaine, le sang porte serait plus représentatif des phénomènes d'absorption que le sang jugulaire (Denton, et Elvehjem, i954; Pion $t$ a al., i963 $b$; Nielsen, I965; Scharrer et ZuCker, I968; ERberSdobler et al., I968), et on peut alors conseiller de recourir à la mesure de l'aminoacidémie libre du sang porte prélevé à l'aide de fistulation permanente (ARSAC et RÉRAT, I962) ; il est ainsi aisé de comparer les courbes d'absorption de la lysine libre et de la méthionine libre avec celles des mêmes acides a minés contenus dans diverses protéines (Pion et Rérat, 1967, 1969).

Une autre méthode récemment mise au point fixe une valeur réciproque d'urée (RUV) basée sur le fait que la valeur biologique des protéines est sensiblement inversement proportionnelle à la concentration de l'urée dans le sang :

$\begin{aligned} & \text { Concentration d'urée dans sang animal } \\ & \text { recevant protéine référence }\end{aligned} \times \begin{aligned} & \text { valeur biologique } \\ & \text { protéine référence }\end{aligned}$
concentration urée dans sang des animaux recevant protéine testée

(Munchow et BERGNER, 1967, I968). Les valeurs ainsi obtenues présentent une relation très directe avec celles trouvées par la méthode des bilans $(r=0,99$ pour le Rat; $r=0,96$ pour le Porc) ; cette méthode est donc très intéressante. 
III. - Disponibilité des aminoacides in vivo

La disponibilité des aminoacides, définie par MAURon (I96I) comme le pourcentage de ces substances qui est utilisé pour la synthèse protéique lorsque chacune d'entre elles constitue le seul facteur limitant du régime, peut être appréciée à l'aide de diverses méthodes, biologiques, enzymatiques ou chimiques. L'estimation in vivo peut clle-même faire appel à divers critères tels que le gain de poids, la rétention azotée, la digestibilité des acides aminés individuels et comme cela a été signalé antérieurement, l'apparition des divers acides aminés dans la circulation sanguine.

Un premier groupe de méthodes tente ainsi de mesurer l'aptitude que possède une protéine de composition connue en aminoacides, à remplacer un acide aminé spécifique en permettant la croissance du Poulet (Schweigert, I948; Ousterhout et al., I959; Hill et al., i966; Kelly, I967; Sмтtн, г968 a; Netкe et Scotr, 1970) ou du Rat (Gupta et al., I958; Pongpaew et Guggenheim, I968; Miller et Carpenter, I967; De Muelenaere et al., I967a et $b$ ) ou le gain de poids du Rat préalablement soumis à une carence azotée (Schweigert et GuTHNECK, I953, I954; Guthneck et al.,.1953) ou l'équilibre du bilan chez le sujet adulte (Linkswiler et al., 1960) ou l'augmentation de l'azote corporel (CalHoun et al., I960; Hepburn et al., I966; De MueleNAERE et al., 1967).

Pour ce faire, on compare les résultats obtenus à l'aide de diverses doses de l'aliment contenant l'acide aminé dont on veut déterminer la disponibilité à ceux, rapportés selon une courbe standard, fournis par le régime de base additionné de diverses doses du même acide aminé sous forme cristalline.

Dans le deuxième groupe de méthodes, on établit la digestibilité apparente ou réelle des acides aminés : cette méthode a été appliquée au Rat (Kuiken, I952; KuIKen et Lyman, I948; SchweIgert et Guthneck, 1953, 1954 ; Pion et Rérat, I962; Ford et al., 1963; Boctor et Harper, I968; Hepburn et al., I966; De Muelenaere et al., I967 $a$ et $b$ ) et au Porc (Harnisch et Rojahn, 1962; DAmmers, I964; Nielsen, ig68). Il existe certaines divergences de résultats entre les deux groupes de méthodes. Il faut noter en particulier que les valeurs fournies par la méthode de digestibilité sont généralement plus élevées que par les méthodes mettant en jeu le poids ou l'azote corporel. Ces divergences peuvent être attribuées d'une part au principe même de chacune de ces méthodes, et d'autre part à la nature des facteurs susceptibles d'intervenir pour modifier leurs résultats.

- En ce qui concerne le premier point, la signification de ces deux groupes de méthodes est différente. La croissance et la rétention azotée sont des critères globaux permettant de rendre compte de l'utilisation réelle de l'acide aminé intéressé par l'organisme; ils ne tiennent pas compte seulement de l'acide aminé perdu dans les fèces,mais également de la perte d'efficacité liée à une hydrolyse retardée. Par contre, la digestibilité de l'aminoacide rend compte à la fois de la digestibilité de la protéine et de l'existence de liens résistants aux enzymes impliquant l'acide aminé intéressé.

- Par ailleurs, les facteurs susceptibles de modifier la valeur des résultats obtenus sont différents selon les critères utilisés par l'une ou l'autre de ces méthodes.

Ainsi, un certain nombre de facteurs susceptibles de modifier l'efficacité d'un régime pour la croissance ou la rétention azotée, sont à même de fausser les résultats concernant la disponibilité appréciée à l'aide de ces critères. Ces facteurs sont connus : le taux azoté, l'équilibre entre acides aminés, le rapport azote/énergie, la nature des sucres et le taux de cellulose représentent ainsi autant de variables qui peuvent modifier les résultats de disponibilité des acides aminés. Ces facteurs ont été particulièrement bien étudiés par DE MUELENAERE et al. (r967 $a$ et $b$ ) qui concluent que les résultats obtenus sont plus reproductibles et moins influencés par les autres facteurs quand la disponibilité est calculée à partir de la consommation de l'acide aminé intéressé (lysine, thréonine, isoleucine ou valine) plutôt qu'en fonction de son taux dans le régime. Selon ces auteurs, l'antagonisme leucine-isoleucine peut être à l'origine de faibles valeurs de disponibilité pour l'isoleucine, et il est bon de prévenir ce genre de phénomène pour obtenir des valeurs 
convenables. Mais cela n'est pas vrai pour tous les déséquilibres par excès, puisque, de leur côté, Netke et al. (1969) considèrent que la présence d'excès d'aminoacides dans des régimes déficients en un acide aminé donné, mais couvrant par ailleurs les besoins d'acides aminés du poussin, n'altère pas l'utilisation de l'acide aminé le plus limitant. Si l'on se rapporte au chapitre I2 concernant les déséquilibres, ce dernier point est sujet à controverse. On peut en conclure qu'il est nécessaire de contrôler sévèrement l'équilibre du régime lorsqu'on veut préciser la disponibilité d'un aminoacide.

Si l'on considère par ailleurs les facteurs susceptibles de modifier les résultats de digestibilité des aminoacides, il faut citer les sécrétions digestives et l'action synthétisante ou prédatrice de la flore microbienne (Ousterhout et al., 1959). Ces deux facteurs sont susceptibles de varier en fonction de la nature du régime fourni, et peuvent jouer aussi bien en exagérant l'excrétion apparente de l'acide aminé intéressé qu'en la réduisant. Le fait de préciser l'excrétion endogène à l'aide d'une période pendant laquelle les animaux reçoivent un régime sans azote (DAmmers, 1964) ou pauvre en azote (Kuiken et LyMAN, I948) ou le régime de base contenant tous les acides aminés sauf celui qui est à l'épreuve (De MUELENAERE et al., 1967a) fournit une certaine sécurité. Il faut du reste préciser, avec Dammers (1964) que le rôle de la flore sur la digestibilité des acides aminés serait pratiquement nul puisque cette digestibilité n'est pas modifiée par l'usage de sulfamides inhibant la flore. En tout état de cause, cette digestibilité globale ne permet pas de rendre compte d'une absorption tardive de cet acide aminé suivie d'une utilisation métabolique réduite.

Ces divers arguments montrent combien il faut être circonspect dans l'usage de ces méthodes. On peut conclure avec Hepburn et al. (1966) que la relation entre l'ingéré d'acide aminé et le dépôt d'azote représente le test le meilleur pour apprécier la disponibilité ; des informations supplémentaires peuvent être fournies par l'analyse fécale, mais celles-ci ne sont pas suffisantes en soi. Selon De Muelennaere et al. (1967 b), c'est la relation entre l'ingéré d'acide aminé et la croissance qui peut être utilisée ; mais en tout état de cause, les valeurs obtenues sont seulement semi-quantitatives, même lorsqu'on élimine tous les facteurs de variation liés à l'équilibre de la ration.

Il apparaît ainsi que ces méthodes doivent encore faire l'objet d'études approfondies pour être valorisées.

$$
\text { IV. - Conclusion }
$$

Les méthodes biologiques ont pour but d'estimer l'aptitude des protéines alimentaires à couvrir le besoin azoté selon des critères variables portant sur la synthèse de divers tissus ou enzymes, sur l'entretien de ces tissus ou encore sur leur régénération.

On peut présumer dès lors que la hiérarchie peut varier selon le critère choisi puisque l'on sait que la composition des diverses protéines corporelles à synthétiser ou à remplacer ainsi que l'intensité de leur catabolisme n'est pas la même d'un organe à un autre, ce qui se traduit par des besoins tissulaires très variés.

Le choix d'une méthode devrait donc tenir compte du besoin particulier à couvrir. Cependant, on peut constater que les résultats obtenus par les méthodes biologiques les plus importantes (poids, rétention azotée, réplétion) concordent parfaitement si l'on en croit divers rapports et notamment celui de la Rutgars University (I9.5). Ces méthodes peuvent en outre être complétées par les nouvclles approches mises au point, basées sur les variations d'aminoacidémie, qui fournissent des renseignements intéressants sur la nature et la disponibilité du facteur limitant. En outre, les méthodes permettant d'apprécier la disponibilité in vivo se révèlent très utiles pour compléter l'information. Quant aux variations des activités enzymatiques tissulaires, on connaît encore trop mal les règles auxquelles elles sont soumises pour pouvoir baser sur elles une méthodologie de série.

\section{B. - MÉthodes Microbiologiques}

Ces méthodes utilisent des microorganismes qui exigent pour se développer les mêmes acides aminés indispensables que le Rat et on mesure, en conséquence, leur réponse de croissance à 
l'apport azoté, soit directement (turbidimétrie), soit indirectement (dosage des produits de leur métabolisme). Ces microorganismes sont tantôt des protozoaires, tantôt des bacilles :

\author{
Tetrahymena Gelii $H$ (DUNn et RockLAND, 1947) \\ Leuconostoc mesenteroides (HORN et al., 1954) \\ Streptococcus faecalis (HALEvy et Grossowicz, 1953)
}

Actuellement, les deux microorganismes principalement utilisés sont Streptococcus zymogenes (FoRD, 1960, 1962) et Tetrahymena pyriformis (FERNELl et ROSEN, 1956). Le premier de ces microorganismes a besoin de 8 acides aminés seulement dont 7 sont indispensables aux animaux : arginine, histidine, isoleucine, leucine, méthionine, tryptophane, valine et acide glutamique ; il n'a pas besoin de lysine, acide aminé qui a toutefois une action stimulante sur sa croissance. Cette croissance est rapide et de ce fait l'essai est court $(2 \mathrm{j}$ ) surtout si la protéine est prédigérée par la papaïne. Tetrahymena pyriformis, de son côté, requiert les to acides aminés considérés comme indispensables pour la croissance des animaux; sa croissance est plus lente et il faut 4 à 5 jours pour réaliser une estimation.

Ces méthodes étaient initialement prévues pour comparer la valeur nutritive de diverses protéines de même nature, ayant subi des traitements, technologiques ou autres, différents. C'est du reste dans ce but que sont encore utilisés S. zymogenes (FERRANDo et al., r965; Ford, 1962) et $T$. pyriformis (BERGNer $e t$ al., I968 $c$; BaUm et HAENeL, 1965; BAUm, I966a et $b$, 1968). Les résultats obtenus sont le plus souvent en accord avec les résultats des méthodes biologiques, surtout lorsque les protéines sur lesquelles portent le dosage sont d'origine animale (ABRAHAM, Peretianu et Vie, I963; Ferrando et al., ig68; Jacguot et al., i968).

Ces méthodes ont été par la suite perfectionnées par les chercheurs de plusieurs laboratoires anglais travaillant en coopération et les deux microorganismes sont actuellement utilisés pour estimer la disponibilité de certains acides aminés (méthionine en particulier pour S. zymogenes; lysine et méthionine pour $T$. pyriformis) : les modalités de ces techniques ont été rapportées par BoYne et al. (1967).

Cependant, pour ces auteurs (BoynE ct al., 1967), malgré la concordance des résultats obtenus par les tests de disponibilité par voie microbiologique et par voie biologique (Rats et Poulets) pour quelques farines animales (WATERWorth, I964; StotT et SMrth, i966), le besoin se fait sentir d'un plus grand nombre de comparaisons sur un plus grand éventail de protéines, afin de déterminer de façon plus exacte les modalités techniques les meilleures.

\title{
C. - MÉthodes Chimiques ét enzymatiques
}

Décrites dans d'autres revues récentes (JACQUOT et RÉRAT, I966; SHEFFNER, I967), elles sont basées sur la comparaison de la composition de la protéine intéressée avec celle d'une protéine de référence considérée comme fournissant à l'animal les acides aminés qui lui sont nécessaires sous un équilibre optimum. En d'autres termes, ces méthodes comparent la protéine alimentaire aux besoins d'acides aminés qu'elle est destinée à couvrir, ceux-ci pouvant arbitrairement être définis à l'aide d'une protéine dont l'utilisation digestive et métabolique soit pratiquement complète. Certaines tiennent compte, en outre, de la vitesse de dégradation des protéines par les enzymes digestives.

\section{I. - Index chimiques}

Le principe des premières méthodes proposées repose sur le fait que, lorsque l'acide aminé limitant ne couvre qu'une fraction du besoin, seule la fraction correspondante de protéine équilibrée est utilisable pour la croissance. On tentait ainsi de prévoir la valeur nutritive des protéines à partir de l'importance du déficit du facteur limitant, déficit calculé soit par rapport à une protéine standard, soit par rapport aux besoins. 
C'est ainsi que la méthode de Block et Mitchell (I946), la plus ancienne, prenait comme référence les protéines totales d'œuf qui sont parfaitement utilisées par le Rat en croissance et à l'entretien, par l'Homme adulte et par le Chien et qui ne sont valorisées par aucune addition d'acides aminés, sauf celle, minime, de lysine (MıтcheLL, 1959) "L'index chimique " indiquait le plus faible pourcentage trouvé en établissant le rapport de chaque acide aminé dans la protéine testée et dans la protéine de référence. La relation entre la valeur biologique mesurée par la technique des bilans, et cet "index chimique " était étroite (coefficient de corrélation : $r=0,86$ pour le Rat; o,83 pour le Porc) (Mitchell, 1954).

Voisine était la méthode préconisée par la suite, par un groupe commun d'experts de la F. A. O. (Food and Agriculture Organisation) et du W. H. O. (World Health Organisation) (1965) pour prévoir la valeur biologique des protéines pour l'Homme : la référence était cette fois constituée par l'estimation provisoire du besoin d'acides aminés. En outre, contrairement à la méthode de Block et Mitchell qui comparait les protéines entre elles à égalité d'apport azoté, la méthode F.A.O.-W.H.O. ramenait la teneur en acides aminés essentiels à leur somme. ce qui permettait de rendre compte à la fois de l'équilibre des acides aminés essentiels entre eux, et de leur quantité totale dans la protéine. Ceci impliquait évidemment que l'apport d'acides aminés non essentiels par la protéine était considéré comme suffisant pour éviter un détournement de l'azote essentiel de sa fonction de formation tissulaire. Cette méthode avait déjà été utilisée par FAUconneaU et ses collaborateurs (FAuconneau, 1964 ; Pion et al., 1963) qui l'appliquent aux animaux domestiques avec quelques nuances.

\section{II. - Index intégrant tous les acides aminés essentiels}

Cependant, ces coefficients ainsi établis n'étaient pas parfaits; en effet, les acides aminés entrent dans un certain nombre de réactions pour lesquelles ils ne sont pas tous nécessaires et, de ce fait, l'utilisation d'une protéine n'est pas entièrement limitée par la déficience d'un seul acide aminé. C'est pourquoi ont été conçus de nouveaux indices "intégrés " qui tiennent compte de l'ensemble des acides aminés essentiels. Citons pour mémoire tout d'abord l'index intégré de KÜHNAU (1949) qui comparait la somme des pourcentages d'acides aminés des protéines à celle trouvée dans une protéine de référence qui était le lait de Femme; le rapport de ces sommes corrigées ou non en fonction des apports excessifs permettait de fixer divers coefficients (valeur totale, valeur pure, valeur de supplémentation), dont l'intérêt s'est trouvé fort diminué par la mise au point d'autres index tels que celui d'OSER (I95I). Cet auteur fixait les bases d'un index d'aminoacides essentiels qui intégrait à la fois la conception des rapports d'acides aminés en comparaison avec l'œuf et certains aspects de l'index de KüHNau en tenant compte de tous les acides aminés essentiels et pas seulement du facteur limitant. La valeur nutritive d'une protéine était ainsi estimée à partir de la moyenne géométrique des rapports des teneurs d'acides aminés essentiels dans cette protéine relativement à leurs teneurs dans les protéines d'ocuf.

Par la suite, Mitchell (1954) a modifié cet index. L'arginine est ainsi omise car elle n'est que partiellement indispensable; par contre, la cystine et la tyrosine sont introduites dans le calcul en raison des économies de méthionine et de phénylalanine qu'elles autorisent. La concordance entre cet index modifié et la valeur biologique est très élevée; la corrélation est de 0,95 pour un ensemble de 48 données chez les différences espèces.

Il apparaît ainsi que cet index modifié représente une méthode très intéressante pour connaître le maximum de la valeur nutritive potentielle d'une protéine, pour préciser la nature de son facteur limitant et par là même les possibilités de sa supplémentation. Cependant, elle n'est pas parfaite car elle ne tient pas compte des phénomènes d'indisponibilité de certains acides aminés, phénomènes liés à leur libération retardée au niveau du tube digestif; on risque ainsi d'obtenir des estimations surévaluées dans certains cas. Pour pallier cet inconvénient, on a tenté d'évaluer cette disponibilité par des méthodes chimiques et enzymatiques in vitro. 


\section{III. - Index tenant compte de la disponibilité des acides aminés}

Divers types de méthodes ont été utilisés; les uns tiennent compte de la libération enzymatique de tous les acides aminés, d'autres tentent de mesurer la disponibilité de la lysine qui est l'acide aminé le plus souvent atteint par les traitements technologiques.

\section{a) Disponibilité de tous les acides aminés.}

Il faut tout d'abord citer l'index des aminoacides libres et résiduels de la digestion pepsique (PDRAA index) mis au point par SHEFFNER et al. (1956). L'équilibre entre les acides aminés libérés par la digestion pepsique révèle des différences entre protéines qu'on ne peut mettre en évidence, ni d'après leur composition en acides aminés, ni d'après l'équilibre des acides aminés libérés ultérieurement par la trypsine et l'erepsine. Les auteurs cités ont donc conçu un index d'aminoacides combinant à la fois l'équilibre d'aminoacides libérés par la pepsine et l'équilibre de ces acides aminés dans le résidu non digéré, en comparant en outrc ce phénomène avec ce qui se passe pour une protéine de référence (protéine d'œuf). La méthode préconisée consiste, après une hydrolyse pepsique partielle des protéines, ajustée pour recréer des conditions naturelles (libération de 30 p. Ioo des acides aminés de l'œuf avant d'atteindre l'intestin), à définir la composition du résidu et de l'hydrolyse, à exprimer la teneur de chaque acide aminé en pourcentage de la somme des acides aminés essentiels, à établir les rapports vis-à-vis de leurs homologues dans le résidu et l'hydrolysat des protéines d'œuf, à calculer l'index d'OSER modifié par MiTchell pour chaque fraction, et enfin à intégrer à ce calcul une correction pour tenir compte de la protéolyse différentielle de la protéine et des protéines d'œuf, et de l'importance quantitative des deux fractions dans la protéine à tester. La valeur obtenue correspond à l'utilisation protidique nette, c'est-à-dire au produit de la digestibilité et de la valeur biologique. La valeur biologique sera obtenue par division du PDR par la digestihilité mesurée in vivo. Les résultats fournis par cette méthode sont en étroite relation avec l'utilisation protidique nette et la valeur biologique mesurées par les techniques biologiques; ainsi SHEFFner (I967) rapporte des coefficients de corrélation de 0,998 pour le Rat en croissance et de 0,984 pour l'Homme ; pour les mêmes protéines, l'index modifié d'Oser présente une relation moins étroite avec la valeur biologique $(\boldsymbol{r}=0,888$ pour le Rat en croissance; 0,947 pour l'Homme). Ceci ressort du reste bien des données du tableau r 3 .

Il est ainsi évident que l'index de ShEFFner représente une amélioration marquée de l'index d'OSer, modifié par Mitchell. Et les multiples essais faits par des promoteurs prouvent qu'il rend parfaitement compte des modifications de disponibilité liées aux divers traitements technologiques des aliments.

Il faut cependant noter que cette procédure est extrêmement longue et complexe, et certains des calculs préconisés sont arbitraires. C'est pourquoi un index simplifié a été préconisé par ShEFFNER ( ${ }^{967}$ ) qui permet de calculer un facteur pour rendre compte de la disponibilité des acides aminés à partir des teneurs en trois acides aminés seulement (lysine, tryptophane, méthionine) dans les produits de đigestion pepsique ; ce facteur est alors intégré à l'index modifié d'acides aminés, ce qui fournit la valeur d'utilisation protidique nette. Les 3 acides aminés choisis sont ceux qui courent le plus de risques lors des traitements technologiques. Cet index, dont certaines modalités sont arbitraires, demande à être mieux précisé.

En son absence, on peut se demander avec OSER (1959), si l'amélioration obtenue par l'index préconisé en 1956 par SHEFFNER justifie le volume considérablement accru de travail, sauf dans des cas très particuliers.

Un certain nombre d'auteurs a cssayé par la suite d'autres enzymes ou diverses combinaisons enzymatiques. C'est ainsi qu'une digestion plus complète a été essayée à l'aide de l'action successive de la pepsine et de la pancréatine (AKEson et StahManN, I964; Bergen et al., 1967; Prahl et TAUfel, ig66), ceci permet d'obtenir des résultats plus conformes à la valeur biologique que les index chimiques tels que celui d'OsER, mais ne fournit aucune amélioration par rapport à ceux de SHEFFNER; les méthodes sont toutefois plus simples. 


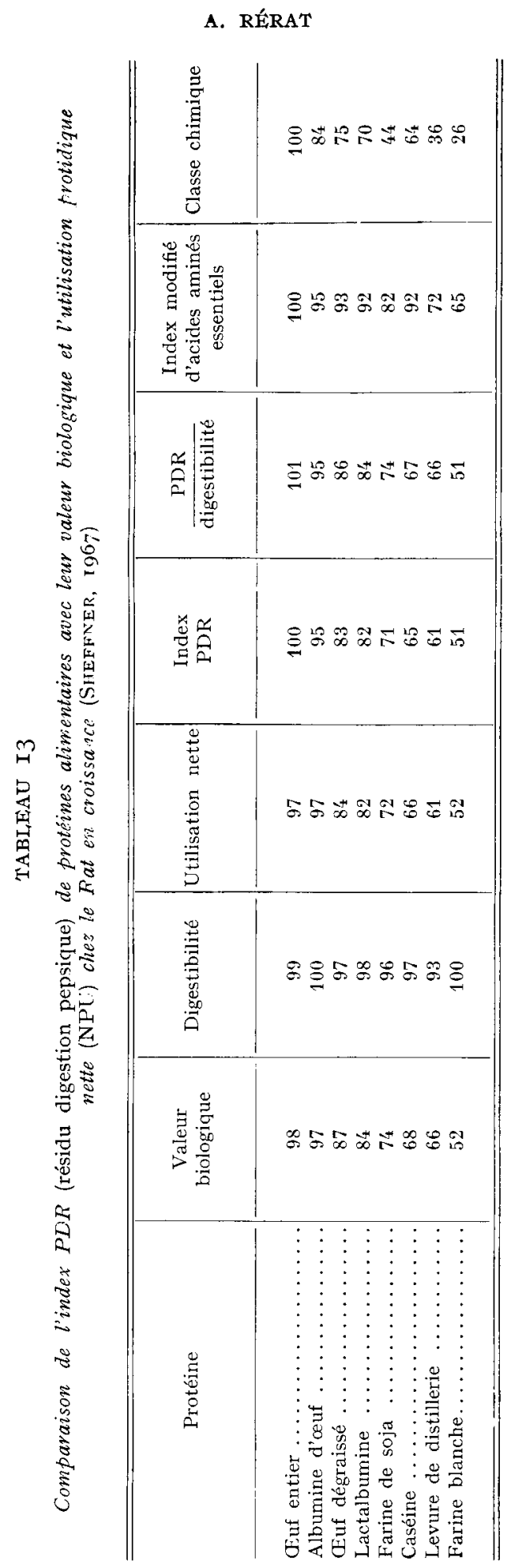


Plus récemment, Ford et SALTER (I966) ont comparé diverses méthodes de digesti on enzymatique : pepsine, et papaïne; pepsine pancréatine et erepsine; pronase. Les résultats étaient généralement concordants et confirmaient ceux des tests biologiques sur Rat. Dvorak (I $968 a$ et $b$ ) propose une méthode basée sur l'usage de papaine, leucylaminopeptidase et protidase. Menden et CREMer (1966) n'utilisaient que la pancréatine et obtenaient ainsi des résultats identiques aux tests biologiques pour la caséine et la viande.

En conclusion, le grand nombre de travaux réalisés au cours des dernières années sur la mesure de la disponibilité des acides aminés à l'aide de tests enzymatiques in vitro montre l'intérêt de ces derniers. Malheureusement, les méthodes mises au point, si elles permettent de prévoir de façon précise la valeur biologique des protéines, sont généralement trop compliquées pour être utilisées de façon habituelle. Elles ne représentent pas de ce fait d'avantages particuliers par rapport aux méthodes de mesure de disponibilité in vivo.

\section{b) Disponibilité de la lysine.}

Parmi les acides aminés, la lysine est certainement l'un des plus sensibles aux traitements technologiques subis par les protéines, notamment l'application de traitements thermiques en vue de la dessiccation. Ainsi, au contact des glucides, les acides aminés subissent une dénaturation lente à froid, plus rapide à chaud avec coloration et formation de mélanoïdes. Ce processus, connu sous le nom de réaction de MAILlARD (1912) met en jeu une série de réactions chimiques complexes, dont la première est constituée par la conjugaison du groupement aminé et de l'aldose avec formation d'une aldosylanine. Dans le cas de la lysine, le composé formé par la réaction entre le groupement $\varepsilon$-aminé de l'acide aminé et le groupement réducteur des sucres n'est pas dissociable et la lysine qu'il renferme n'est que très difficilement libérée dans le tube digestif, ce qui provoque une diminution de l'efficacité protidique.

Ceci explique l'intérêt particulier que soulève le dosage de la lysine disponible, qui est effectué à l'aide de méthodes chimiques et enzymatiques. Le principe de la méthode chimique préconisée par Carpenter et ses collaborateurs (Carpenter et Ellinger, i955; Bruno et Carpenter, I957) consiste à ne considérer comme utilisable que la lysine présentant des groupements $\varepsilon$-aminés libres. On mesure ainsi la lysine disponible par la réaction des groupements aminés libres avec le fluoro 2-4 dinitrobenzène (FDNB) : la dinitrophényllysine libérée par la suite après une hydrolyse acide peut être mesurée par colorimétrie. La méthode, telle qu'elle était préconisée à ses débuts, permettait d'obtenir des valeurs de lysine disponible présentant une corrélation étroite avec les résultats obtenus sur la Volaille concernant la valeur de supplémentation pour la plupart des protéines animales, mais non pour les protéines végétales (Carpenter et al., i957; Carpenter, 1963). Une modification ultérieure permit à son auteur (CARPENTER, I960) d'éliminer les interférences avec l'arginine libre, et ceci permettait de différencier des échantillons ayant plus de 5 p. roo d'écart dans leur teneur de lysine disponible. Cette technique modifiée en I960, est actuellement utilisée largement pour le contrôle des farines de poisson et de viande ; elle est préconisée par les Nations Unies pour éprouver la qualité des farines de poisson destinées à l'alimentation des enfants dans les pays en voie de développement.

Les difficultés soulevées par la méthode de CARPENTER utilisée avec les céréales et les tourteaux concernent une récupération insuffisante de la DNP-lysine et des résultats variables, en relation avec une destruction de ce composé par les glucides pendant l'hydrolyse et la formation d'autres produits jaunes difficiles à séparer de la DNP-lysine (CARPENTER et al., 1957). C'est pourquoi récemment diverses modifications ont été proposées à cette méthode par diverses équipes (RAo et al., 1963 ; BLOM et al., 1967 ; RoAch et al., 1967).

La méthode préconisée par ROAch et al. (1967) est basée sur la mesure de la lysine totale et de la lysine restant après traitement des farines au fluorodinitrobenzène : elle peut être considérée comme une méthode de routine.

Enfin, toujours sur ce même principe KAKADE ct LIENER (I969) ont suggéré l'utilisation de l'acide 2. 4. 6-trinitrobenzènesulfonique (TNBS) à la place du fiuoro 2-4-đinitrobenzène. 
La disponibilité de la lysine est également appréciée à l'aide d'une méthode enzymatique préconisée par MAURon et al. (1955). Ces auteurs mesurent la disponibilité par une digestion in vivo des protéines à l'aide de pepsine. puis de trypsine, une dialyse étant opérée tout au long de l'opération. Cette méthode a été appliquée à la mesure de la dénaturation de la valeur nutritive de la poudre de lait et les résultats concordent parfaitement avec le coefficient d'efficacité protidique chez le Rat en croissance (Mauron et Mortu, I958). Bien entendu, du fait que ce sont les acides aminés soufrés qui représentent le facteur limitant des protéines du lait, cette relation entre disponibilité de la lysine et résultats des méthodes biologiques est surtout mise en évidence dans les régimes où la poudre de lait est utilisée pour supplémenter des aliments pauvres en lysine (céréales) (Pion et Rérat, I962).

Cette méthode est assez laborieuse, mais plus sûre que la méthode de CARPENTER, surtout quand la disponibilité de la lysine est très faible (MAURon, I96r).

D'une façon générale, que ce soit l'une ou l'autre de ces méthodes qui soit en jeu, on peut conclure avec MAURon (I96I) qu'clles représentent un progrès dans l'évaluation de la valeur nutritive des protéines in vitro. Le temps et l'appareillage nécessaires sont moins importants que pour le dosage des acides aminés totaux et elles permettent de connaître les dommages causés par l'application de traitements thermiques.

\section{IV. - Limites des méthodes in vitro}

Il existe certains désaccords entre les résultats obtenus par les méthodes in vitro et ceux obtenus par les méthodes in vivo. Il existe à ce fait plusieurs raisons. Les tests in vitro ne sont en effet pas sensibles aux déséquilibres par excès d'acides aminés, à la présence éventuelle de substances toxiques, aux différents constituants non azotés du régime comme le sont les épreuves sur animaux. On ne peut donc attendre les mêmes services de ces deux types de méthodes qui sont complémentaires; les unes permettent de préciser la valeur nutritive globale des protéines les autres d'analyser les raisons de leur médiocrité éventuelle et de pallier leurs déséquilibres. L'essentiel est de ne pas tenter d'obtenir plus de renseignements de chacune d'entre elles qu'elle ne peut en fournir, et de la choisir en fonction du but poursuivi.

\section{CONCLUSIONS}

Au cours des dernières années, un nombre important de travaux a continué à porter sur les besoins d'acides aminés de diverses espèces animales, en particulier à l'aide de techniques basées sur les variations de l'aminoacidémie. On dispose ainsi de recommandations permettant d'ajuster les apports aux besoins pour un certain nombre de productions. Des précisions sont en outre fournies sur les apports d'acides aminés « utiles " et sur la valeur des sources d'azote ammoniacal ou uréique pour les monogastriques. Par ailleurs, les déséquilibres par excès ont été très largement étudiés, et les mécanismes physiologiques de ces déséquilibres, sans être parfaitement élucidés, commencent à être micux connus.

Les relations entre besoin azoté et besoin énergétique ont été précisées : on sait notamment qu'en alimentation séparée, la consommation spontanée de principes énergétiques est directement proportionnelle à la rétention azotée permise par la qualité et la quantité des protéines ingérées, mais que cet ajustement n'est plus aussi bon en régime mixte. Par ailleurs, la discussion reste ouverte sur la forme des relations entre rétention azotée et taux azoté du régime.

Sur le plan méthodologique, des améliorations sont périodiquement apportées aux techniques classiques faisant appel aux variations de poids ou de rétention azotée : il faut noter dans ce domaine la méthode d'alimentation séparée qui permet d'obtenir des résultats extrêmement précis et répétables. D'autres méthodes biologiques ont fait l'objet de développements, basées 
sur l'aminoacidémie ou les variations de teneurs enzymatiques de divers tissus; ces méthodes sont toutefois très limitées dans leurs applications, et leurs modalités demanderaient à être étudiées. La disponibilité de ces acides aminés peut maintenant être éprouvée in vivo avec une certaine précision. Quant aux méthodes in vitro, qu'elles soient d'ordre microbiologique, chimique ou enzymatique, elles ont subi un certain nombre d'améliorations qui les rendent très utiles pour compléter l'information fournie par les méthodes biologiques et orienter les moyens à mettre en œuvre dans la valorisation des protéines.

Reçu pour publication en décembre 1970.

\section{SUMMARY}

THE, BIOLOGICAL VALUE OF PRO'TEINS : SOME RECENT DATA

INTRODUCTION

\section{I. - FACTORS CONDITIONING THE BIOL,OGICAI, VAL,UE \\ OF THE PROTEINS}

\section{A. - Intrinsic factors}

I. The amino acid requirements of the rat, poultry and pig.

a) Methods of determining the amino acid requirement based upon the aminoacidemia.

b) Recommendations (rat, poultry, pig).

c) Supply of non essential nitrogen.

2. Amino acid imbalances.

3. Conclusions.

I. Protein level (rate).

B. - Extrinsic factors

2. Economy of nitrogen by the energy supply.

\section{II. - METHODS OF MEASURING THE BIOLOGICAL VALUE}

\section{A. - Biological methods}

I. Weight, nitrogen retention and nutritive value of the proteins.

a) Weight method.

b) Nitrogen retention.

- N-balance methods.

- Methods based upon the body analysis.

- Net value of the food proteins.

- Comparison of the biological methods in the entire animal. 
2. Other biological methods.

a) Variations of the tissular enzymatic activities.

b) Methods based upon the variations in the plasma contents of non protein-N.

3. in vivo availability of the amino acids.

4. Conclusions.

\section{B. - Microbiological methods \\ C. - Chemical and enzymatic methods}

I. Chemical index.

2. Index integrating all essential amino acids.

3. Index taking into account the availability of the amino acids.

a) Availability of all amino acids.

b) Availability of lysine.

4. Limits of the in vitro methods.

\section{CONCLUSIONS}

\section{RÉFÉRENCES BIBL,IOGRAPHIQUES}

Abernathy R. P., Miller J., i965. Effects of imbalances or antagonisms among non essential aminoacids on growth and nitrogen utilization by rat. $J$. Nutr., 86, 23 I-235.

Abraham J., Calet C., RÉrat A., JaCQuot R., Ig6r. Solidarité des besoins énergétique et protéique de croissance : l'ajustement spontané des calories et des protides. C. R. Acad. Sci., Paris, 253, $2768-2770$

Abraham J., Peretianu J., Vie R., I963. Intérêt et limite d'emploi de la méthode microbiologique de Ford pour l'estimation in vitro de la valeur nutritionnelle des protéines. Ann. Biol. anim. Bioch. Biophys, 3, no h.-S., 47-48.

Abraham J., De Saintaurin M., Jacquot R., I969. Étude de l'ajustement spontané, entre les ingérés calorique et protéique réalisé par le Rat placé à l'alimentation séparée : influence du rythme de distribution des repas. C. R. Acad. Sci., 268 D, 2727-2729.

Adkins J. S., Wertz J. M., Hove E. L., I966. Influence of non essential L-amino acids on growth of rats fed high levels of essential L-amino-acids. Proc. Soc. Exp. Biol. Med., 122, 5 I9-523.

Adkins J. S., Wertz J. M., Boffman R. H., Hove E. L., I967. Influence of addition of water or non essential nitrogen on growth of rats fed low levels of essential aminoacids. Proc. Soc. Exp. Biol. Med., 126, 500-504.

Adrian J., Rérat A., 1958. Méthodes d’évaluation de la valeur nutritive des protéines. C. N. R.S., Paris.

Akeson W. R., Stahmann M. A., I964. A pepsin pancreatin digest index of protein quality evaluation. J. Nutr., 83, 257-26r.

Alam S. Q., Becker R. V., Stucki W. P., Rogers Q. R., Harper A. E., I966a. Effect of threonine on the toxicity of excess tyrosine and cataract formation in the Rat. J. Nutr., 89, 9I-96.

Alam S. Q., Rogers Q. R., Harper A. E., Ig66 b. Effect of tyrosine and threonine on free aminoacids in plasma, liver, muscle and eye in the rat. $J$. Nutr., 89, 97-I05.

Alam S. Q., Boctor A. M., Rogers Q. R., Harper A. E., I967. Some effect of aminoacids and cortisol on tyrosine toxicity in the rat. $J$. Nutr., 93, 317-323.

Albanese A. A., I959. Criteria of protein nutrition, In Albanese A. A. "Protein and aminoacid nutrition ", 297-347, Acad. Press, New York, London.

Allison J. B., I955. Biological evaluation of proteins. Physiol. Rev. 35, 664-7oo.

Allison J. B., I956. Supplementation with methionine. In ColE W. H. "Some aspects of aminoacids supplementation ", 69-85, New-Brunswick, New Jersey, Rutgers Univ. Press.

Allison J. B., I957. Nitrogen balance and the nutritive value of proteins. J. Amer. Med. Assoc., 164, 283-289.

Allison J. B., rg64 in Munro H. N., Allison J. B. Mammalian Protein metabolism, vol. II, 4I-86, Acad. Press, New York, London. 
Allison J. B., Anderson J. A., 1945. The relation between absorbed nitrogen, nitrogen balance and biological value of protein in adult dogs. J. Nutr., 29, 4I3-420.

Allison J. B., Wannemacker R. W. Jr., Middleton E. J., Spoerlein T., i959. Protein requirements and problems in supplementation for man. Food Technol., 13, 597.

Anantharaman K., Carpenter K. J., Nesheim M. C., r968. The nutritional value of poor proteins fed at high levels, $2 /$ Species differences. Brit. J. Nutr., 11, I99-205.

Anderson G. H., Bowland J. P., I967. Lysine and fat supplementation of weanling pig diets. Can. J. Anim. Sci., 47, 47-56.

Anderson H. L., Benevenga N. J., Harper A. E., I969. Effect of prior high protein intake on food intake, serine dehydratase activity and plasma aminoacids of rats fed aminoacid imbalanced diets. $J$. Nutr., 97, 463-474.

Arkerson C. W., Ham W. E., Mussehl F. B., I940. The utilization of food element by the growing chicks. IX. The nitrogen of urea. Nebr. Univ. Agr. Exp. Sta. Bull. $n^{\circ} 120$.

Arsac M., Rérat A., ig62. Technique de fistulation de la veine porte chez le Porc. Ann. Biol. anim. Bioch. Biophys., 2, 335-343.

Baker D. H., Becker D. E., Norton H. W., Jensen A. H., Harmon B. G., ig66. Some qualitative amino-acid needs of adult swine for maintenance. J. Nutr., 88, 382-390.

Barnes R. H., Bosshard T. K., I946. The evaluation of protein quality in the normal animal. Ann. N. Y. Acad. Sci., 47, 273-296.

BAUM F., rg66a. Estimation of biological value of protein with "Tetrahymena pyriformis ». 2. Protein value of different foods and feeds. Nahrung., 10, 453-459.

BAUM I., I 966 b. Listimation of biological value of protein with "Tetrahymena pyriformis. " 3 . Effect of added amino-acids and time of storage on protein value of cereal flours. Nahrung., 10, 57I-580.

BAUM F., 1968. Estimation of biological value of protein with "Tetrahymena pyriformis. "4. Effect of the baking process on protein value of mixed rye bread. Nahrung., 12, 6I-67.

BAUM F., HAENEL H., I965. Estimation of biological value of protein with "Tetrahymena pyriformis." I. Method and estimation of the value of some foods. Nahrung., 9, $517-525$.

BEATon J. R., I967. Effect of increased metabolism and of hyperphagia on dietary aminoacid imbalance in the rat. Can. J. Physiol. Pharmacol, 45, rori-rorg.

BECKER M., HARNisch S., I958. Recent studies on the significance and exactness of nitrogen balances in metabolism trials on living animals. 2. Comparison of the $\mathrm{N}$ retention calculated from the balance with the actual $\mathrm{N}$ increment in the body in growth studies with rats. Arch. Tierernähr., 8, 40I-4I9.

Bender A. E., I956. Relation between protein efficiency and net protein utilization. Brit. J. Nutr., 10, I $35-\mathrm{I} 43$.

Bender A. E., 1958. Biological methods of evaluating protein quality. Proc. Nutr. Soc., 17, 85-90.

Bender A. E., Doell B. H., 1957. Biological evaluation of proteins : a new aspect. Brit. J. Nutr., 11, $140-148$.

Bender A. E., Miller D. S., 1953. A new brief method of estimating net protein value. Biochem. J., 53, VII.

Benevenga N. J., Harper A. E., I967. Alleviation of methionine and homocystine toxicity in the rat. J. Nutr., 93, 44-52.

Benevenga N. J., Harper A. E., Rogers Q. R., 1968. Effect of an amino acid imbalance on the metabolism of the most limiting amino acid in the rat. J. Nutr., 95, 434-444.

Benton D. A., Harper A. E., Spivey H. E., Elvehjem C. A., r956. Phenylalanine as ari aminoacid antagonist for the rat. Arch. Biochem. Biophys., 60, 156-I63.

Berdanier C. H., Brush M. K., Fisher H., I967. Significance of the endogenous nitrogen excretion in protein evaluation studies with rats. $J$. Nutr., 93, 4 I I-4I7.

Bergen W. G., Purser D. B., Cline J. H., ig67. Enzymatic determination of the protein quality of individual rumen bacteria. J. Nutr., 92, 357-364.

Bergner H., I966. Amino acid imbalance : studies on rats with large supplements of lysine. Arch. Tierernähr., 16, I-IO.

Bergner H., 1967. Toxicity of methionine. I. Effects of large methionine supplements to different protein diets on toxicity, absorption of methionine $\mathrm{S}^{35}$ and excretion of $\mathrm{S}^{35}$ in urine of rats. Arch. Tierernähr., 17, I85-195.

Bergner H., Hock A., Radischeski R., I964. Xanthine oxidase activity in liver and the biological value of food protein. Arch. Tierernähr., 14, 45 I-468.

Bergner H., Wirthgen B., Münchmeyer R., ig68a. Toxicity of methionine. 3. Changes in activity of glutamic oxaloacetic transaminase, glutamic pyruvic transaminase, leucine amino peptidase, ornithine carbamoyl transferase and arginase in the liver of rats given excess methionine. Arch. Tieremähr., 18, 5 18-526.

Bergner H., Münchow H., Wirthgen B., ig68 b. Evaluation of proteins in feedingstuffs. 4. Changes in enzyme activity of leucine amino peptidase, arginase, glutamate pyruvate transaminase and glutamate oxaloacetate transaminase in serum of pigs fed different diets. Arch. Tierernähr., 18, 5-I6.

Bergner H., Münchow H., Koch R., I968c. Evaluation of protein in feedingstuffs. 5. - Comparative studies of protein quality in animal trials and on microbiological basis with the protozooa Tetrahymena pyriformis. Arch. Tierernähr., 18, 212-221. 
Block R. J., Mitchell H. H., I946. The correlation of the amino acid composition of proteins with their nutritive value. Nuir. Abs. Rev., 16, 249-278.

Blom L. B., Hendricks P., Caris J., I967. Determination of available lysine in foods. Anal. Biochem., 21, 382 .

Boctor A. M., Harper A. E., I968. Measurement of available lysine in heated and unheated foodstuffs by chemical and biological methods. J. Nutr. 94, 289-296.

Boomgaardt J., McDonald B. E., I 969 . Comparison of fasting plasma aminoacid patterns in the pig, rat and chicken. Can. J. Physiol. Pharmacol., 47, 392-395.

Boorman K. N., Fishrer H., I966. The arginine-lysine interaction in the chick. Brit. Poult. Sci., 7, $39-44$.

Bothwell J. W., Williams J. N., 1954. Effects of a lysine deficiency upon enzyme activity in rat liver. Proc. Soc. Exp. Biol. Med., 85, 544-547.

Bowland J. P., I962. Levels and ratios of energy and protein in swine rations. Feedstuffs., 34 (I3), 30-32.

Boyne A. W., Price S. A., Rosen G. D., Stott J. A., ig67. Protein quality of feedingstuffs. Progress report on collaboration studies on the microbiological assay of available aminoacids. Brit. $J$. Nutr., 21, I $81+206$.

Braham J. E., Bressani R., I969. Effect of sample preparation, and of fat and crude fiber in the diet on the determination of net protein utilization. Arch. Latinoameric. Nutricion., 19, 35-40.

Braham J. E., Elias I. G., 1)E ZaGhi S., Bressani R,, 1967. Effect of protein level and duration of test on carcass composition, net protein utilization ( $N \mathrm{PU}$ ) and on protein efficiency ratio (PER). Nutritio et Dieta., 9, 99-I I.

Brissani R., Braham J. E., Elias L., G., I965. Relationship between net protein utilization (NPU) and nitrogen efficiency ratio (NER). Nutritio et Dieta, 7, 161-174.

Breuer L. H. (Jr), Warner R. G., Benton D. A., Loosli J. K., I966. Dietary requirement of asparagine and its metabolism in rats. J. Nutr., 88, I43-I 50 .

Brune H., Ther E., Borchlert F., ig68. Discrepancy of protein utilization by rats and pigs and the variability of their metabolic data. Z. Tierphysiol. Tierernähr. Futtermittelk., 24, IO8-II7

Bruno D., Carpenter K. J., I957. A modified procedure for the estimation of available lysine in food proteins. Biochem. J., 67, 13 p.

Bunce G. E., King K. W., I 969 a. Aminoacid retention and balance in the young rat fed varying levels of lactalbumin. J. Nutr., 98, I59-167.

Bunce G. E., KING K. W., I969 $b$. Aminoacid retention and balance in the young rat fed varying levels of casein. J. Nutr., 98, I68-I 76 .

Calet C., Joundet C., Baratou J., ig6i. Variation de la consommation spontanée d'énergie du poussin en fonction de la nature des matières azotées du régime. Ann. Biol. anim. Bioch. Biophys., 1, 5-9.

Caliovn W. K., Hepbyrs li N., J3Radley W. B., 1960. The availability of lysine in wheat, flour, breed and gluten. J. Nutr., 70, 337-347.

Calloway D. H., Spector H., 1954. Nitrogen balance as related to caloric and protein intake in active young men. Amer. J. Clin. Nutr., 2, 405-412.

Carloway D. H., Spector H., I95. a. Nitrogen utilization during caloric restriction. I. The effect of dietary fat content. J. Nutr., 56, 533-544.

Calloway D. H., Spector H., 1955 b. Nitrogen utilization during caloric restriction. 2, The effect of variation in nitrogen intake. J. Nutr., 56, 545-554.

Calloway D. H., Spector H., I955c. Nitrogen utilization during caloric restriction. 3. The effect of preceding diet. J. Nutr., $\mathbf{5 7}, 73-88$.

CAMPBELI. J. A., I963. Methodology of protein evaluation. A critical apparaisal of methods for evaluation of protein in foods. American Univ. Beirut, Fac. Agric. Sci. Publ. no 21, June 1963, pp. 104.

Cannon P. R., r948. Protein and amino acid deficiencies, Springfield. III, C. C. Thomas, ed.

Cannon P. R., Humphreys E. R., Wissler R. W., Frazier L. E., ig44. Chemical, clinical, and immunological studies on the products of human plasma fractionation. 23. The effects of feeding possible blood substitutes on serum protein generation and weight recovery in the hypoproteinemic rat. $J$. Clin. Invest., 23, 60I-606.

Carpenter K. J., ig6o. The estimation of the available lysine in animal Protein foods. Biochem. $J$. $77,604-6$ IO

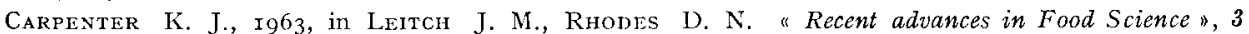
IO4, Butterworths, London.

Carpenter K. J., Elimang J., I955. The estimation of available lysine in protein concentrates. Biochem. J., 61, XI-XII.

Carpenter K. J., Ellinger G. M., Munro M. I., Rolfe E. J., I957. Fish products as protein sup plements to cereals. Brit. J. Nutr., 11, 162-173.

Chance R. E., Ig62. Free amino-acids and related compounds in the plasma of chinook salmon and swine, Thesis Univ. Microfilms Purdue Univ. Chem. Biol., 64-194.

Charkey L. W., Wilgus H. S., Patton A. R., Gassner F. X., I950. Vitamin $B_{12}$ in aminoacid metabolism. Proc. Soc. Exp. Biol. Med., 73, 21-29. 
Chavez R., Thomas J. M., Reid B. L., I966. The utilization of non-protein nitrogen by laying hens Poult. Sci., 45, 547-553.

Childs G. R., Сомвs G. F., I964. Use of chick plasma non-protein nitrogen in evaluating fish meals. Poult. Sci., 43, I220-1222

Clark A. J., Yamada C., Swenseid M. E., I968. Effect of L-leucine or aminoacid levels in plasma and tissue of normal and diabetic rats. Amer. J. Physiol., 215, I324-1328.

Clawson a. J., Blumer T. N., Smart W. W. G., Barrick E. R., ig62. Influence of energy-protein ratio on performance and carcass characteristics of swine. $J, A \mathrm{nim}$. Sci, 21, 62-68.

Combs G. E., Conness R. G., Berry T. H., Wallace H. D., ig67. Effect of raw and heated soybeans on gain, nutrient digestibility, plasma aminoacids and other blood constituents of growing swine. J. Anim. Sci, 26, I067-I07I.

Combs G. F., Romoser G. L., I955. Maryland Univ. Agric. Exptl. Sta. Misc. Pub., 226.

Cooke R., Lodge G. A., Lewis D., I966. N balance in pigs and aminoacids in plasma, In Proc. 9th Intern. Congr. of Anim. Prod., Edimburgh, 1966, p. 104-105, Oliver and Boyd Ltd, Edinburgh.

ČUperlovic M., Stošic D., r970. Some effects of protein deficiency in young growing pigs. II. Blood plasma free aminoacids. Acta Vet. Scand., 11, 1-15.

Dammers J., I964. Étude de la digestibilité chez le Porc. Les facteurs qui influencent la digestibilité des aliments. Digestibilité des aminoacides. These Drukkerij "West Friesland"Hoorn, Universiteit Van Leuven, Landbouvinstitut.

Daniel R. G., Waisman H. A., I968. The effects of excess aminoacids on the growth of the young rat. Growth., 32, $255-265$.

Davidson J., Williams R. B., 1968 . A note on the estimation of nitrogen retention in chicks by body analysis and balance methods. Brit. J. Nutr., 22, 29 I-295.

DEAN W. F., ScotT H. M., I 965 . The development of an amino acid reference diet for the early growth of chicks. Poult. Science, XLIV, no $3,803-808$.

Dean W. F., Scotr H. M., I 968 . Ability of arginine to reverse the growth depression induced by supplementing a crystalline aminoacid diet with excess lysine. Poult. Sci., 47, 34 r-342.

De Muelenaere H. J. H., Martin R. S., Murdoch M. G., 1965. Applicability to chicks of the carcass analysis method for determination of net protein utilization. 2. Effect of protein, calorie and fiber level. J. Nutr., 85, 386-392.

De Muelenaere H. J. H., Chen M. L., Harper A. E., 1967 a. Assessment of factors influencing estimation of lysine availability in cereals products. J. Agric. Food. Chem., 15, 3 Io.

De Muelenaere H. J. H., Chen M. L., Harper A. E., I $967 b$. Assessment of factors influencing estimation of threonine, isoleucine and valine availability in cereals products. J.A gric. Food. Chem., 15,3 I 8 .

Denton A. E., Elvenjem C. A., 1954. Availability of aminoacids in vivo. J. Biol. Chem., 206, $449-454$.

Derse P. H., I962. Evaluation of protein quality (biological method). J. Assoc. Offic. A gric. Chemists., $45,4 \mathrm{r} 8-422$.

Derse P. H., 1965. Evaluation of protein quality (biological method). J. Assoc. Offic. Agric. Chemists., 48, $847-850$.

Dolan G., Godin C., I966. Phenylalanine toxicity in rats. Can. J. Biochim., 44, I43-I45.

Donaldson W. E., Combs G. E., Romoser G. L., SuppleE W. C., I955. Effect of calorie-protein ratio of diet on body composition, energy intake, feed-efficiency and growth of chickens. Poult. Sci., 34, I 190 (abstr.).

Donaldon W. E., Combs G. F., Romoser G. L., I956. Studies on energy levels in poultry rations. I. The effect of calorie-protein ratio of the ration on growth nutrients utilization and body composition of chicks. Poult. Sci., 35, r Ioo-r ro5.

DREYeR J. G., I968. The biological assessment of protein quality : a formula for rapid estimation of metabolic faecal nitrogen excretion in albino rats. S. African of Nutrition, 4, 2-22 in S. African. Med. $J ., 42, n^{\circ}$ I 5 .

Dudley W. A., Becker D. E., Jensen A. H., Jensen S. W., Terrill S. W., Norton H. W., I962. Crystalline aminoacid mixtures as the sole source of nitrogen for the baby pig. J. Anim. Sci., 21, 639642 .

DunN M. S., Rockland L. B., I947. Biological value of proteins determined with Tetrahymena geleii. Proc. Soc. Exp. Biol. Med., 64, 377-379.

DVoR̉AK Z., I968 a. Availability of essential amino acids from proteins. I. Beef serum albumin. $J$. Sci. Food A gric., 19, 71-76.

Dvor̆ak Z., I968 b. Availability of essential amino acids from proteins. 2. Food proteins. J. Sci. Food Agric., 19, 77-82.

Elias L. G., Kumta U. S., Harper A. E., I959-I96r (unpublished work) in Harper A. E., I964Amino-acid toxicities and imbalancees, 87-134, in Munro H. N., Allison J. P. "Mammalian protein metabolism, " I I, I964, Acad. Press. New York, London.

Ellison J. S., I968. Studies on an acute aminoacid imbalance in the rat. Dissert. Abstr., 28, 3355 B: $3356 \mathrm{~B}$. 
Elvehjem L. A., KReHL W. A., r955. Dietary interrelationships and imbalance in nutrition. Borden's Rev. Nutr. Research., 16, 69-84.

Erbersoobler H., Dummer H., Zucker H., I968. Analytical and physiological characteristics of aminoacid damages after heat treatment of foods and feeds. 2. The effect of availability of aminoacids on the flow of free aminoacids in the portal vein plasma. Z. Tierphysiol. Tierernähr. Futtermittelk., 24, I $36-152$.

Fauconneau G., 1964. Méthodes modernes de dosage des acides aminés des tourteaux. Rev. Fr. des Corps Gras, n० spécial, I48-161.

Fauconneau G., 1967. Quelques aspects actuels de la nutrition azotée des animaux monogastriques. Proc. IXth Int. Congr. Anim. Prod. 46-59, Edinburgh.

Fauconneau G., Pion R., r969. Quelques aspects nouveaux du métabolisme de l'azote chez le Porc et leurs conséquences pour la satisfaction de ses besoins en protéines. Commission d'étude de la F.E.Z., Helsinki.

Fauconneau G., Michel M. C., I97o. The role of the gastrointestinal tract in the regulation of protein metabolism, in "Mammalian protein metabolism ", 4, chap. 37, 481-522, Acad. Press Inc. New York, London.

Featherston W. R., Bird H. R., Harper A. E., Ig62. Effectiveness of urea and ammonium nitrogen for the synthesis of dispensable amino-acids by the chick. J. Nutr., 78, 198 .

FERnell W. R., Rosen G. D., I956. Microbiological evaluation of protein quality with Tetrahymena pyriformis. I. Characteristics of growth of the organism and determination of relative nutritive values of intact proteins. Brit. J. Nutr., 10, I43-I56.

Ferrando R., Henry N., Constantin J. L., I965. Comparaison de l'efficacité protéique des farines de poisson en utilisant soit le Rat, soit Streptococcus Zymogenes. Rec. Med. vét., 141, I37-I4I.

Ferrando R., Henry N., Larvor P', ig68. The protein quality of meat meals as assayed with the rat and with Streptococcus Zymogènes. Brit. J. Nutr., 22, 129-17ı.

FÉVRIír C., RÉRAT A., I964. Influence du lactose sur la croissance et sur la composition corporelle du Rat blanc. I. Relations avec le taux protidique de la ration. Ann. Biol. anim. Bioch. Biophys., 4, 423439 .

Fisher H., Griminger P., 1969. Importance of dietary protein level in the carcass analysis method for determining net protein in the chick. J. Sci. Food. Agric., 20, 382-384.

Food and Agriculture Organization, 1957. Committee on protein requirements. Food Agric. Organ. U.N.F.A.O. Nutr. Studies, 16.

Ford J. E., r960. A microbiological method for assessing the nutritional value of protein. Brit. J. Nutr., 14, 485-497.

Ford J. E., I962. A microbiological method for assessing the nutritional value of protein. 2. The measurement of available methionine, leucine, isolencine, arginine, histidine, tryptophan and valine. Brit. J. Nutr., 16, 409-425.

Ford J. E., Salter D. N., I966. Analysis of enzymically digested food proteins by sephadexgel filtration. Brit. J. Nutr., 20,843-860.

Ford J. E., Henry K. M., Porter J. W. G., I963. Availability of amino acids in food proteins.

6 th Int. Congr. Nutrition, Edimburgh, August pp 488 .

Foster G. L., Schoenheimer R., Ritteniserg D., i939. Studies in protein metabolism 5. The utilization of ammoria for anino acid and creatine formation in animals. J. Biol. Chem., 127, 319-327.

Frost D. V., 1959. Methods of measuring the nutritive value of proteins, protein hydrolyzates and aminoacid mixtures. The repletion method., in Albanese A. A. "Protein and aminoacid Nutrition", 225-279 ; Acad. Press., New York, London.

Frost D. V., SANDY H. R., I951. Utilization of non-specific nitrogen sources by the adult, proteindepleted rat. J. Biol. Chem., 189, 249-260.

Furuya S., TAKahashi S., KameokA K., r97o. A new method for the estimation of percentage of absorbed nitrogen retained by rats and pigs. J. Nutr., 100,67I-677.

GaEbler O. H., ChoItz H. C., I965. Eiffects of protein intake and growth hormone on utilization of $\mathrm{N}^{15}$ from ammonium citrate. Metabolism, 14, 819-825.

Geiger Li., I947. Experiments with delayed supplementation of incomplete amino acid mixture. $J$. Nutr., 34, $97-1 \mathrm{II}$.

Godin C., I967. Effect of threonine on tyrosine metabolism of rats fed a low protein diet. J. Nutr., 92, 503-506.

Greenstein J. O., Wrintz M., I96r. Chemistry of the amino acids, vol. I, p. 286, Wiley, New York.

Guggenheim K., Halevy S., Friedmann N., i960. Levels of Jysine and methionine in portal blood of rats following protein feeding. Arch. Biochem. Biophys., 91, 6-1o.

Guillaume J., Fendry M., I964. Modes d'expression de l'ajustement des besoins énergétique et azoté chez le Poussin. Ann. Biol, anim. Bioch. Biophys., 4, 95-97.

Gupta J. D., Dakroury A. M., Harper A. E., Elvehjem C. A., r958. Biological availability of lysine. J. Nutr., 64, 259-270.

Guthneck B. T., Bennetr B. A., Schweigert B. S., i953. Utilization of aminoacids from foods by the Rat. II-Lysine. J. Nutr., 49, 289-294. 
Halevy S., Grossowicz N., I953. A microbiological approach to nutritional evaluation of proteins. Proc. Soc. Exp. Biol. Med., 82, 567-571.

Hankes L. V., Henderson L. M., Elvehjem C. A., I949. Effect of cystine and threonine on the growth of rats receiving tryptophan-deficient rations. J. Biol. Chem., 180, I027-1035.

Hanson L. E., FERrin E. F., I955. The value of urea in a low-protein ration for weaning pigs. $J$. Anim. Sci., 14, 43-48.

Harimaran K., Desai B. L. M., Rao S. V., Swaminathan M., Parpia H. A. B., ig68. The ratio between free serum non-essential to essential aminoacids in rat depleted on protein free diet and repleted on diets containing different protein. J. Nutrition Dietetics, India, 5, 52-56.

HARKER C. S., I967. Effect of four levels of aminoacids on plasma aminoacids in the growing rat. Dissert. Abstr., B, 27, 2242 B.

Harker C. S., Allen P. E., Clark H. E., ig68. Growth and concentration of aminoacids in plasma of rats fed four levels of aminoacids. J. Nutr., 94, 495-503.

Harnisch W., Rojahn J., I962. Digestibility of crude protein and some aminoacids in trials with pigs fed on naked and awned barley ground to different degrees of fineness (all.). Arch. Tiercrnähr., 11, $284-292$.

Harper A. E., 1958. Balance and imbalance of amino acids. Ann. N. Y. Acad. Sci, 69, ro25-204I.

HARper A. E., I964, in Munro H. N., Allison J. B. Mammatian protein metabolism vol. 2, 87-I34, Acad. Press., New York, London.

HARPer A. E., I968. Imbalance and toxicity of amino-acids. Nutr. Rev., 26, II5-II8.

Harper A. E., Kumta U. S., I959. Amino acid balance and protein requirement. Fed Proc., 18, II36-II42.

Harper A. E., Rogers Q. R., I965. Amino-acid imbalance. Proc. Nutr. Soc., 24, I73-I89.

HARPER A. E., Rogers Q. R., 1966. Effect of amino acid imbalance on rats maintained in a cold environment. Amer. J. Physiol., 210, 1234-I239.

Harper A. E., Becker R. V., Stucki W. P., 1966. Some effects of excessive intakes of indispensable amino acids. Proc. Soc. Exp. Biol. Med., 121, 695-699.

Hartman D. R., KING K. W., I 967 . Assimilation by rats of limiting amino-acid into protein imbalanced dietary sources. J. Nutr., 92, 455-459.

Hays V. W., Ashton G. C., Liu C. H., Speer V. C., Catron D. V., i957. Studies or the utilization of urea by growing swine. J. Anim. Sci., 16, 44-54.

Hegsted D. M., Chang Y. O., I965a. Protein utilization in growing rats. 1. Relative growth index as a bioassay procedure. $J$. Nutr., 85, $159^{-168 .}$

Hegsted D. M., Chang Y. O., I965 b. Protein utilization in growing rats at different levels of intake. J. Nutr., 87, I9-25.

Hegsted D. M., Worcester J., I967. Assessment of protein quality with young rats Proc. VIIth Intern. Congr. Nutrition, Hamburg, vol. 4, (problems of world Nutrition), p. 318-325, Pergamon Press Ltd, Headington Hill, Oxford.

Hegsted D. M., NEFF R., Worcester J., I968. Determination of the relative nutritive value of proteins. Factors affecting precision and validity. J. Agric. Food. Chem., 16, I90-I95.

Henderson L. M., Koeppe O. J., Zimmerman H. H., I953. Niacin-tryptophan deficiency resulting from amino-acid, imbalance in non-casein diets. J. Bisl. Chem., 201, 697-7o6.

HENRY K. M., I 965 . A comparison of biological methods with rats for determining the nutritive value of proteins, Brit. J. Nutr., 19, I25-I35.

HENRY K. M., ToOthill J., I962. A comparison of the body water and nitrogen balance-sheet methods for determining the rutritive value of proteins. Brit. J. Nutr., 16, I25-133.

HENRY Y., I968. Libre consommation de principes énergétiques et azotés chez le Rat et chez le Porc selon la nature de la source azotée, sa concentration dans le régime et le mode de présentation. Ann. Nutr. Aliment., 22, $12 \mathrm{I}-\mathrm{I} 4 \mathrm{O}$.

Henry Y., Rérat A., I962. Influence de la qualité et de la quantité des matières azotées ingérées sur la consommation spontanée d'énergie chez le Rat en croissance : note préliminaire. Ann. Biol. anim. Bioch. Biophys., 2, 267-276.

Henry Y., Rérat A., Ig63. Étude de l'ingestion spontanée d'éléments énergétiques et de protéines chez le Rat en croissance par la méthode du libre choix. Ann. Biol. anim. Bioch. Biophys., 3, ro3-II7.

HenRY Y., RÉrat A., I964. Variations des taux énergétique et azoté dans l'alimentation du Porc en croissance : observations préliminaires. Ann. Biol. anim. Bioch. Biophys., 4, 263-27I.

HENRY Y., RÉrat A., I965. Ingestion spontanée d'éléments énergétiques en régimes mixtes et séparés chez le Rat en croissance. Ann. Biol. anim. Bioch. Biophys., 5, 283-292.

HENRY Y., RÉRAT A., I966. Évolution de l'ingestion spontanée de principes énergétiques en fonction de la vitesse de croissance et de la protéinogenèse chez le Rat blanc, in Cahier A.E.C. $\mathrm{n}^{\circ} 6:$ Amino- $^{-}$ acides, Peptides, Protéines ", $24 \mathrm{I}-262$.

Henry Y., Rérat A., I968. Libre consommation de principes énergétiques chez le Porc en croíssance soumis à l'alimentation séparée. Proc. and Wld. Conf. Anim. Prod., College Park Maryland, session 13, $460-46 r$. 
Hepburn F. N., Calhoun W. K., Bradley W. B., ig66. The biological availability of essential aminoacids in wheat, flour bread, and gluten. Cereal. Chem., 43, 271-283.

Hill D. C., Olsen E. M., I963. Effect of starvation and a non protein diet on blood plasma amino acids and observations on the detection of amino acids limiting growth of chicks fed purified diets. $J$. Nutr., 79, 303-310.

Hill D. C., Singh J., Ashton G. C., I966. A chick bioassay for lysine. Poult. Sci., 45, 554-560.

Hill F. W., Dansky L. M., I950. Studies of the protein requirements of chicks and its relation to dietary energy level. Poult. Sci., 29, 763 . Proc.

Hintz H. F., Pond W. G., Visek W. J., I969. A note on the effect of amino-acid or urea supplements to barley diets for the finishing pig. Anim. Prod., 11, 553-556.

Hock A., Lehman H., I 968 a. Influence of ecological factors on the results of estimation of protein quality. I. Infuence of a methionirıe supplement to casein on the protein quality. Arch Tierernähr., 18, 205-2II.

Hock A., LehmanN H., Ig68 b. Influence of ecological factors on the results of estimation of protein quality. 2. Influence of the environmental temperature and strain of rats on results of estimation of protein quality. Arch. Tievernähr., 18, 292-299.

Horn M. J., Blum A. E., Womack M., r954. Availability of aminoacids to microorganisms. I I. A rapid microbial method of determining protein value. J. Nutr., 52, 375-38I.

IsAKSSON B., SJöGREN B., 1967. A critical evaluation of the mineral and nitrogen balances in man. Proc. Nutr. Soc., 26, 106-116.

JACQUOT R., 1952, in "Les facteurs d'efficacité alimentaire. Les aliments " extrait du cours de nutrition donné en I955-1956 à Marseille sous les auspices de la F.A.O. et de l'O.M.S.

Jacquot R., Peretianu J., I970. Protein efficiency ratio and related methods. British Encyclopedic Nutrition, Pergamon Press (sous presse).

Jaçuot R., RÉRAT A., r966. La valeur biologique des protéines. Congrès Mondial Alimentation animale (Madrid), 1, 329-407.

Jacquot R., Abraham J., Peretiand J., Iierrando R., Henry N., ig68. Intérêt et limites du test Streptococcus zymogènes comme méthode de routine pour le classement d'aliments protidiques de même origine. Ann. Zootech., 17, 307-319.

Jones J. D., I964. Lysine-arginine antagonism in the chick. J. Nutr., 84, 3I3-32 r.

Jones J. D., Petersburg S. J., Burnetr P. C., 1967. The mechanism of the lysine-arginine anta gonism in the chick : effect of lysine on digestion, kidney arginase and liver transamidinase. J.Nutr. 93, IO3-II6.

Jones H. L., Combs G. F., I952. Effect of aureomycin $\mathrm{HCl}$ on the utilization of inorganic nitrogen by the chick. 'Poult. Sci., 32, 873 .

Kakade M. L., Lierner I. E., I969. Determination of available lysine in proteins. Anal. Biochem. 27, 273-280.

KEAN E. A., 1967. The relationship between nutritive value of dietary protein and activity of live arginase and kidney transamidinase enzymes. Brit. J. Nutr., 21, 29-36.

KELLY M. A., 1967. A comparison of assay techniques for determining the availability to the chick of aminoacids in intact proteins. Dissertation Abstr. B, 27, $3733 \mathrm{~B}$.

Kies C. E., Williams E., Fox H. M., I965. Effect of "non-specific " nitrogen intake on adequacy of cereal protein for nitrogen retention in Human adultes. J. Nutr., 86, 357-36r.

Kiriyama S., Iwao H., Ashida K., 1967. Dietary protein quality and liver arginase activity of rats. Agric. Biol. Chem., Japan., 31, 67I-674.

Klain G. J., Vaughan D. A., I963. Alteration of proteins metabolism during cold-acclimation. Fed. Proc., 22, 862-867.

Klain G. J., Vaughan D. A., Vaughan L. N., I962. Interrelationships of cold exposure and aminoacid imbalances. J. Nutr., 78, 359-364.

Knipfel J. E., Botting H. G., Noel F. G., Mclaughlan J. M., ig69. Amino-acids in blood plasma and tissues of rats following glucose force-feeding. Can. J. Biochem., 47, 323-327.

Kornegay E. T., Mosanghini V., SneE R. D., r97o. Urea and aminoacid supplementation of swine diets. J. Nutr., 100, 330-340.

Kornegay E. T., Miller E. R., Ulerey D. E., Vincent B. H., Hoefer J. A., I965. The influence of dietary urea on the performance, antibody production and hematology of growing swine. J.Anim. Sci., 24, 95I-954.

Kosterlitz H. W., Campbell R. M., 1945-r946. Nutr. Abs. Rev., 15, 1.

KRISS M., MARCY L. F., I940. The influence of urea ingestion on the nitrogen balance and energy metabolism of rats. J. Nutr., 19, I5I-I60.

KRYsčiak J., Ostrowski H., Ryś R, rg66. Changes in the content of free amino-acids in pig blood plasma after ingestion of food. Acta. Biochim. polon., 13, 229-235.

Kučukalic E,, Milenković M., 1968. Effect of different protein intakes on aminoacids in blood and urine of rats. Veterinaria, Sarajevo., 17, 29-38.

Kühnay J., I949. Biochemie des Nahrungseiweisses. Angew. Chem., 61, 357-365. 
KutKen K. A., r952. Availability of the essential aminoacids in cottonseed meals. J. Nutr., 46, 13-25. Kuiken K. A., Lyman C. M., I948. Availability of aminoacids in some foods. J. Nutr., 36, 359-368.

Kumta U. S., Harper A. E., I962. Amino-acid balance and imbalance. IX. Effect of amino-acid imbalance on blood amino-acid pattern. Proc. Soc. Exp. Biol. Med., 110, 512-5I7.

LARDY H. A., FeldotT G., I949. The net utilization of ammonium nitrogen by the growing rat. J. Biol. Chem., 179, 509-5 Io.

LehmaN H., Hock A., I968. Influence of ecological factors on the results of estimation of protein quality. 3. Influence of the amount of protein eaten on the protein quality. Arch. Tierernähr., 18, 447-457.

Leibetseder J., HAMED M. Y., I968. Estimating biological value of protein for chickens. $Z$. Tierphysiol. Tierernähr. Futtermittelk., 23, 239-242.

Leifer E., Roth L. G., Hempelmann L. H., I948. Metabolism of C14 labelled urea. Science, 108 748 .

Leong K. C., Sunde M. N., Bird H. R., Eıvehjem C. A., I955. Effect of energy-protein ration on growth rate, efficiency feathering, and fat deposition in chickens. Poult. Sci., 34, I206.

Lerner J. T., I968. Contribution à l'étude du besoin de lysine en relation avec le taux énergétique chez le Rat et le Porc. Thèse Doc. $3^{\mathrm{e}}$ cycle, Paris, Fac. Science.

Leung P. M. B., Rogers Q. R., 1969. Food intake : regulation by plasma aminoacid pattern. Life Sci., 8, I-9.

Leung P. M. B., Rogers Q. R., Harper A. E., I964. Effect of amino acid imbalance on food intake and preference. Fed. Proc., 23, 185.

Leung P. M. B., Rogers Q. R., Harper A. E., i968 a. Effect of amino acid imbalance on dietary choice in the rat. J. Nutr., 95, 483-492.

Leung P. M. B., Rogers Q. R., Harper A. E., 1968 b. Effect of amino acid imbalance in rats fed ad libitum, interval-fed, or force-fed. J. Nutr., 95, 474-482.

Leung P. M. B., Rogers Q. R., HARper A. E., I968 c. Effect of cortisol on growth food intake, dietary preference and plasma aminoacid pattern of rats fed aminoacid imbalanced diets. $J . N u t r ., 96$, I39-I 5 I.

Levenson S. M., Growley L. V., Horowitz R. E., Malm O. J., I959. The metabolism of carbonlabelled urea in the germ free rat. J. Biol. Chem., 234, 206I-2062.

LEWIS D., I965. The concept of agent and target in amino-acid interactions. Proc. Nutr. Soc., 24, I96202.

Linkswiler H., Fox H. Z., Crooke Fry P., I960. Availability to man of amino-acids from foods. $J . N u t r ., 72,389-403$.

Litwack G., Williams J. N., Chen L., Elvehjem C. A., 1952. A study of the relationship of liver xanthine oxydase to quality of dietary protein. J. Nutr., 47, 299-306.

Liu C. H., Hays V. W., Suec H. J., Catron D. V., Ashton G. C., Speer V. C., I955. The fate of urea in growing pigs. J. Nutr., 57, $24 \mathrm{I}-247$.

Long J. I., I966. Relationship of free plasma amino-acid levels to dietary protein in swine. Dissertation Abstr., B, 27, ro-B.

Long J. I., Hays V. W., SpeER V. C., I965. Effect of supplemental amino-acids on growth and plasma aminoacids of pigs. J. Anim. Sci., 24, 894 (Abstr.).

Longenecker J. B., I963. Utilization of dietary in Albanese A. A., ed., Newer Methods of nutritional Biochemistry, 1, Ir 3-r44, Acad. Press, New York, Londort.

LONGENECKer J. B., Hause F. L., 1959. Relationship between plasma amino-acids and composition of the ingested protein. Arch. Biochem. Biophys., 84, 46-59.

McLaughtan J. M., Ig64. Blood amino-acid studies. 5. Determination of the limiting amino-acid in the diets. Can. J. Biochem., 42, I353-1360.

McLaughlan J. M., Illman W. I., I967. Use of free plasma aminoacid levels for estimating aminoacid requirements of the growing rat. J. Nutr., 93, $2 \mathrm{I}-24$.

McLaughlan J. M., Morrison A. B., I968. Dietary factors affecting plasma amino-acid concentration in LeAthem J. H. Protein nutrition and free amino-acid patterns, 3-I 8, Rutgers University Press, New Brunswick, New Jersey.

Mclaughlan J. M., Venkat Rao S., Noel F. J., Morrison A. B., I967. Blood amino acid studies. VI. Use of plasma amino acid score for predicting limiting amino acid (s) in dietary proteins. Can. $J$. Biochem., 45, 3I-38.

Maignon F., r933. The role of fat in glycogenesis and the utilization of proteins. Nutr. Abstr. Rev., 3, 345-353.

Maillard L. C., I $9 \mathrm{I} 2$. Action des acides aminés sur les sucres : formation des mélanoïdines par voie méthodique. C. R. Acad. Sci., Paris, série D, 154, 66.

Matterson L. D., Potter L. M., Stinson L. D., Singsen E. P., I955. Protein and energy levels for poultry. Poult. Sci., 34, I210.

Mauron J., I96I in Progress in Meeting Protein Needs of Infants and preschool children. Nat. Acad. Sci., Nat. Res. Council Publ., 843, 425-442.

Mauron J., 1967. The value of measuring enzyme activities in assessing the adequacy of protein diet. Proc. VIIth Int. Congr. Nutr., Hambourg, 4, 367-38I, Pergamon Press L.T.D. 
Mauron J., Mottu F., 1967 in Mauron J., I967. The value of measuring enzyme activities in assessing the adequacy of protein diet. Proc. VIIth Int. Congr. Nutr., Hambourg, 4, 367-38I, Pergamon Press L.td.

Mauron J., Mottu F., I958. Relation between in vitro lysine availability and in vivo protein evaluation in milk powder. Arch. Biochem. Biophys., 77, 312-327.

Matron J., Mottu F., Bujard E., Egli R. H., I955. The availability of lysine, methionine and tryptophan in condensed milk and milk powder. In vitro digestion studies. Arch. Biochem. Biophys., $\mathbf{5 9}, 433-45 I$.

Menden E., Cremer H. D., I966. A laboratory method for the evaluation of changes in protein quality. Nutritio et Dieta., 8, I88-I89.

Meyer J. H., Nelson A. O., 1963. Efficiency of feed utilization by various animal species fed similar ration. J. Nutr., 80, 343-349.

Miller D. S., Bender A. E., r955. The determination of the net utilization of proteins by a shortened method. Brit. J. Nutr., 9, 383-388.

Miller D.S., PAyne P. R., I961 $a$. Problems in the prediction of protein values of diets. The influence of protein concentration. Brit. J. Nutr., 15, I I-Ig.

Miller D. S., Payne P. R., Ig6r $b$. Problems in the prediction of protein value of diets : the use of food composition tables. J. Nutr., 74, 413-419.

Miller E. L., Carpenter K. J., I967. Availability of sulphur amino-acids in protein foods. I. Total sulphur amino-acid content in relation to sulphur and nitrogen balance studies with the Rat. J. Sci. Food. Agric., 15, 8ro-820.

Miller L. L., I948. Changes in Rat liver enzyme activity with acute inanition. Relation of loss of enzyme activity to liver protein loss. J. Biol. Chem., 172, I13-I2I.

Mrtchel, H. H., I924. The nutritive value of proteins. Physiol. Rev, 4, 424-478.

Mrtchell H. H., Beadles J. R., 1930. The paired-feeding method in nutrition experiments and its application to the problem of cystine deficiencies in food proteins. J. Nutr., 2, 225-243.

Mrtchell H. H., I944. Determination of the nutritive value of the proteins of food products. Ird. Eng. Chem. Anal. Ed., 16, 696-70o.

Mitcheld H. H., I948 in Sahyun M. Proteins and amino-acids in nutrition 46-8I, Reinhold Publishing Corporation, New York.

Mrtchell H. H., I954, in Nehring K. : Die Betwertung der Futterstoffe und andere Probleme der Tierernährung, vol. V, Deutsche Akademie der Landwirtschaft wiss Abhandl., Berlin.

Mitchell H. H., r959. Some species and age differences in aminoacid requirements in Albanese A. A. Protein and aminoacid nutrition,. I I-43, Acad. Press, New York and London.

Mitchell J. R. Jr, Becker D. E., Harmon B. G., Norton H. W., Jensen A. H., ig68a. Some aminoacid needs of the young pig fed semi-synthetic diet. J.Anim. Sci., 27, I322-1326.

Mitchell J. R. Jr, Becker D. E., Jensen A. H., Harmon B. G., Norton H. W., 1968 b. Determination of aminoacid needs of the young pigs by nitrogen balance and plasma free aminoacids. $J$. Anim. Sci., 27, r327-r33r.

Morrison A. B., Middleton E. J., Mclaughlan J. M., ig6i. Blood amino-acid studies. 2. Effects of dietary lysine concentration, sex, and growth rate on plasma free lysine and threonine levels in the rat. Can. J. Biochem. Physiol., 39, I675-1680.

Morrison A. B., Sabry Z. I., Gridgeman N. T., Campbell J. A., I963. Evaluation of protein in foods. 8. Influence of quality and quantity of dietary protein on net protein utilization. Can. J. Biochem. Physiol., 41, 275-28r.

Morrison M. A., Caldwell M. J., I966. Tryptophan utilization in a threonine induced amino-acid imbalance in weanling rats : gain in weight and carcass nitrogen with two feeding methods. $J$. Nutr., 89, I49-I 57 .

Mottu F., Mauron J., I966, in Mauron J., 1967. The value of measuring enzyme activities in assessing the adequacy of a protein diet. Proc. VIIth Int. Congr. Nutr., Hambourg, 4, 367-381, Pergamon Press L.td.

Müller R., I964. Scheme for protein evaluation in trials of growing rats. Z. Tierphysiol. Tierernähr. Futtermittelk., 19, 305-308.

Munchow H., Bergner H., I967. Valeur biologique des protéines dans les fourrages. 2. Concentration des protéines alimentaires chez le rat et le Porc. Arch. Tierernähr., 17, I4 I-I 50.

Munchow H., Bergner H., I968 a. Recommandations for evaluation of protein feedingstuffs by estimation of urea in blood of rats and pigs. Arch. Tierernähr., 18, 222-228.

Munchow H., Bergner H., I $968 b$. Evaluation of protein in feedingstuffs. 7. Comparison of protein utilization in rats and pigs. Arch. Tierernähr., 18, 484-49o.

Munro H. N., I95I. Carbohydrate and fat as factors in protein utilization and metabolism. Physiol. Rev., 31, 449-488.

Munro H. N., I964, in Munro H. N., Allison J. B. : Mammalian protein metabolism, 1, 382-48I, Acad. Press, New York, London.

Munro H. N., Wikramanayake T. W., I954. Absence of a time factor in the relationship between level of energy intake and protein metabolism. J. Nutr., 52, 99-I I4. 
Muramatsu K., Ashida K., 1962. Effect of dietary protein level on growth and liver enzyme activities of rats. J. Nutr., 76, 143-I50.

National Research Council, Committee on Animal Nutrition, i962. Nutrient requirements for laboratory animals, publ., 990, National Academy of Sciences, Washington $\mathrm{D}$. C.

National Research Council, Committee on Animal Nutrition, I962. Nutrient requirements of Poultry, publ., 827, National Academy of Sciences, Washington D.C.

National Researcii Council, Committee on Animal Nutrition, ig64. Nutrient requirements of swine. Publ., 1192, National Academy of Sciences, Washington D.C.

National Research Council, Committee on Animal Nutrition, 1968. Nutrient requirements of swine. Publ., 1599, National Academy of Sciences, Washington D.C.

Netke S. P., Scott H. M., AlleE G. L., 1969. Effect of excess aminoacids on the utilization of the first limitingaminoacid in chick diets. J. Nutr., 99, 75-8I.

NetKe S. P., ScotT H. M., I970. Estimates of the availability of amino-acids in soybean oil meal as determined by chick growth assay : methodology as applied to lysine. J. Nutr., 100, $281-288$.

NiELSEN A. J., I968. Digestibility of aminoacids in relation to digestibility of nitrogen in bacon pigs. Royal Veterinary and Agricultural college. Yearbook I968, 79-88, Copenhague.

Nielsen J. J., $1^{6} 5 \mathrm{a}$. Determination of the digestibility of aminoacids A. In vitro by analysis of pepsine hydrochloric acid dissolved nitrogen. Thesis Royal Vet. Agric. College, Copenhague, $3^{8} \mathrm{pp}$.

Nielsen J. J., $1965 \mathrm{~b}$. Determination of the digestibility of aminoacids B. In vivo by analysis of plasma from the portal vein. Thesis Royal Vet. Agric. College, Copenhague, $3^{8} \mathrm{pp}$.

NJAA L. R., I962. A rote on the method of Miller and Payne for prediction of protein value. Brit. $J$. Nutr., 16, I $85-190$.

Osborne T. B., Mrndel L. B., I9I5. Protein minima for maintenance, J. Biol. Chem., 22, 24 I-258.

Osborne T. B., Mendel L. B., igi6. A quantitative comparison of casein, lactalbumin and edestin for growth or maintenance. J. Biol. Chen., 26, I-23.

Osborne T. B., Mendel L. B., I9x7. The relative value of certait protein and protein concentrates as supplement to corn gluten. J. Biol. Chem., 29, 69-92.

Osborne T. B., Mrndel L. B., FerRy E. L., I9I9. A method for expressing numerically the growthpromoting. J. Biol. Chem., 37, 223-229.

Oser B. L., I95I. Method for integrating essential amino-acid content in the nutritional evaluation of proteit. J. Am. Dietet. Assoc., 27, 396-402.

OSER B. L., 1959. An integrated essential aminoacid index for predicting the biological value of proteins. In Albanese A. A. Protein and amino-acid nutrition Acad. Press, New York, Chap. 1o, 28I295 .

Ousterhout L. E., Grau C. R., Lundholm B. S., I959. Biological availability of aminoacids in fish meals and other protein sources. J. Nutr., 69, 65-73.

OWen E. C., I967. Nitrogen balances. Proc. Nutr. Soc., 26, I 6 6-124.

Pastuszewska B., 1967. The use of urea in the nutrition of baby pigs. Roczniki Nauk. Roln., 89, B-4, 503-509.

PAWLAK M., PION R., I966. Les aminoacides libres du sang et du muscle comme méthode d'évaluation des protéines. Groupe de discussion sur la qualité des protéines. Proc. VIIth Inter. Congr. Nutr., Hambourg, I967, 4, 338-34I, Pergamon Press Ltd.

Pawlak M., Pion R., r967. Influence de la composition des protéines alimentaires sur les teneurs en acides aminés libres du sang total et du muscle du Rat en croissance. C. R. Acad. Sci., 264 D, $380-382$.

Pawlak M., Pion R., I969. Les concentrations en acides aminés libres comme critère de la valeur nutritive des protéines. Journées Recherche Porcine en France, I.N.R.A., Paris 20-21 février, I37-I4I.

Payne P. R., JACOB M., I965. Iiffect of environmental temperature on utilization of dietary protein by the growing Rat. J. Nutr., 87, $221-227$.

Pelletr P. L., 1967 . The $\mathrm{N} / \mathrm{H}_{2} \mathrm{O}$ ratio in the sprague-dawley rat and its variation with diet under the conditions of determination of net protein utilization. Brit. J. Nutr., 21, 609-6I6.

Peng Y., Bentevenga N. J., Harper A. F., i969. Aminoacid balance and food intake : effect of previous diet on plasma amirioacids. Amer. J. Physiol., 216, 1020-1025.

Peng Y., Harper A. E., I97o. Amiro-acid balance and food intake : effect of different dietary aminoacid patterns on the plasma amino-acid pattern of rats. J. Nutr., 100, 429-437.

Peretianu J. (Communication personnelle).

Peretianu J., Abraham J., ig63a. Nouvelle technique de mesure du coefficient d'efficacité protéique Ann. Nutr. Aliment., 17, $8 \mathrm{I}-\mathrm{IO} 2$.

Peretianu J., Abraham J., I963 $b$. Quelques nouveaux aspects de la régulation des ingérćs caloriques au cours de la croissance du rat blanc. Arch. Sci. Physiol., 17, 467-477.

Peretianu J., Abraham J., I964. Le phénomène de déséquilibre par excès d'un acide aminé. Étude des effets supplétifs de la méthionine selon les modalités de son emploi en régime mixte ou en alimentation séparée. I. Cas de la caséine. Arch. Sci. Physiol., 18, 253-264.

Peretianu J., Abraham J., I965. Le phénomène de déséquilibre par excès d'un acide aminé : étude des effets supplétifs de la méthionine selon les modalités de son emploi en régime mixte ou en alimentation séparée. 2. Cas de la protéine de soja. Arch. Sci. Physiol., 19, 29-43. 
Pfander W. H., Royer R. F., Tribble L. F., I968. Changes in free aminoacids levels in the blood of growing swine as an index to protein quality and availability. Univ. Missouri. Agric. Expt. Sta. Res. Bull., no $93^{8}$, pp. 8.

Pion R., Rírat A., Ig62. Influence des procédés de fabrication sur la valeur nutritive des poudres de lait. $16^{\mathrm{c}}$ Congr. Int. de Laiterie, Copenhague, 993-Ioor.

Pion R., Rérat A., 1967. Influence d'une supplémentation en lysine sur l'évolution de l'aminoacidmie porte dı porc en croissance, au cours de la digestion d'une ration à base de blé. C. R. Acad. Sci. Paris, 264 1), 632-635.

Pion R., Rírat A., I969. Influence d'une supplémentation en lysine des protéines du blé et du tournesol sur la variation de l'aminoacidémie porte chez le porc pendant la digestion (All.). Z. Tierphysiol. Tierernähr. Futtermittelk. Band 25, H $6,363-368$.

Pion R. Belsunce C., de, Fauconneau G., I963a. Composition en acides aminés de quelques aliments. Ann. Biol. anim. Bioch. Biophys., 3, no h. s., I I-I8.

Pion R., Fauconneau G., Rérat A., $1963 b$. Fitude cinétique de la composition en acides aminés du sang porte chez le Porc. Ann. Biol, anim. Bioch. Biophys., 3, h.-S., 3I-37.

Pol G., Den Hartog C., I966. The dependence on protein quality of the protein to caloric ratio in freely selected diet and the usefulness of giving protein and calories separately in protein evaluation experiments. Brit. J. Nutr., 20,649-66r.

Poley G. E., SEERLEY R. W., I96r. Energy protein relationship in rations for growing-finishing swine. J. Anim. Sci., 20, 946-947 (abstr.).

Pongpaew P., Guggenherm K., I968. The nutritional availability of tryptophan in foods. Nutritio and dieta., 10, 297-308.

Poppe S., Wiesemülter W., r968. Aminoacid requirements of growing pigs. I. Estimating the lysine by the $\mathrm{N}$ balance method. Arch. Tierernähr., 18, 392-404.

POPPE S., WIESEMÜLler W., I969. Untersuchungsergebnisse und Vorschlag zum Problem der Aminosauren Bedarfsermittlung bei mastchweinen. Internationale Zeitschrift der Landreirtschaft, 6.

Prahl L., TAüfel L., r966. Digestion of protein in vitro with simultaneous dialysis. Nährung., 10, $31-36$.

Puchal F., Hays V. W., Speer V. C., Jones J. D., Catron D. V., ig62. The free blood plasma amino-acids of swine as related to the source of dietary proteins. J. Nutr., 76, I I-I6.

Rafalski H., Nogal E., 1964. Short method for indirect calculation of $N$ in rat carcase applied to studies on protein availability. I. Elaboration of indices for indirect calculation of N. Rocz. panstwowego. Zakl. Hig., 15, 257-266.

Rafalski H., Nogal E., I 967 a. A modification of body N technique for NPV determiration. Proc. VIIth Int. Congr. Nattr, 4, 307-317. Hamburg, Pergamon Press, Ltd.

Rafalski H., Nogal E., I967 b. A comparison of N.P.R., P.E.R., N.P.U. Methods for the evaluation of dietary proteins. Proc.VIIth Int. Congr. Nutr, 4, 317., Hambourg, Pergamon Press ed.,

Rafalski H., Ponomarenko W., Nogal E., I968. Chemical indices of the nutritive value of proteins, based on the estimation of total aminoacids in foods. Rocz. panstwowego. Zakb. Hig., 19, 6r9-632.

Rao M. N., Morrison A. B., I966. Evaluation of protein in foods. I2. Effects of caloric restriction. Can. J. Biochem., 44, I365-1375.

Rao S. R., Carter F. L., lirampton V. L., I963. Determination of available lysine in oilseed meal proteins. Anal. Chem., 35, 1927-I930.

Rao S. V., Noel F. J., Mclaughlan J. M., I968. Blood aminoacid studies-prediction of limiting aminoacid in mixtures of dietary proteins. Can. J. Physiol. Pharmacol, 46, 707-7II.

Read W. W. C., Mclaren D.S., Tchalian M., Nassar S., I969. Studies with $\mathrm{N}^{15}$ labelled ammonia and urea in the malnourished child. J. Clin. Invest., 48, 143-149.

Rérat A., Desmovlin B., 1970. Influence d'une restriction alimentaire, énergétique et azotée sur la croissance et la composition corporelle du Rat blanc. Ann. Zootech., 18, Io3-I I4.

Rérat A., HenRy Y., $1963 b$. Besoin en lysine du Rat en croissance : principe d'une méthodologie et résultats expérimentaux. C. R. Acad. Sci., 25\%, 3045-3048.

Rérat A., Henry Y., r 963 c. Étude de l'ajustement de la consommation spontanée d'énergie en fonction de l'apport azoté chez le Rat en croissance. Ann. Biol. anim. Bioch. Biophys., 3, 263-298.

Rérat A., Henry Y., i965. Détermination du besoin en acides aminés soufrés chez le Rat blanc en croissance. Ann. Biol. anim. Bioch. Biophys., 5, 469-483.

Rérat A., Lougnon J., rg66. Les besoins en amino-acides du Porc en croissance (revue). Cahier A.E.C. $n^{\circ}$ 6, "A mino-acides, peptides, protéines ", 344-422.

Rérat A., Henry Y., Desmoulin B., I97I. Influence d'une restriction énergétique sur le besoin azotó de croissance du Porc femelle. Journées de la Recherche Porcine en France, I.N.R.A., Paris, $65-72$.

RÉrat A., Henry Y., Jaçvot R., I963. Relation entre la consommation spontance d'énergie et la rétention azotée chez le Rat eı croissance. C. R. Acad. Sci., Paris, 256, 787-789.

Rérat A., Février C., Henry Y, Lougnon J., I964. Évolution de la composition corporelle chez le Rat blanc en croissance. Ann. Biol. anim. Bioch. Biophys., 4, 35-47.

Rérat A., Lerner J., Henry Y., Bourdon D., I97o. Etude du besoin de lysine du Porc en crois - 
sance en relation avec le taux énergétique du régime. Journées Recherche Porcine en France, I.N.R.A., Paris, $79-84$.

Rérat A., Lougnon J., I969. Amino-acid requirements of growing pigs. Wld Rev. Anim. Prod., vol. IV, no 17, 84-95

Richardson L. R., Blaylock L. G., Lyman C. M., 1953a. Influence of the level of vitamins in the diet on the concentration of free amino-acids in the plasma of chicks. J. Nutr., 49, $21-28$.

Richardson L. R., Blaylock L. G., Lyman C. M., I953 b. Influence of dietary amino-acid supplements on the free amino-acids in the blood plasma of chicks. J. Nutr., 51, 5I5-522.

Richardson L. R., Hale F., Ritchey S. J., ig65. Effect of fasting and level of dietary protein on free amino acids in pig plasma. J. Anim. Sci., 24, 368-372.

Richardson C. F., TeEkell R. A., Watts A. B., I968. The effects of energy levels on nitrogen components of urine. Poult. Sci, 47, 288-292.

Rio M. E., Closa S. J., Sanahuya J. C., r97o. Changes in body composition in rats fed natural imbalanced diets. J. Nutr., 100, 69-77.

Rippel R. H., Harmon B. G., Jensen A. M., Norton H. W., Becker D. E., I965. Some aminoacids requirements of the gravid gilt fed on purified diet. J. Anim. Sci., 24, 378-382.

Roach A. G., Sanderson P., Williams D. R., I967. Comparison of methods for the determination of available lysine value in animal and vegetal protein sources. J. Sci. Food. Agric., 18, 274-278.

Rogers Q. R., Harper A. E., I965. Aminoacid diets and maximal growth in the rat. J. Nutr., 87, 267-273.

Rogers Q. R., Harper A. L., I968. Significance of tissue pools in the interpretation of change in plasma aminoacid concentrations, in LeATHEM J. H., Protein nutrition and free-amino-acid patterns, 107-126. Rutgers University press, New Brunswick, New Jersey.

Rogers Q. R., Spolter P. D., Harper A. E., I962. Effect of leucine-isoleucine antagonism in plasma amino acid pattern of rats. Arch. Biochem. Biophys., 97, 497-504.

Rogers Q. R., Tannous R. I, Harper A. E., I967. Effects of excess leucine on growth and food selection. J. Nutr., 91, 56r-572.

Rose W. C., DekKer E. E., 1956. Urea as a source of nitrogen for the biosynthesis of aminoacids. $J$. Biol. Chem., 223, I07-I2I.

Rose W. C., Smith L. C., Womack M., Shane M., I949. The utilization of the nitrogen of ammonium salts, urea and certain other compounds in the synthesis of non-essential amino-acids in vivo. $J$. Biol. Chem., 181, 307-3I6.

Rosenberg H. R., Culik R., Eckert R. E., 1959. Lysine and threonine supplementation of rice. J. Nutr., 69, 2I7-228.

Rutgers UNIVERSITY, I950. Bureau of biological Research : Report on cooperative determination of the amino acid content and of the nutritive value of six selected protein food sources, I946-I950, New Brunswick-New Jersey, ri4 pp, in Allison J. B., I955. "Biological evaluation of proteins". Physiol. Rev., 35, 664 .

Said A. K., Hegsted D. M., I969. Evaluation of dietary protein quality in adult rats. J. Nutr., 99, $474-480$.

SALMON W. D., 1958. The significance of amino-acid imbalance in nutrition. Amer. J. Clin. Nutr., 6, $487-494$.

Sanahuya J. C., Harper A. E., 1962. Aminoacid balance and imbalance. VIII. Effect of amino-acid imbalance on food intake and reference. Amer. J. Physiol., 202, I65-I70.

Sanahuya J. C., Harper A. E., ig63. Amino-acid balance and imbalance. XII. Effect of aminoacid imbalance on self selection of diet by the rat. $J$. Nutr., 81, 363-37I.

SanAhuYa J. C., Rio M. E., I967. Initial effects of aminoacid imbalance in the rat. J. Nutr., 91, 407-4I4.

SanAhuya J. C., Rio M. E., I968. Effect of imbalanced diets containing natural proteins on appetite and body composition in the rat. $J$. Nutr., 95, 295-302.

Sanahuya J. C., Rio M. E., Lede M. N., 1965. Decrease in appetite and biochemical changes in aminoacid imbalance in the rat. J. Nutr., 86, 424-432.

SaUberlich H. E., I96I. Studies on the toxicity and antagonism of aminoacids for weanling rats. J. Nutr., 75, 6I-72.

Saunders S. J., Truswell A. S., Barbezat G. O., Wittman W., Hansen J. D. L., ig67. Plasma free aminoacid pattern in protein-calorie malnutrition. Reappraisal of its diagnostic value. Lancet., 2, 795-797.

Scharrer E., Zucker H., I967. Diminution de la consommation lors d'une alimentation riche en protéines. I. Effet dynamique spécifique et appétence. (All.). Z. Tierphysiol. Tierernähr. Futtermittelk., 22, I $4 \mathrm{I}-\mathrm{I} 60$,

Scharrer E., Zucker H., ig67. The reduction of intake on protein rich diet 3. Changes in rate of absorption of aminoacids by adaptation to protein rich diet. Z. Tierphysiol. Tierernähr. Futtermittelk., 23, $169-180$.

Scharrer E., Zucker H., ig68. Aminoacid concentrations in the blood of the aorta and portal vein of rats after meals of casein or aminoacids. Z. Tierphysiol. Tierernähr. Futtermittelk., 23, 321-330.

Scharrer E., Erberspobler H., Zucker H., 1967. The reduction of intake on protein rich diet. 
2. Relations between food intake and free aminoacids in plasma after differing adaptation to protein rich feeding. Z. Tierphysiol. Tierernähr. Futtermittelk., 22, 267-275.

Schoenheimer R., I942. The dynanic statc of body constituants, p. 5o. Harvard Univ. Press, Cambridge, Massachussets.

Scholz R. W., Featuerston W. R., I968. Effect of alterations in protein intakes on liver xanthine dehydrogenase in the chick. J. Nutr., 25, 27I-277.

Schweizer W., 1947. Studies on the effect of L-tyrosine on the white rat. J. Physiol., 106, I67-I 76.

Schweigert B.S., I948. Availability of tryptophan from rations products for growth of chicks. Arch. Biochem., 19, 265-272.

Schweigert B.S., Guthneck B. T., i 953. Utilisation of aminoacids from food by the rat. I. Method of testing for lysine. $J . N u t r ., 49,277-287$.

Schwergert B. S., Gutheck B. T., I954. Utilisation of aminoacids from food by the rat. IT. Methionine. $J$. Nutr., 54, 333-344.

Scrimshaw N. S., 1962. Food Tech., 16, 26.

Scrimshaw N. S., Young V. R., Huang P. C., Thanangkul O., Cholakos B. V., r969. Pattial dietary replacement of milk protein by non specific nitrogen in young. men. $J$. Nutr., 98, 9-17.

Shankon D. W. F., Blair R., D'Mello J. P. F., ig69. Utilisation of ammonium nitrogen by the adult hen. Brit. Poult. Sci., 10, $38 \mathrm{I}-383$.

Sheffner A. L., Eckfeldt G. A., Sphctor H., I956. The pepsin-digest residue (PDR) amino-acid index of net protein utilization. J. Nutr., 60, 105-г20.

Sheffner A. I., 1967. In vitro protein evaluation in Albanese A. A., Newer methods of mutritional biochemistry, 1, chap. 3, 125-196. Acad. Press, New York, London.

Shelton D. C., Beeson W. M., Mertz E. T., I950. Growth of weanling pigs on a diet containing ten purified aminoacids. Arch. Biochem. Biophys., 29, 446-447.

SidRansky H., Verney E., rg68. Chemical pathology of acute aminoacid deficiencies : morphologic and biochemical changes in young rats force-fed a threoniue deficient diet. J. Nutr., 96, 349-358.

Smith E. B., Johnson B. C., I967. Studies of aminoacid requirements of adult rats. Brit. J. Nutr. 21, $17-27$.

Smith G. H., I.kwis D., I964. Agent and target in aninoacid interactions. Proc. Nutr. Soc., 23 XXVIII-XXIX.

Smiтh R. E., I968. a. Assessment of the availability of aminoacids in fish meals and other protein sources. Poult. Sci. 47, I624.

Sмrтн R. E., 1968 . Effect of arginine upon the toxicity of excesses of single aminoacids in chicks. J. Nutr., 95, 547-553.

Sмiтh R. E., Scotт H. M., 1965. a Biological evaluation of fish meal proteins as sources of aminoacids for the growing chick. Poult. Sci., 44, 394-40o.

Sмгтн R. E., Scotт H. M., I965 b. Use of free amino-acid concentrations in blood plasma in evaluating the amino-acid adequacy of intact proteins for chick growth. J. Nutr., 86, 37-50.

Snyderman S. F., Holt L. E. Jr, Dancis J., Roitman L., Boyer A., Balis M., E., I962. Unessential nitrogen : a limiting factor for human growth. J. Nutr. 78, 57-72.

Soliman A. G. M., KING K. W., r 969 . Metabolism derangements in response of rats to ingestion of imbalanced aminoacid mixtures. J. Nutr., 98, 255-27o.

Spolter P. D., Harper A. E., ig6r. Leucine-isoleucine antagonism in the Rat. Am. J. Physiol., 200, 5I $3-518$.

Standal B. R., 1963. Nutritional value of proteins of oriental soybean foods. J. Nutr., 81, $279-\mathbf{2} 85$.

Stockland W. L., Meade R. J., Melliere A. L., I97o. Lysine requirement of the growing rat : plasma free lysine as a response criterion. J. Nutr., 100, 925-934.

Sтотт J. A., Sмгтн H., ig66. Microbiological assay of protein quality with Tetrahymena pyriformis. 4. Measurement of available lysine, methionine, arginine and histidine. Brit. J. Nutr., 20, 663-673.

StUCKI W. P., Harper A. E., r96I. Importance of dispensable amino-acids for normal growth of chicks. J. Nutr., 74, 377-383.

Stucki W. P, Harper A, F., 1962. Effects of altering the ratio of indispensable to dispensable aminoacids in diets for rats. J. Nutr., $78,278-286$.

Sugahara T., Sugaimara M., I963. On the possibility of measuring the nutritive value of food protein through a rat's liver enzyme activity. Jap.J. Nutr. 21, I55-I66.

Sugahara M., ARivoshi S., I968. The role of dispensable aminoacids for the maximum growth of chicks. Agric. Biol. Chem. Japan, 32, $153-160$.

Sullivan T. W., BiRd H. R., I957. Effect of quantity and source of dietary nitrogen on the utilization of the hydroxy-analogues of methionine and glycine by chicks. J. Nutr., 62, I43-I5o.

SUNDE M. L., 1956. A relationship between protein level and energy level in chick rations. Poult. Sci., 35, $350-354$.

Swanson P., I959., in Albanese A. A. Protein and amino-acid nutrition. 195-224. Acad. Press, New York, London

Swenseid M. E., Villalobos J., Friedrich B., 1963. Ratios of essential to nou essential aminoacids 
in plasma from rats fed different kinds and amounts of proteins and aminoacids. $J . N u t r ., 80,99-102$.

Swenseip M. E., Villaloibos J., Figuliroa W. G., Drenick E. J., i965. The effects of test doses of leucine, isoleucine or valine on plasma aminoacid levels. The unique effect of leucine. Amer. J.Clin. Nutr., 17, 317-32x.

Swenseid M. E., Yamada C., Vinyard F., Figueroa W. G., ig68. Plasma aminoacids levels in young subjects receiving diets containing I4 or 3,5 or nitrogen per day. Amer. $J$. Clin. Nutrition, 21, I $381 \cdots 1383$.

Tacie M. A., Donoso G., 1967. Effect of protein level on utilization of casein and gluten by weanling rats, J. Nutr., 93, 579-583.

Tamime H. S., Pscheidt G. R., I966. Effect of feeding 5 p. roo I.-phenylalanine to young chicks. Comp. Biochem. Physiol., 17, 609-62r.

Tannous R. I., Rogers Q. R., Harper A. J., 1966. Effect of leucine isoleucine antagonism on the aminoacid pattern of plasma and tissues of the rat. Arch. Biochem. Biophys., 113, 356-36I

Terroine E.-T., I933. Le métabolisme de l'azote. I. Dépenses, besoins, couvertures. Presses Univ. France, Paris, $562 \mathrm{pp}$.

Terroine E.-15., 1953. La synthèse protéique. C. N. R. S. ed., 539 pp.

Uhremans H., Poppe S I969. Estimation of proteins by determining the $\mathrm{N}$ balance. 3. Comparative studies on the protein utilization by growing albino rats, using different $\mathrm{N}$ balance methods. Arch. Tievernähr, 19, 59-69.

Van der Meulen J. B., I943. The effect of urea in the feeding of laying hens. Landbouwk. Tijdschr., 55, 5 .

Van Pilsum J. F., Speyer J. F., Samuels L. T., I957. Essential amino-acid deficiency and enzyme activity. Arch. Biochem. Biophys., 68, 42-53.

Walser M., Bodenlos L. J., i959. Urea metabolism in man. J. Clin. Invest., 38, r6r7-i626.

Waterworth D. G., 1964. The nutritive quality and available amino-acid composition of some animal protein concentrates. Brit. J. Nutr., 18, 503-517.

Watts J. H., Tolbert B., RufF W. L., 1964. Nitrogen balances for young adult males fod two sources of non essentiel nitrogen at two levels of total nitrogen intake. Metabolism, 13, I72-r8o.

Whipple G. H., I948. Hemoglobin, plasma-protein and cell protein. Springfield III, C. C. Thomas ed.

Whipple G. H., Robscheit-Robbins F. S., Miller L. L., i946. Ann. N.Y. Acad. Sci., 47, 3 I7.

Wiesemüller W., Poppe S., I968 a. Amino-acid requirements of growing pigs. 2. Estimating the requirements for S-aminoacids by the N balance method. Arch. Tierernithr, 18, 405-4I6.

WifSem liller W., Poppe S., I968 b. Estimation of protein by determining N balance. 2 . Studies on rats and pigs investigating the time of maximum $\mathrm{N}$ excretion in urine and faeces after feeding. Arch. Tierernähr, 18, 474-483

Wissemüller W., Poppe S., ig69a. Biological value of some dietary proteins for pigs. Arch. Tierernähr. 19, x 57-I 7I.

Wiesemijller W., I’OPPE S., Ig69 b. Estimation of proteins by determining the N-balance. IV. Method for conducting $\mathrm{N}$-balance studies on pigs receiving varying levels of protein. $\mathrm{V}$. Determination of true digestibility in $\mathrm{N}$-balance trials with rations containing varying protein levels. Arch. Tierernähr., 19 , I33 et I 49 .

Witsemililer W., Poppe S., Kristen H., i $96 \%$ Evaluation of protein by estimation of $\mathrm{N}$ balance. I. Theoretical basis for evaluation of $\mathrm{N}$ balance trials with different protein levels. Arch. Tierernähr, 17, 15 I-I 56

Williams J. N. Jr., Elvehjem C. A., T950. The effects of tryptophan deficiency upon enzyme activity in the rat. J. Biol. Chem., 183, 539-544.

Williams J. N. Jr, IEenton A. E., Elvehjem C. A., I949. Fffect of methionine deficiency upon enzyme activity in the Rat. Proc. Soc. Exp. Biol. Med., 72, 386-388.

Wомаск M., r969. Aminoacid feeding studies : effects of various non essential nitrogen sources and added water. Proc. Soc. Exp. Biol. Med., 131, 977-979.

Womack M., Marshall M. W., Parks A. B., 1953. Some factors affecting nitrogen balance in the adult rat. J. Nutr. 151, II7-I 30 .

WoOdнAм A. A., I 968 a. A chick growth test for the evaluation of protein quality in cereal-based diets. I. Development of the method. Brit. Poult. Sci., 9, 53-64.

Woodham A. A., MCDONALD I, $1968 \mathrm{~b}$. A chick growth test for the evaluation of protein quality in cereal-based diets. II. Comparison of the total protein efficiency method with gross protein value method Brit. Poult. Sci., 9, 65-70.

World Health organization. 1965. Protein requirements. Report of a joint FAO/WHO expert group. World Health Organ. Tech. Rept. Ser. 301.

Yamashita K., Ashida K., 1969. Fate of threonine and leucine in rats fed threonine deficients diets. J. Nutr., 97, 367-374.

Yокота F., 1964. Effects of excess glycine on rats. Jap. J. Nutr. 22, 190-197.

Yoshida A., Harper A. E., Elvehjem C. A., r957. Effects of protein per calorie ratio and dietary level of fat on calorie and protein utilization. J. Nutr. 63, 555-57o. 
Yoshida A., Leung P. M. B., Rogers Q. R., Harper A. E., I966. Effect of amino acid imlalance on the fate of the limiting amino acid. J. Nutr., 89, 80-9o.

Young R. J., Griffith M., Desai I. D., ScotT M. L., I956. The response of laying hens fed low protein diets to glutamic acid and diammonium citrate. Poult Sci., 44, 1428-1429.

Young V. R., SCRImshaw N. S., 1968. Endogenous nitrogen metabolism and plasma free aminoacids in young adult given a "protein free" diet. Brit. J. Nutr., 22, 9-20.

Young V. R., ZAMora J., I968. Effect of altering the proportions of essential to non essential aminoacids on growth and plasma aminoacid levels in the rat. $J$. Nutr., 96, 2 I-27.

Zenisek Z., Lautner V., rg69. Non protein N, urea, for laying hens. Zivoc. Výr., 14, 262-268.

Zimmerman R. A., ScotT H. M. I965. Interrelationship of plasma amino acid levels and weight gain in the chick as influenced by suboptimal and superoptimal dietary concentrations of single aminoacids. J. Nutr., 87, I3-1 8 . 